Biotic interactions and trait-based ecosystem functioning in soil

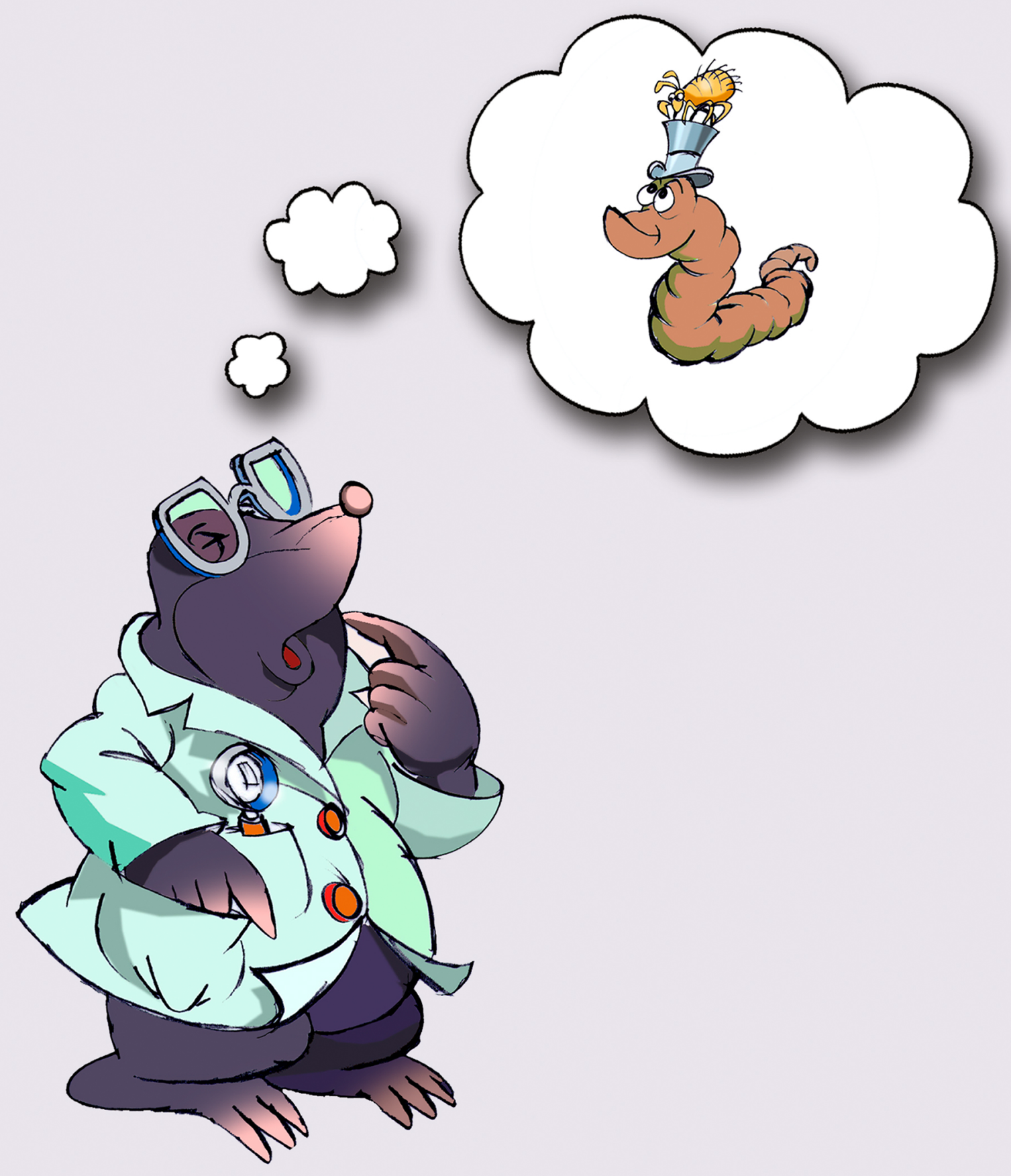

Valentina Sechi 


\section{Biotic interactions and trait-based ecosystem functioning in soil}




\section{Thesis committee}

\section{Promotor}

Prof. Dr L. Brussaard

Professor of Soil Biology and Biological Soil Quality

Wageningen University \& Research

\section{Co-promotors}

Dr R.G.M. de Goede

Assistant professor, Department of Soil Quality

Wageningen University \& Research

Dr C. Mulder

Principal Research Scientist

National Institute for Public Health and the Environment, Bilthoven

Dr M. Rutgers

Principal Research Scientist

National Institute for Public Health and the Environment, Bilthoven

\section{Other members}

Prof. Dr P.C. de Ruiter, Wageningen University \& Research

Prof. Dr J.P. Sousa, University of Coimbra, Portugal

Prof. Dr M. Bonkowski, University of Cologne, Germany

Prof. Dr T.M. Bezemer, Leiden University

This research was conducted under the auspices of the Graduate School for Production Ecology and Resource Conservation 


\title{
Biotic interactions and trait-based ecosystem functioning in soil
}

\author{
Valentina Sechi
}

Thesis

submitted in fulfilment of the requirements for the degree of doctor at Wageningen University

by the authority of the Rector Magnificus,

Prof. Dr A.P.J. Mol, in the presence of the

Thesis Committee appointed by the Academic Board to be defended in public

on Thursday 8 June 2017

at 11 a.m. in the Aula. 
Valentina Sechi

Biotic interactions and trait-based ecosystem functioning in soil, 180 pages.

PhD thesis, Wageningen University, Wageningen, the Netherlands (2017) With references, with summary in English

DOI: $10.18174 / 409675$

ISBN: 978-94-6343-131-6 


\section{Table of contents}

1. General introduction and research questions $\quad 7$

2. Does introduction of clover in an agricultural grassland affect the food base and functional diversity of Collembola? 19

3. A community trait-based approach to ecosystem functioning in soil 49

4. Choice of resolution by functional trait or taxonomy affects allometric scaling in soil food webs

5. Functional diversity in nematode communities across terrestrial ecosystems

6. General discussion

References

Summary

Riassunto (Summary in Italian)

Acknowledgements

Curriculum Vitae

PE\&RC Training and Education Statement 

Chapter 1

General introduction and research questions 



\section{General introduction and research questions}

\section{Background}

Ensuring the continuous delivery of the benefits mankind obtains from ecosystems, i.e. ecosystem services, is a key challenge for the future of our society and for our planet. If maintaining the provision of ecosystem services provides the rationale to preserve the integrity of ecosystem functioning, it remains a challenge how to link multiple processes to sometimes conflicting ecosystem services.

There is an urgent need to develop new practical and reliable tools (Carpenter et al. 2008, Rockström et al. 2009) for the assessments of our natural capital and the services it provides (Costanza et al. 1997, Tilman et al. 1997a, Mulder 2006, de Groot et al. 2010).

Recent emphasis on ecosystem services as a framework to evaluate ecosystems and to promote their sustainable use (MEA 2005) has drawn attention to how organisms contribute to the delivery of services within boundaries set by environmental conditions (Díaz et al. 2007, Suding et al. 2008, Brussaard 2012).

Soil is one of the most complex systems on Earth (Young and Crawford 2004). Soil attributes and biotic interactions play important roles in ecological processes (e.g. soil formation, nutrient turnover, carbon sequestration and transformation) and, consequently, in the related delivery of ecosystem services (van der Heijden et al. 1998, Griffiths et al. 2004, Blum 2005, Hooper et al. 2005, Mulder 2006, Mulder and Elser 2009, Adhikari and Hartemink 2016). Despite its importance, soil has often been considered a black box (Fitter 2005) and hence, understanding how soil organisms interact between each other and how

they respond to environmental pressures is fundamental to preserve soil functioning and provide a meaningful assessment of ecosystem services.

\section{Functional traits}

Ecosystem functioning and related services are strongly influenced by the characteristics (i.e. functional traits) of living organisms (Díaz et al. 2007, Díaz et al. 2013). Functional traits capture characteristics of an organism that influence its performance and 
reflect physical, chemical and biological characteristics of the environment (Lavorel et al. 1997, Mulder et al. 2012, Mouillot et al. 2013). As such, a functional trait determines individual responses to pressures (response trait) and its effects on ecosystem functioning (effect trait) (Figure 1.1).

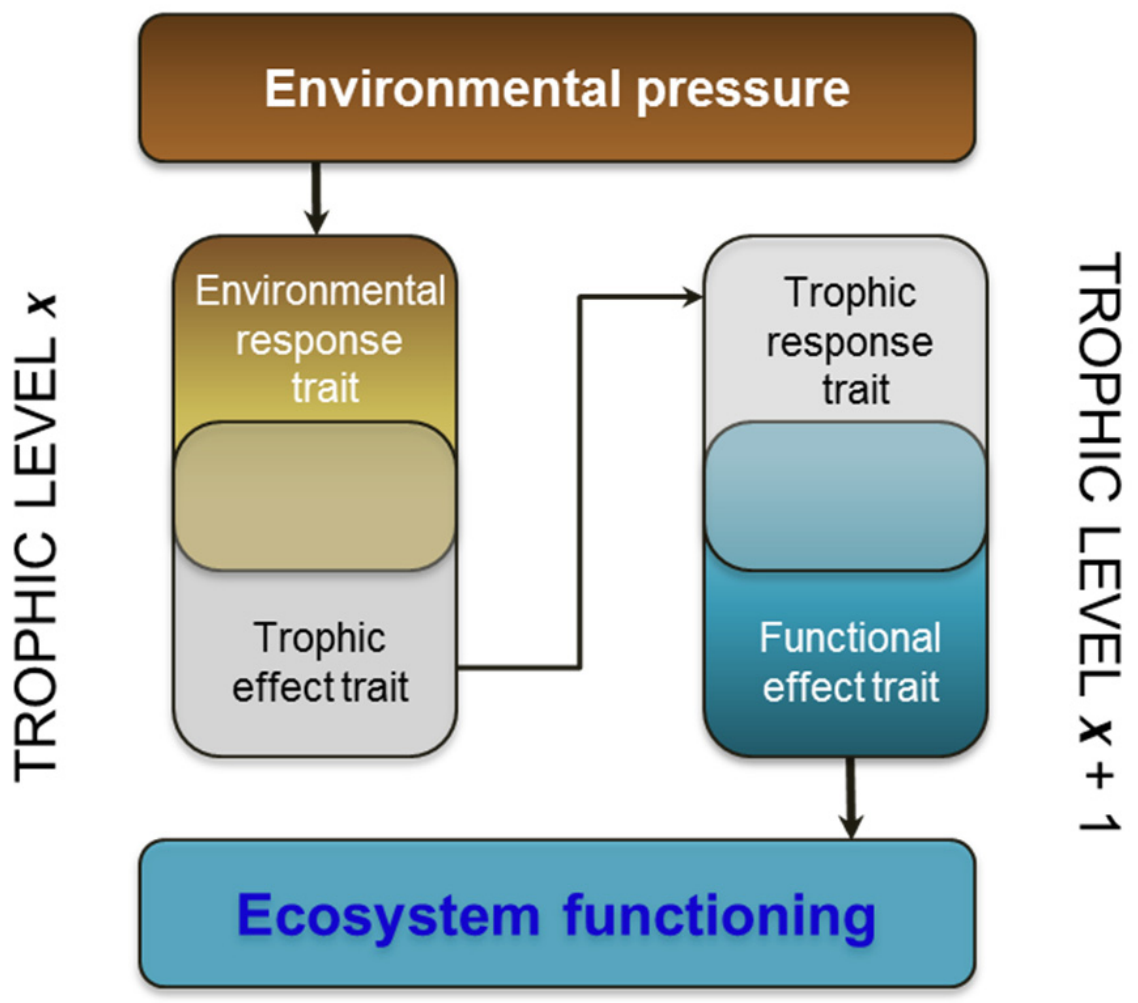

Figure 1.1 - Framework articulating functional responses and effects within and across two adjacent trophic levels to forecast ecosystem functioning. Figure from Mulder et al. (2012).

Plant traits have been widely used to evaluate ecosystem functioning allowing to scaleup from organism to higher organizational levels (i.e. the community and ecosystem levels). In soil, most of the studies on traits concentrate on one single taxonomic group (Makkonen et al. 2011, Fournier et al. 2012, Salmon et al. 2014, Martins da Silva et al. 2016) and there are still few examples of trait-based studies focusing on the community as a whole due to difficulties in finding measurable (and interpretable) common traits for each component of the soil community. However, investigating soil ecosystems from a holistic trait-based 
perspective offers an interesting opportunity to link the multiple functional responses of the organisms to environmental pressures and to give insight into how the entire community influences ecological processes.

\section{Body size and allometric scaling}

The size of organisms determines most of the multitrophic interactions among the organisms, shaping the structure and the function of communities (Elton 1927). Size is related to many life-history traits (Peters 1983, Calder 1984, Hendriks and Mulder 2008) and reflects both life strategies and individual adaptations. Size is a continuous trait potentially measurable in all organisms. Moreover, the combination of mass and abundance of soil organisms can be seen as trait-mediated response to the environment (Mulder et al. 2012) that mirrors the shape of the food web (Cohen et al. 2003, Jonsson et al. 2005, Mulder et al. 2005a), and can be used to better understand ecological processes in biological communities.

Because numerical abundance $(N)$ is exponentially related to the body-size average $(M)$, as soon as $\mathrm{N}$ decreases, with every step in a food chain, the $\mathrm{N}$ of a consumer will be on average a constant fraction of the $\mathrm{N}$ of its prey (Elton 1927). Extending this line of reasoning to an entire food web implies that the shape of the mass-abundance relationship (i.e. allometric scaling) reflects the food-web structure (Jonsson et al. 2005). Mulder et al. (2005a) showed that under different environmental conditions, changes in the mass-abundance distribution enable the identification of trait-mediated responses to environmental (and mostly human-driven) pressures. Thus, if a defined allometric relationship corresponds to specific environmental conditions, allometry can be used as an integrated measure for the anthropogenic influence on soil food webs (Mulder and Elser 2009) (Figure 1.2). 


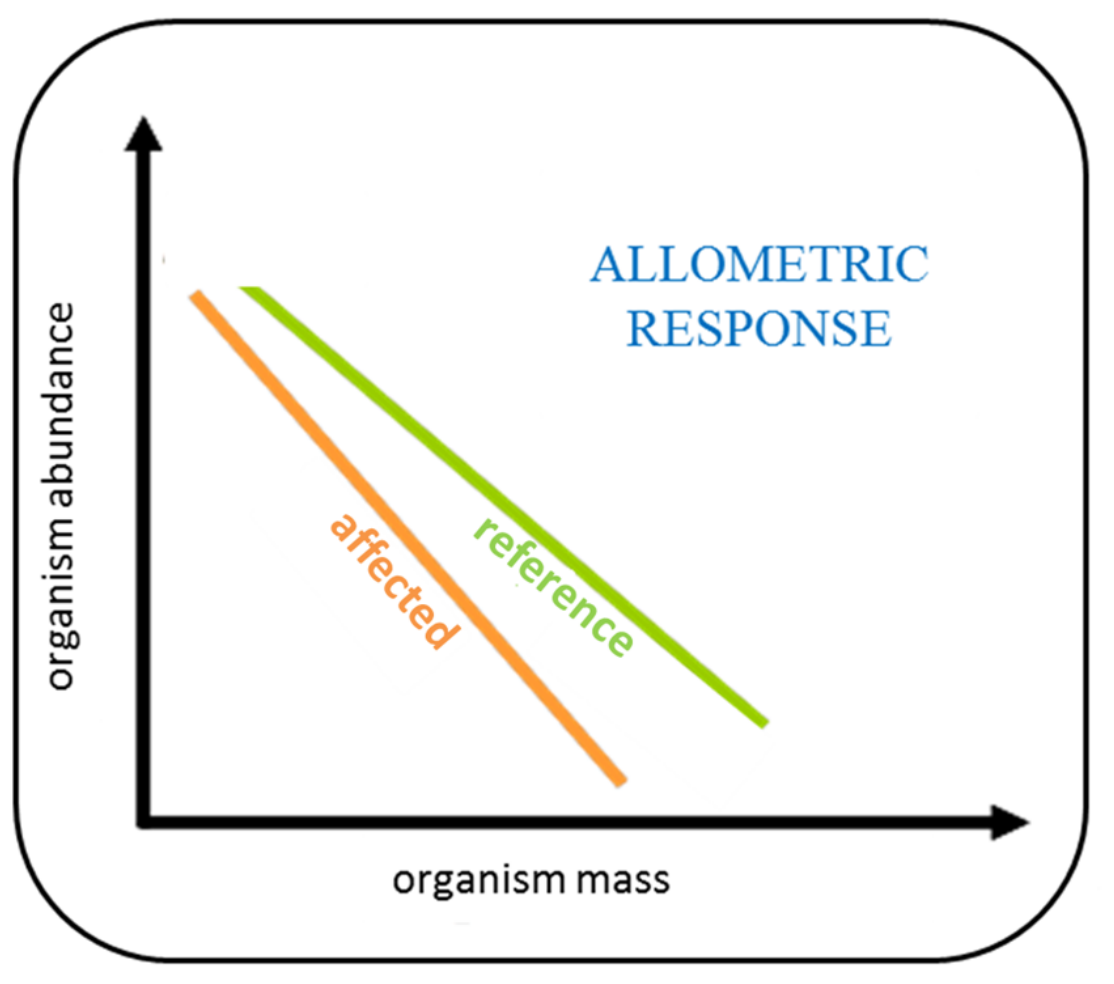

Figure 1.2 - Theoretical change of the allometric scaling from a "reference" to an "affected" situation in response to hypothetical environmental pressures. Figure modified from Mulder et al. (2011).

\section{Functional diversity}

Functional diversity can be defined as the distribution of trait values in a community (Díaz and Cabido 2001). It has been suggested both as indicator of environmental pressure (Villéger et al. 2008) and of ecosystem functioning (Petchey and Gaston 2002). Functional diversity is commonly assumed to be a better predictor of ecosystem functioning than species diversity (Gagic et al. 2015), given that competitive interactions and species filtering by disturbance are, at least partly, driven by species' functional traits (Mouillot et al. 2013). In the last decades, many indices have been proposed to quantify functional diversity and to capture the different aspects of trait distributions between species assemblages (Botta-Dukát 2005, Mason et al. 2005, Villéger et al. 2008, Laliberté and Legendre 2010).

At first, functional diversity was assessed mainly as functional group richness. Although it is generally much easier to identify functional groups than to measure continuous traits, 
gathering species into groups imposes a discrete structure on functional differences that can result in the loss of information on intraspecific variation (Fonseca and Ganade 2001). While functional traits measured for each individual are difficult to obtain, they promise a higher resolution in comparison with categorical traits (Petchey and Gaston 2002). More recently, indices based on continuous and/or multiple (discrete and continuous) traits and their abundance have been formulated (Botta-Dukát 2005, Mason et al. 2005, Villéger et al. 2008, Laliberté and Legendre 2010). In particular, Mason et al. (2005) defined three main components of functional diversity and their related indices: functional richness (the amount of niche space filled by species in a community), functional evenness (i.e. the evenness of abundance distribution in the filled functional space) and functional divergence (i.e. the degree to which abundance distribution in functional space maximises divergence in functional characters within a community). Up to now, the performance of functional diversity indices to describe species assemblages and to recognize environmental pressures has mostly been assessed using simulated data (Mouillot and Wilson 2002, Villéger et al. 2008, Mouchet et al. 2010). Thus, there is little knowledge about how these indices of functional diversity change in response to specific environmental pressures in empirical conditions (Pakeman 2011), especially in soil systems. The functional diversity indices as described in Mason et al. (2005) have the advantage of considering site-specific trait measurements instead of averaged trait values and of being based on one single trait. Therefore, they can provide a finer resolution and are potentially easier to interpret than the ones based on averaged multiple traits. Figure 1.3 shows theoretical changes of a trait distribution depending on functional index values. 


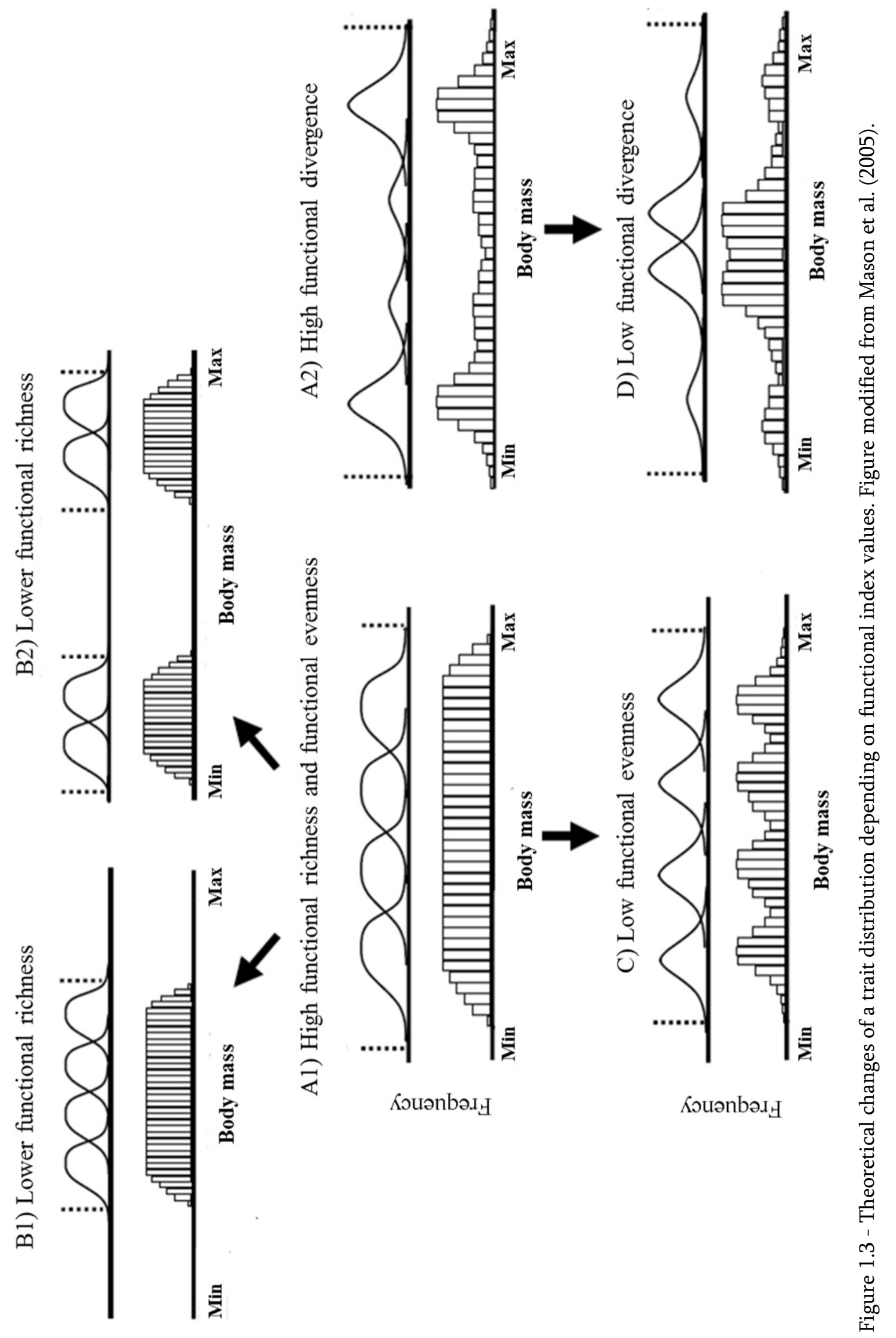




\section{Box 1 GLOSSARY}

Allometry - The change in organisms and populations related to proportional changes in body size such as shape, anatomy, physiology, numerical abundance or behaviour. Here, it refers specifically to body mass-abundance scaling.

Biomass - Total weight of a given group of organisms. It is a trait-derived parameter being equal to $\mathrm{M} \times \mathrm{N}$, where $\mathrm{M}$ is the average body mass of a given group of organisms and $\mathrm{N}$ is their total abundance.

Body mass - The weight of an organism. Here, it refers to dry weight.

Community Weighted Mean - The mean of a trait value in the community, weighted by the abundance.

Eco-physiological traits - Physiological traits characterizing the microbial community.

Ecosystem functioning - Set of the ecosystem processes that underpin the capacity of an ecosystem to provide goods and services.

Ecosystem services - The benefits people obtain from ecosystems.

Effect trait - Functional trait that captures (multiple) effects of an organism on ecosystem functioning.

Environmental filter - Abiotic factors that prevent the establishment or persistence of species in a particular location.

Functional diversity - The diversity and the distribution of functional trait values in a community. It is described by three main components:

1. Functional richness - The amount of functional space filled by species in the community;

2. Functional evenness - The evenness of abundance distribution in a filled functional space;

3. Functional divergence - The degree to which abundance distribution in functional space maximises divergence in functional characters within the community.

Functional group - A collection of organisms with similar functional trait attributes.

Functional space - Also called functional niche: the range of functional trait values.

Functional trait - Characteristic of an organism that influences its performance.

Isometry - A proportional scaling relationship equal to 1.

Response trait - Functional trait that determines the individual response to pressures.

Trait - Any morphological, physiological, phenological and behavioural feature measurable at the individual level.

Trophic group - Collection of organisms with similar feeding habits. Here used as behavioural trait. 


\section{Objectives and research questions}

The objective of this thesis is to develop and to test concepts for a trait-driven quantification of ecosystem services through the assessment of the effects of land management on soil processes. In particular, it focuses on exploring the potential of a trait-based approach in identifying and better understanding the response of soil biota to environmental pressures. The study analyses the responses of soil organisms in terms of changes in functional trait distribution and multitrophic interactions. The general hypotheses underpinning this research are that: a) the effect of a certain environmental pressure on ecosystem functioning results from the responses of each trophic level to this pressure through biotic interactions with adjacent trophic levels; b) individual responses to pressures and their effect on ecosystem functioning will be captured by functional response and effect traits (Figure 1.1).

Specific hypotheses are extensively formulated in the introduction of each chapter.

The research outlined in this thesis aims to answer the following research questions, which are dealt with in successive chapters.

Chapter 2 investigates taxonomic and functional changes in an important component of the soil fauna community (Collembola) in agricultural grassland with either perennial ryegrass, white clover or a mixture of both. In particular, it focuses on seven morphological and four ecological traits of collembolans and on the related changes in functional diversity. It deals with the following research question 1 :

- To what extent is a trait-based approach in soil ecosystem studies suitable for detecting changes in the soil community and giving insight into soil functioning? Which traits are suitable?

Chapter 3 extends the trait-approach developed in Chapter 2, investigating the trait-based responses of the entire soil community to overall agricultural management (i.e. arable fields vs. field margins). It explores the suitability of three groups of functional traits (i.e. ecophysiological traits, behavioural traits and faunal morphological traits) to analyse how different components of the soil biota (fungi, bacteria, micro- and mesofauna) respond to 
agricultural management and to what extent the selected traits detect effects on soil functioning. This leads to research question 2:

- To what extent do body mass and the related allometric scaling change as a function of environmental gradients? Does taxonomic or functional classification matter?

Chapters 2 and 3 show how body mass is a robust functional trait, being a continuous and measureable trait applicable to the whole soil community.

Chapter 4 explores the potential of using body mass in revealing the response of the soil community to different agricultural managements. It questions whether the resolution at the local scale based on either a taxonomic taxonomic (i.e., species and genera level) or a functional classification (based on trophic groups) implies changes in the allometric relationships. With this aim, shifts in allometric scaling ( $\log \mathrm{N}-\log \mathrm{M}$ relationships) in three abandoned grasslands with different (former organic) management have been studied to answer the research question 3:

- How do body size traits and the related functional diversity in a soil community change in response to environmental pressures?

Chapter 5 extends the study of body size done in Chapter 4, focusing on the nematode traits distribution along ecosystem types (arable fields, managed grassland, shrublands/woodlands). This chapter analyses how functional indices (i.e. functional richness, evenness and divergence) change in different ecosystems.

Chapter 6 provides a general discussion on the main findings of this work, its main perspectives and several implications for sustainable land management in the near future. 


\section{Data sources}

To investigate the aforementioned questions, this $\mathrm{PhD}$ project relies on data from three field experiments and on one existing data set.

The new data sets comprise:

- Taxonomic and functional composition of collembolan communities in a grassland crop rotation experiment of Aarhus University, in Denmark;

- Soil abiotic and biotic parameters (species composition, abundances and trophic preference) from arable fields and field margins in Hoeksche Waard, the Netherlands;

- Measured body-size values and abundances of individuals from a former organic farm in the surroundings of Soest, the Netherlands, where past management led to differences in soil nutrient availability.

The existing data set, published as electronic data paper (Mulder and Vonk 2011), contains trait measurements of nematode specimens and describes the (a)biotic variation in different combinations of soil types and ecosystem types across the Netherlands. 


\section{Chapter 2}

Does introduction of clover in an agricultural grassland affect the food base and functional diversity of Collembola? 



\title{
Does introduction of clover in an agricultural grassland affect the food base and functional diversity of Collembola?
}

\author{
Current, revised version under review for publication in \\ Soil Biology and Biochemistry
}

\author{
Alessandra D'Annibale, Valentina Sechi, Thomas Larsen, \\ Søren Christensen, Paul Henning Krogh, Jørgen Eriksen
}

\begin{abstract}
Introduction of legumes (i.e. white clover) in agricultural grasslands is a common practice to improve yields, but how this affects soil fauna populations, particularly mesofauna, is still poorly understood. We investigated taxonomical and functional differences of Collembola communities between plots with either perennial ryegrass (Lolium perenne L.), white clover (Trifolium repens L.) or a mixture of both in a Danish agricultural grassland 6 and 14 months after establishing the leys (September and May, respectively). Diet preferences were investigated via stable isotope analyses (SIA) of carbon $\left({ }^{13} \mathrm{C}\right)$ and nitrogen $\left({ }^{15} \mathrm{~N}\right)$. Collembolan abundance data were used to analyse morphological and ecological traits of the collected taxa and to calculate functional diversity indices. Our stable isotope results show that root-derived resources made larger contributions to epedaphic and hemiedaphic species in the white clover than ryegrass plots. Changes in taxa specific density and traits distribution as a response to the C:N ratio of plant material, suggest that plant material quality was the main factor affecting the collembolan community, especially when comparing the two sampling occasions. Functional richness decreased under conditions of low quality material. In contrast to our hypothesis, under mixture treatment population densities did not increase and functional richness decreased. Our results suggest that habitat changes, via different plant composition, can affect some functional groups, having in turn effects on the functional diversity of the community.
\end{abstract}




\section{Introduction}

Collembola, or springtails, are a key group of microarthropods within the soil food web that feed on soil microbiota with derived effects on soil nutrients dynamics (Rusek, 1998). Collembola form feeding guilds of microbial feeders (Bardgett, 1998; Rusek, 1998) or generalist feeders foraging on microbiota, plant roots and nutrient rich detrital matter (Hopkin, 1997). Our understanding of collembolan feeding habits at the species or functional group level is steadily increasing (Chamberlain et al., 2006; Ngosong et al., 2011; A.A. Potapov et al., 2016; Ruess et al., 2007; Sechi et al., 2014a), but several gaps still exist. It is known that Collembola are closely associated with the rhizosphere food web being nutritionally supported by root-derived resources (Endlweber et al., 2009; Larsen et al., 2007; Sabais et al., 2012 Larsen et al. 2016b), but the path through which they obtain these resources is not yet clear. While euedaphic and hemiedaphic species have been shown to incorporate recent photosynthate carbon (C) from crops (Larsen et al., 2007; Ostle et al., 2007), A.M. Potapov et al. (2016) recently demonstrated that only a fraction of these plant

derived resources derives from direct foraging on roots. Hence, Collembola are influenced by plant-related changes that affect availability, quality and palatability of microbial derived food sources. Introduction of legumes in agricultural grasslands - a practice for reducing the dependence on amended nitrogen $(\mathrm{N})$ fertilizers - can constitute a change in the soil habitat, possibly having consequences for the soil biota. Some studies have been carried out testing the effects of plant diversity (Sabais et al., 2011; Salamon et al., 2004) and presence of legumes on soil fauna (Birkhofer et al., 2011; Larsen et al., 2016a; Mulder et al., 2002; Schon et al., 2011; van Eekeren et al., 2009), but the effects of these crop types on the community composition of Collembola are complex and have not yet been resolved (Eisenhauer et al., 2011; Kooistra, 1964; Salamon et al., 2004; Sechi et al., 2014a).

In Denmark more than 500.000 ha (20\%) of the agricultural land is grassland and 60\% of these grasslands are in rotation with cultivation every 2-4 years (Pedersen and Pedersen, 2013). These crop rotations represent a crucial stage in building up soil fertility for the next crops. While increased plant diversity in production grasslands increases organic matter and microbial biomass, legumes are crucial for increasing soil $\mathrm{N}$, especially for soils poor in 
nutrients (Küchenmeister et al., 2012; Nyfeler et al., 2011). Perennial ryegrass and white clover, commonly used in combination in production grasslands, have distinct characteristics. Ryegrass has a much denser root system, which in turn positively affects the microbial biomass (van Eekeren et al., 2009), while white clover may have a negative effect on fungal biomass, suppressed by $\mathrm{N}$ in root exudates or litter (de Vries et al., 2006). Therefore, ryegrass generally increases microbial biomass and fungal:bacteria ratio (see also Sechi et al., 2014a), more than white clover, which instead tends to support a more bacterial- dominated food channel. Taken together, these distinct characteristics are likely to affect the food base for Collembola. In a study that took place in the same experimental field site as ours, Sechi et al. (2014a) found that Collembola living in ryegrass plots obtained most of their $C$ from fungalrather than from plant-derived sources, and vice versa for Collembola living in white clover plots. The authors also found in mixed ryegrass-clover plots that Collembola obtained relatively more $C$ from grass- than clover-derived resources (Sechi et al., 2014a).

Our study investigated the influence of ryegrass, white clover and a mixture of both crops on the taxonomic diversity of a collembolan community. We used a Danish agricultural grassland as setting for the experiment, and we studied the community in two different seasons, autumn and spring. In addition, In addition to measuring taxonomic diversity, we characterized the collembolan community via a trait-based approach. The use of traits, which first became popular in plant ecology and later transferred to animal ecology, consists in characterizing a community based on morphological, physiological or phenological traits which impact species fitness via their effects on growth, reproduction and survival (functional traits) (Violle et al., 2007). We investigated the response of the community to the different environmental conditions, by selecting a set of functional response traits. Response traits are a certain type of functional traits able to capture the different characteristics of an organism by determining its response to environmental pressures, and are considered to reflect variation in environmental conditions (Lavorel et al., 1997, 2013; Mulder et al., 2012). Functional traits can be used to calculate the functional diversity of a given community, which has been defined by Díaz and Cabido (2001) as "the value and range of functional traits of the organisms present in a given ecosystem". As demonstrated in recent ecological research 
with Collembola (e.g. Makkonen et al., 2011; Martins da Silva et al., 2016; Salmon and Ponge, 2012; Salmon et al., 2014; Santorufo et al., 2015), the study of functional traits distribution allows to identify the response of the community to environmental changes (e.g. land use, soil properties, temperature). Thus, we used a traits-based approach to disentangle the influence of different plant crops on the functioning of the collembolan community. Trophic interactions in the community and $\mathrm{C}$ and $\mathrm{N}$ pathways were also studied by analysing natural abundances of $\mathrm{C}$ and $\mathrm{N}$ stable isotopes $\left({ }^{13} \mathrm{C}\right.$ and $\left.{ }^{15} \mathrm{~N}\right)$ in Collembola, soil and plants, for the purpose of identifying Collembola possible food sources. Both isotope species are ideally suited for studying dietary contributions from clover and ryegrass to Collembola, because the two crops have significantly different ${ }^{13} \mathrm{C}$ and ${ }^{15} \mathrm{~N}$ values (Larsen et al., 2016a).

We hypothesized that (i) Collembola would be trophically associated with the respective crops, i.e. the isotope values of Collembola would resemble those of either white clover or ryegrass where (ii) we expect to find more bacterial feeders, such as e.g. Brachystomella parvula (Schaeffer, 1896) (Adams and Salmon, 1972), in the former and more fungivorous species, such as e.g. Lepidocyrtus cyaneus Tullberg, 1871 (Berg et al., 2004, Sechi et al. 2014a), in the latter. We also hypothesized that (iii) Collembola abundance and functional richness would be greatest in plots with mixed crops because mixtures of grasses and legumes have been shown to improve soil structure and fertility compared to soils with monocultures (e.g. Nyfeler et al., 2011). Finally, because in the late season (September) senescent plants provide a pulse of easily decomposable $C$ to support microbial growth, difference in belowground nutrients and exudates inputs will be more evident than in the early season (May) (Bardgett et al. 2005). Therefore, we hypothesized that (iv) differences in collembolan population densities/traits between ryegrass and white clover would be greater in September than in May.

\section{Methods}

\section{Experimental setting and sampling}

The experimental plots were located in the dairy crop rotation experiment of Aarhus University at Foulum $\left(9^{\circ} 34^{\prime} \mathrm{E}, 5^{\circ} 29^{\prime} \mathrm{N}\right)$, with mean annual rainfall of $770 \mathrm{~mm}$ and mean 
annual temperature of $7.7^{\circ} \mathrm{C}$. Since 1987 the site has had intensive dairy farming with grassland-arable crop rotations (Eriksen et al., 1999, 2004). The soil is classified as a typical hapludult with $6.4 \%$ clay, $8.5 \%$ silt, $44 \%$ fine sand, 39\% coarse sand and $1.6 \%$ carbon.

In spring 2011, we established leys with ryegrass (Lolium perenne L., $28 \mathrm{~kg} \mathrm{ha}^{-1}$ ), white clover (Trifolium repens L., $6 \mathrm{~kg} \mathrm{ha}^{-1}$ ) or a mixture of the two species (4 $\mathrm{kg} \mathrm{ha}^{-1}$ white clover and 24 $\mathrm{kg} \mathrm{ha}^{-1}$ ryegrass) after ploughing. Each crop was established in 4 separate plots (each $3 \times 18 \mathrm{~m}$ ) according to a randomized block design, where each block in the field comprised the three different treatments (crops), randomly positioned next to each other, resulting in a total of 12 plots. We tested the effect of the treatments on the collembolan community taxonomic composition, traits distribution and functional diversity at two sampling occasions in different seasons (September 2011 and May 2012), when we sampled soil, plant material and collembolans. In spring we also used the collected materials to analyse natural abundances of $\mathrm{C}$ and $\mathrm{N}$ stable isotopes $\left({ }^{13} \mathrm{C}\right.$ and $\left.{ }^{15} \mathrm{~N}\right)$, as described below.

Soil core samples $(\varnothing 6 \mathrm{~cm}$; depth $5 \mathrm{~cm}$ ) were taken from each plot (one soil core per plot in September and three soil cores per plot in May) and used to extract Collembola by a modified MacFayden high gradient extractor (MacFadyen, 1961). Sampling was more extensive in May than September because the sampling campaign in September 2011 was running parallel to other work-demanding project activities at the same location (Sechi et al., 2014a, Larsen et al., 2016a). This sampling design allowed us to carry out a more thorough comparison of the effect of crop type on the community composition of Collembola for 14 rather than 6 months after establishing the leys. Specimens were collected in benzoic acid and later transferred to glycerol for counting and long-term storage. Those samples were used for identification and counting. Specimens were identified at species level when possible, or else they were identified at higher taxonomic levels, using the keys of Fjellberg $(1998,2007)$.

\section{Traits analysis and functional diversity}

The collembolan community was analysed by selecting seven morphological and four ecological traits (Table 2.1 and Table 2.2). The seven morphological traits correspond to the collembolan life-form classification sensu Gisin (1943), which can be considered as a composite trait. Trait values were obtained from the online trait database soilbiostore.au.dk 
and are the same list of traits as Makkonen et al. (2011), plus the mouthparts and the lifeform traits.

Community-weighted mean (CWM) trait score values (Lavorel et al., 2008) were calculated using the formula:

$$
C W M=\sum_{i=1}^{n} p_{i} x_{i}
$$

where $p_{i}$ is the relative abundance of the $i$-th species and $x$ is the trait attribute of the $i$-th species (Garnier et al., 2004).

To investigate the community structure of Collembola we calculated the following multidimensional functional diversity (FD) indices based on our selected functional traits: functional richness, functional evenness, functional divergence (Mason et al., 2005; Villéger et al., 2008). These indices explore the different aspects of functional diversity. They quantify the functional structure of communities describing the distribution of the species and their abundances in a multidimensional space defined by trait values (Laliberte and Legendre, 2010; Mouillot et al., 2013; Villéger et al., 2008). The functional richness represents the amount of functional space filled by the community (Villéger et al., 2008) and it is used as an indicator for potentially used or unused niche space and thus, e.g., for productivity (Mason et al., 2005). The functional evenness quantify the regularity of the trait abundance distributions (Mason et al., 2005), while the functional divergence reflects how abundance is spread within

the functional traits space occupied by species. High functional divergence indicates high niche differentiation, and thus low resource competition (Mason et al., 2005).

\section{C:N ratios and stable isotopes analyses}

In May 2012 we collected samples of soil, plants and Collembola to analyse C and N stable isotopes $\left(\delta^{13} \mathrm{C}\right.$ and $\left.\delta{ }^{15} \mathrm{~N}\right)$ natural abundances, in order to track the trophic structure of the community. We also calculated carbon:nitrogen $(\mathrm{C}: \mathrm{N})$ ratios on the same samples via the stable isotopes analysis procedure. Three soil samples per plot (soil cores $\varnothing 2.5 \mathrm{~cm}$ ) were taken at 0-5 cm depth. The soil was sieved at $2 \mathrm{~mm}$, dried overnight at $60{ }^{\circ} \mathrm{C}$ and then grinded. Soil blocks $20 \times 20 \times 20 \mathrm{~cm}$ (two per plot) were taken from the plots to collect biomass of shoots and roots. Plants were immediately sorted into leaves and roots and were 
washed with ELGA-water, frozen, freeze dried and crunched. Samples of soil and plants were stored at $-18{ }^{\circ} \mathrm{C}$ until further analyses. Collembola were extracted alive on plaster of Paris mixed with activated charcoal $(8: 1 \mathrm{w}: \mathrm{w})$ to collect them. Collembola samples were only prepared for the taxa that reached the biomass needed for the stable isotopes analyses (0.3-1 mg dry weight per sample), representing two out of three life-forms: Lepidocyrtus cyaneus Tullberg, 1871 (hemiedaphic), Brachystomella parvula (Schaeffer, 1896) (hemiedaphic), Isotoma anglicana Lubbock, 1862 (epedaphic), Isotoma viridis Bourlet, 1839 (epedaphic), juveniles of Isotomidae (epedaphic) and Symphypleona (epedaphic). Hence, our stable isotope analyses could not include euedaphic specimens. When needed, individuals from different plots within a treatment were pooled to meet the sufficient biomass.

Table 2.1 - Collembola traits used in the traits analysis.

\begin{tabular}{|c|c|c|c|}
\hline & Trait & Type & Units/levels \\
\hline \multirow{7}{*}{$\begin{array}{l}\text { Morphological } \\
\text { traits }\end{array}$} & No. of ocelli & Quantitative & $0-8$ \\
\hline & Body size (max.) & Quantitative & $\mathrm{mm}$, to the nearest $0.1 \mathrm{~mm}$ \\
\hline & $\begin{array}{l}\text { Body pigmentation level } \\
\text { (max) }\end{array}$ & Ordinal & 0 white, 1 lightly, 2 intensely \\
\hline & Body pigmentation pattern & Ordinal & 0 absent, 1 present, 2 spotted \\
\hline & Modified hairs or scales & Binary & 0 absent, 1 present \\
\hline & Furca development & Ordinal & $\begin{array}{l}0 \text { absent, } 1 \text { reduced, } 2 \text { fully developed short, } 3 \\
\text { fully developed long }\end{array}$ \\
\hline & Antenna estimated length & Ordinal & 0 short, 1 medium, 2 long \\
\hline \multirow[t]{4}{*}{ Ecological traits } & Habitat width & Ordinal & $\begin{array}{l}0 \text { stenotopic, } 1 \text { steno/eurytopic, } 2 \text { eurytopic and } \\
\text { eurytopic/syntopic }\end{array}$ \\
\hline & Moisture preference & Ordinal & $\begin{array}{l}0 \text { xeroresistant, } 1 \text { xero-mesophilic, } 2 \text { indifferent, } \\
3 \text { mesophilic, } 4 \text { meso-hydrophilic }\end{array}$ \\
\hline & Mouthparts & Ordinal & 1 sucking, 2 grinding, 3 piercing \\
\hline & $\begin{array}{l}\text { Vertical habitat preference } \\
\text { life-form sensu Gisin (1943) }\end{array}$ & Ordinal & 1 epedaphic, 2 hemiedaphic, 3 euedaphic \\
\hline
\end{tabular}


Table 2.2 - Trait values for each taxon, used in the traits analysis. N. ocel: number of ocelli; M: body size; Pigm. Lev: body pigmentation level; Pigm. Pat: body pigmentation pattern; Mod. Ha/Sc: modified hairs or scales; Furca Dev: furca development; Ant. Len: antenna estimated length; Hab. Width: habitat width; Mouth: mouthparts; Moist. Pref: moisture preference; Vert. Hab: vertical habitat preference life-form sensu Gisin 1943.

\begin{tabular}{|c|c|c|c|c|c|c|c|c|c|c|c|c|}
\hline Family/Order & Id. Taxon & $\begin{array}{l}\mathrm{N} . \\
\text { ocel }\end{array}$ & $\mathbf{M}$ & $\begin{array}{c}\text { Pigm. } \\
\text { lev }\end{array}$ & $\begin{array}{l}\text { Pigm. } \\
\text { Pat }\end{array}$ & $\begin{array}{l}\text { Mod. } \\
\mathrm{Ha} / \mathrm{Sc}\end{array}$ & $\begin{array}{l}\text { Furca } \\
\text { Dev }\end{array}$ & $\begin{array}{l}\text { Ant. } \\
\text { Len }\end{array}$ & $\begin{array}{l}\text { Hab. } \\
\text { Width }\end{array}$ & Mouth & $\begin{array}{c}\text { Moist. } \\
\text { Pref }\end{array}$ & $\begin{array}{l}\text { Vert. } \\
\text { Hab }\end{array}$ \\
\hline Brachystomellidae & Brachystomellidae sp. & 8 & 1 & 1 & 0 & 0 & 2 & 0 & 1 & 1 & 4 & 2 \\
\hline \multirow[t]{3}{*}{ Entomobryidae } & Entomobryidae sp. & 8 & 2 & 2 & 1 & 1 & 3 & 2 & 2 & 2 & 1 & 2 \\
\hline & Lepidocyrtus cyaneus & 8 & 2 & 1 & 0 & 1 & 3 & 1 & 2 & 2 & 3 & 2 \\
\hline & Pseudosinella alba & 2 & 1.1 & 0 & 0 & 1 & 3 & 1 & 2 & 2 & 2 & 3 \\
\hline \multirow[t]{2}{*}{ Hypogastruridae } & $\begin{array}{l}\text { Ceratophysella } \\
\text { succinea }\end{array}$ & 8 & 1.2 & 2 & 0 & 0 & 2 & 0 & 2 & 2 & 4 & 2 \\
\hline & Willemia sp. & 0 & 0.8 & 0 & 0 & 0 & 0 & 0 & 2 & 2 & 3 & 3 \\
\hline \multirow[t]{7}{*}{ Isotomidae } & Desoria tigrina & 8 & 2.1 & 2 & 0 & 0 & 3 & 1 & 2 & 2 & 3 & 2 \\
\hline & Folsomia fimetaria & 0 & 1.4 & 0 & 0 & 0 & 3 & 1 & 2 & 2 & 3 & 3 \\
\hline & Isotomiella minor & 0 & 1.1 & 0 & 0 & 0 & 3 & 1 & 2 & 2 & 4 & 3 \\
\hline & Isotoma sp. & 8 & 3.4 & 2 & 0 & 0 & 3 & 2 & 2 & 2 & 3 & 1 \\
\hline & Isotomodes productus & 0 & 0.9 & 0 & 0 & 0 & 1 & 1 & 2 & 2 & 3 & 3 \\
\hline & Isotomurus sp. & 8 & 3 & 1 & 0 & 0 & 3 & 1 & 2 & 2 & 4 & 1 \\
\hline & Parisotoma notabilis & 4 & 1 & 1 & 0 & 0 & 3 & 1 & 2 & 2 & 3 & 2 \\
\hline Neanuridae & Micranurida pygmaea & 2 & 0.5 & 1 & 0 & 0 & 0 & 0 & 2 & 3 & 3 & 3 \\
\hline Neelidae & $\begin{array}{l}\text { Megalothorax } \\
\text { minimus }\end{array}$ & 0 & 0.4 & 0 & 0 & 0 & 3 & 0 & 2 & 2 & 3 & 3 \\
\hline Symphypleona & Symphypleona & 8 & 0.8 & 2 & 1 & 0 & 3 & 1 & 2 & 2 & 2 & 1 \\
\hline Tullbergiidae & Tullbergiinae & 0 & 0.7 & 0 & 0 & 0 & 0 & 0 & 2 & 2 & 2 & 3 \\
\hline
\end{tabular}

The samples for stable isotopes analyses were prepared in tin capsules $5 \times 8 \mathrm{~mm}$, assuring a $\mathrm{C}$ and $\mathrm{N}$ content of $200-2000 \mu \mathrm{g}$ and $20-150 \mu \mathrm{g}$, respectively. Stable isotope analyses were performed by the UC Davis Stable Isotope Facility, Department of Plant Sciences (One Shields Ave, Mail Stop 1 Davis, CA 95616 USA). International standards VPDB (Vienna PeeDee Belemnite) and Air for carbon and nitrogen, respectively, have been used and further details are available at http://stableisotopefacility.ucdavis.edu/13cand15n.html. 
The isotopic data are reported in the conventional $\delta$ notation as follows:

$$
\delta X(\%)=\left[\left(R_{\text {sample }} / R_{\text {standard }}-1\right)\right] \times 1000
$$

where $X={ }^{13} C$ or ${ }^{15} N$ and $R$ stands for the ratio between the heavier and the lighter isotope $\left({ }^{13} \mathrm{C} /{ }^{12} \mathrm{C}\right.$ for carbon and ${ }^{15} \mathrm{~N} /{ }^{14} \mathrm{~N}$ for nitrogen) in the sample or in the standard.

\section{Statistics}

All statistical analyses were performed using $\mathrm{R}$ software 3.3.1 (R Core Team, 2016). Stable isotopes ${ }^{13} \mathrm{C}$ and ${ }^{15} \mathrm{~N}$ values of soil, plants and Collembola were analysed via linear mixedeffects models comparing ryegrass and white clover plots. Since the Collembola dataset was unbalanced, due to low availability of replicates, collembolan taxa were treated as fixed factors, together with treatments (i.e. crops), in order to increase the degrees of freedom and to highlight differences between taxonomical groups. Plots were included in the model as a random factor.

The taxonomic abundances of Collembola were first visually analysed by Principal Coordinate Analysis (PCoA) after Hellinger transformation. The ordination plot was obtained using the pcoa function in the R package \{ape\} (Paradis et al., 2004), where we used the mean between subsamples per plot in May, in order to simplify plot and visualization of relevant patterns.

The analyses of the collembolan abundances dataset were ran only on the taxa having (on the average of samples) more than one specimens in all the time $\mathrm{x}$ treatment combinations. This condition held true for the following taxa: Brachystomellidae, Willemia sp., Desoria tigrina Nicolet, 1842, Parisotoma notabilis (Schaeffer, 1896), Micranurida pygmaea Börner, 1901, Symphypleona and Tullbergiinae. Isotoma sp., which was absent only in ryegrass plots in September, was also included in the model, as it did fit the statistical model, thanks to the high abundance of the taxon in May. Thus, abundances of the most sampled taxa were analysed with a linear mixed-effects models using the generalized least squares (GLS) method with the function gls from the R package \{nlme\} (Pinheiro et al., 2016). Given the unbalanced design (one vs. three samples per plot in September and May, respectively), we calculated the mean per plot for the May sampling before the analyses, as this new dataset resulted in a better fit to the model. Model choice was done following Zuur et al. (2009), thus 
incorporating different constant variance functions in the models and making model selection using Akaike Information Criterion (AIC). Pair-wise comparisons of mean values were done calculating least squares means (lsmeans) with Tukey's post hoc test.

Functional diversity (FD) indices and community-weighted mean trait score values (CWM) were calculated through the R package $\{F D\}$ (Laliberte and Legendre, 2010) using the function dbFD. The function uses a distance-based framework: a distance matrix is computed from the (species $\times$ trait) matrix, and analysed through PCoA. The resulting PCoA axes are used as new traits to compute the functional diversity indices. The function calculates also CWM values, where for a continuous trait (in our case no. of ocelli and body size), CWM is the mean trait value of all species present in the community weighted by their relative abundances, and for ordinal and binary traits, the relative abundance of each individual class is computed. PCoA was performed on CWM values (mean between subsamples in May was again calculated before the analysis) and these, together with FD indices, were then tested calculating Pearson correlations with plants C:N ratios, while differences between treatments and samplings were tested via linear mixed-effects models.

\section{Results}

\section{Plants and soil C:N ratios}

The C:N ratios of plants and soil are listed in Table 2.3. The C:N ratio of plant shoots was significantly higher in May 2012 than in September 2011 and, like the root C:N, was different between treatments in both occasions. C:N of roots was instead significantly lower in May compared to September only for the white clover and mixture treatments. Finally, soil C:N was significantly higher in September 2011. White clover plants, both above and below-ground, showed significant lower C:N ratio than ryegrass.

\section{Stable isotopes natural abundances}

While soil isotopic values were similar among treatments, ryegrass and white clover each had distinct isotope values, with white clover being enriched in $\delta^{13} \mathrm{C}$ and depleted in $\delta^{15} \mathrm{~N}$ compared to ryegrass (Figure 2.1 and Table 2.4). The collembolan community was 
distributed over a range of approximately $6 \delta$ units in $\delta^{15} \mathrm{~N}$, equating three trophic groups, assuming a difference between trophic levels of approximately 3\%o (Minagawa and Wada, 1984). The first group, most depleted, containing specimens of Isotoma sp. and Symphypleona, the second with $L$. cyaneus and the last one with B. parvula (Table 2.4).

The difference between the latter two groups, in terms of $\delta^{15} \mathrm{~N}$, was particularly pronounced in ryegrass plots. $\delta^{15} \mathrm{~N}$ values of all Collembola groups, except Symphypleona, were significantly higher in white clover plots compared to ryegrass. Moreover, values of Isotoma sp. and Symphypleona were much closer to the values of plants roots and shoots in white clover plots, compared to ryegrass. Ranges in $\delta^{13} \mathrm{C}$ values of Collembola were approximately $1.4 \%$ in ryegrass and $1.7 \%$ in white clover. Isotoma sp. and Symphypleona together showed a much broader range in ryegrass plots, compared to white clover plots, where their values were within only $0.4 \%$. Moreover, Collembola in ryegrass plots were enriched in $\delta^{13} \mathrm{C}$ compared to the plant material, while under white clover their $\delta^{13} \mathrm{C}$ values were much more close to the ones of plant material (Fig. 2.1 and Table 2.4). The species $B$. parvula was significantly enriched in $\delta^{13} \mathrm{C}$ compared to the other groups, in both crops.

Table 2.3 - Carbon:nitrogen (C:N) ratio of plants and soil (mean \pm standard error). Values for the mixture treatment are an average between ryegrass and white clover plant samples. Small letters indicate significant differences $(\mathrm{p}<0.05)$ between treatments (ryegrass, mixture and white clover) within the same sampling, while capital letters indicate significant differences between treatments across samplings.

\begin{tabular}{|c|c|c|c|c|c|c|c|c|c|}
\hline \multirow[b]{2}{*}{ Variables } & \multicolumn{4}{|l|}{ September 2011} & \multicolumn{5}{|l|}{ May 2012} \\
\hline & Ryegrass & Mixture & White clove & & Ryegrass & & Mixture & & White clover \\
\hline C:N shoots & $17.4 \pm 0.43 \quad$ a,A & $13.3 \pm 0.35 \quad \mathbf{b}, \mathbf{A}$ & $8.5 \pm 0.27$ & C,A & $34.1 \pm 0.6$ & a,B & $20.8 \pm 0.4$ & b,B & $10.8 \pm 0.13 \quad \mathbf{c}, \mathbf{B}$ \\
\hline $\mathrm{C}: \mathrm{N}$ roots & $53.5 \pm 1.94$ a & $37.1 \pm 1.07 \quad$ b,A & $19.1 \pm 1.79$ & C,A & $55.5 \pm 1.33$ & a & $32.5 \pm 0.48$ & b,B & $15.1 \pm 0.48 \quad \mathbf{c}, \mathbf{B}$ \\
\hline C:N soil & $10.8 \pm 0.05 \quad a b, A$ & $10.8 \pm 0.03 \quad \mathbf{b}, \mathbf{A}$ & $10.6 \pm 0.02$ & $a, A$ & $10.3 \pm 0.03$ & B & $10.3 \pm 0.03$ & B & $10.2 \pm 0.02 \quad$ B \\
\hline
\end{tabular}




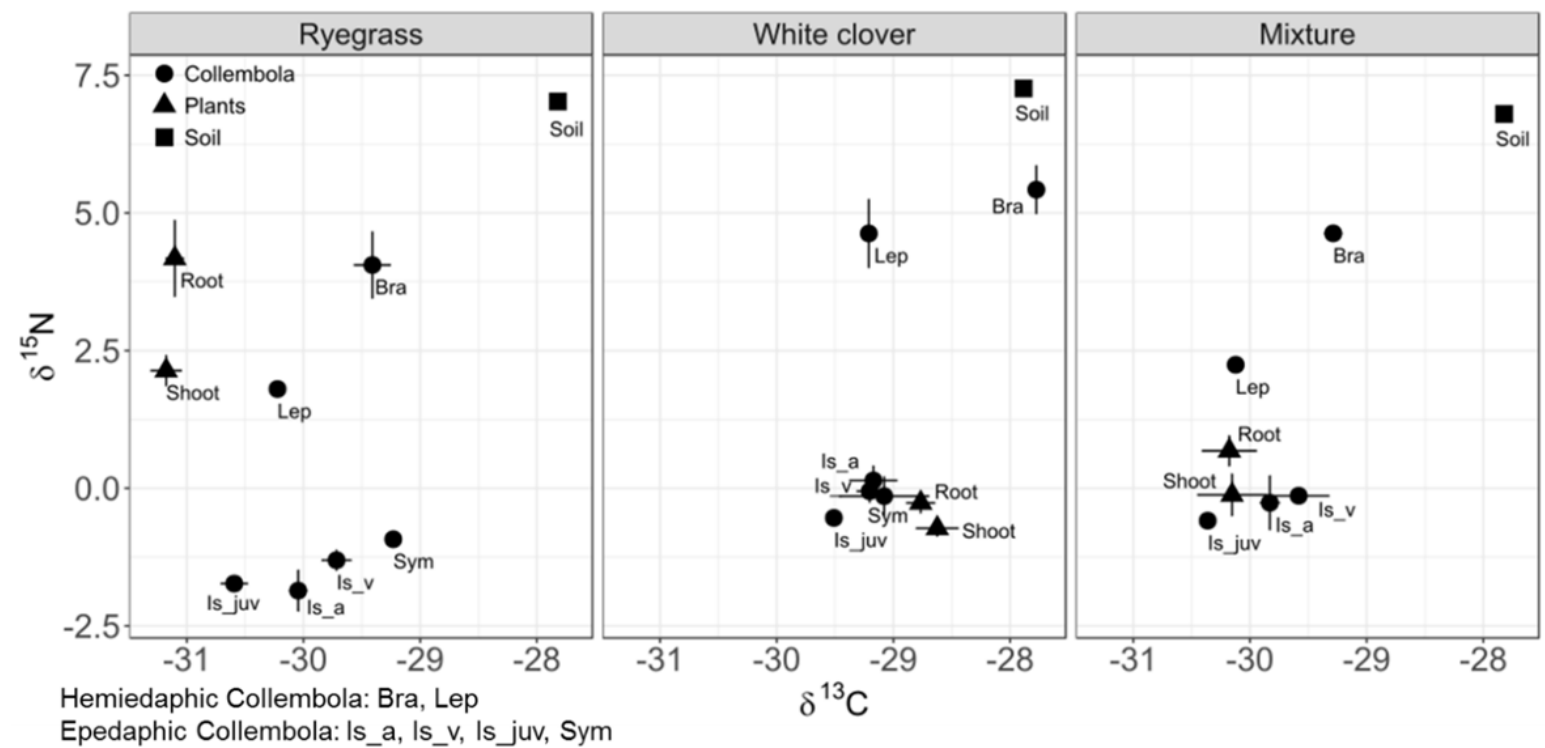

Figure 2.1 - Plot of stable isotopes $\left(\delta^{13} \mathrm{C}\right.$ and $\left.\delta^{15} \mathrm{~N}\right)$ mean and standard error (SE) values of Collembola, soil and plants collected in May 2012. Is_a=Isotoma anglicana, Is_v=I. viridis, Is_juv=Isotomidae juveniles, Bra=Brachystomella parvula, Lep=Lepidocyrtus cyaneus, Sym=Symphypleona. The figure shows that Collembola species tend to track the $\delta^{13} \mathrm{C}$ values of ryegrass and white clover vegetation in contrast to $\delta^{15} \mathrm{~N}$ where collembolans from the ryegrass treatment were the most depleted in spite of ryegrass being more $\delta^{15} \mathrm{~N}$ enriched than white clover.

\section{Collembolan community structure}

Total Collembola densities did not reveal any significant differences across treatments and sampling periods (Table 2.5). However, PCoA ordination of taxonomic abundances (Fig. 2.2) showed that differences between sampling dates dominated, while the sampled community in each season did not show clear differences between crops. A total of 17 taxa were identified in the samplings (10 species, 3 genera, 1 subfamily, 2 families and 1 order), and they were grouped into eight higher taxa at the level of family or order; the Isotomidae family alone included five of the identified species. Twelve of the identified taxa belonged to three families (Entomobryidae, Hypogastruridae, Isotomidae) whereas the remaining five taxa were distributed with one in each family/order (Table 2.2).

The family Isotomidae was the most abundant at both samplings, with the species $D$. tigrina being the most abundant in September among the whole community, while the genus Isotoma sp. was the most abundant in May. In September, D. tigrina and P. notabilis 
Table 2.4 - Mean and standard error of Collembola, plants and soil carbon and nitrogen stable isotopes natural abundances $\left(\delta^{13} \mathrm{C}\right.$ and $\left.\delta^{15} \mathrm{~N}\right)$ in ryegrass and white clover plots. Significant differences between crops (i.e. Treat) are indicated with an asterisk $\left(^{*}\right)$. Epe: epedaphic; Hemi : hemiedaphic. Different letters next to isotopes values indicate significant $(\mathrm{p}<0.05)$ differences between species/groups of Collembola within the same type of crop.

\begin{tabular}{|c|c|c|c|c|c|c|c|}
\hline \multirow[b]{2}{*}{ Taxa } & \multirow[b]{2}{*}{$\begin{array}{l}\text { Life } \\
\text { form }\end{array}$} & \multicolumn{3}{|c|}{$\delta^{13} \mathrm{C}$} & \multicolumn{3}{|c|}{$\delta^{15} \mathrm{~N}$} \\
\hline & & Treat & Ryegrass & White clover & Treat & Ryegrass & White clover \\
\hline Isotoma anglicana & Epe & * & $-30 \pm 0.1 b$ & $-29.2 \pm 0.2 \mathbf{b}$ & * & $-1.9 \pm 0.4 \mathrm{c}$ & $0.1 \pm 0.3 \mathbf{b}$ \\
\hline Isotoma viridis & Epe & * & $-29.7 \pm 0.1 \mathbf{b}$ & $-29.2 \pm 0.1 \mathbf{b}$ & $*$ & $-1.3 \pm 0.2 c$ & $-0.1 \pm 0.2 \mathbf{b}$ \\
\hline Isotomidae juveniles & Epe & * & $-30.6 \pm 0.1 c$ & $-29.5 \mathbf{b}$ & * & $-1.7 \pm 0.1 c$ & $-0.5 \mathbf{b}$ \\
\hline Symphypleona & Epe & & $-29.2 \mathrm{a}$ & $-29.1 \pm 0.4 \mathbf{b}$ & & $-0.9 c$ & $-0.1 \pm 0.4 \mathbf{b}$ \\
\hline Lepidocyrtus cyaneus & Hemi & * & $-30.2 b c$ & $-29.2 \pm 0 \mathbf{b}$ & * & $1.8 \mathrm{~b}$ & $4.6 \pm 0.6 \mathrm{a}$ \\
\hline Brachystomella parvula & Hemi & * & $-29.4 \pm 0.2 \mathrm{a}$ & $-27.8 \pm 0.1 \mathrm{a}$ & * & $4.1 \pm 0.6 \mathrm{a}$ & $5.4 \pm 0.4 \mathrm{a}$ \\
\hline Roots & & * & $-31.1 \pm 0.1$ & $-28.8 \pm 0.1$ & * & $4.2 \pm 0.7$ & $-0.3 \pm 0.2$ \\
\hline Shoots & & $*$ & $-31.2 \pm 0.1$ & $-28.6 \pm 0.2$ & * & $2.1 \pm 0.3$ & $-0.7 \pm 0.2$ \\
\hline Soil & & & $-27.8 \pm 0.0$ & $-27.9 \pm 0.0$ & & $7 \pm 0.1$ & $7.3 \pm 0.1$ \\
\hline
\end{tabular}

represented more than half of the sampled community in ryegrass and white clover plots, while in the mixture plots this was covered by $D$. tigrina and Tullbergiinae sub-family.

In May, Isotoma sp. and Tullbergiinae were present in more than half of the sampled community in all the treatments. The community did not show changes in terms of dominant species, comparing different plant cover, since the family Isotomidae was always the dominant taxon in all the treatments.

In terms of abundance of individual species or genera, we did not find treatments effects within the same sampling occasion, except for $P$. notabilis and Syphypleona. Brachystomellidae, Willemia sp., D. tigrina, Isotoma sp. and M. pygmaea showed a significant effect of time only in certain treatments (Table 2.5). P. notabilis and Symhypleona were significantly more abundant in white clover compared to other plots in September and May, respectively. Collembola of the subfamily Tullbergiinae, small euedaphic springtails which were, the most abundant euedaphic specimens in our samplings, were the only ones present in both samplings and all treatments, while not showing any significant differences between seasons or treatments. 
Table 2.5 - Mean and standard error of abundances, expressed as 103 individuals per $\mathrm{m} 2$, of identified taxa per treatment (ryegrass, mixture, white clover) and sampling date. Functional diversity (FD) values for the total community are showed. Small letters indicate significant differences $(p<0.05)$ between treatments within the same sampling, while capital letters indicate significant differences between treatments across samplings. Epe: epedaphic; Hemi: hemiedaphic; Eu: euedaphic. Pearson correlation coefficients between FD indices and plants $\mathrm{C}: \mathrm{N}$ are reported below the table only for the significant correlations.

\begin{tabular}{|c|c|c|c|c|c|c|c|c|}
\hline \multirow[b]{2}{*}{ Family/Order } & \multirow[b]{2}{*}{ Identified taxon } & \multicolumn{4}{|c|}{ September 2011} & \multicolumn{3}{|c|}{ May 2012} \\
\hline & & $\begin{array}{l}\text { Life- } \\
\text { form }\end{array}$ & Ryegrass & Mixture & White clover & Ryegrass & Mixture & White clover \\
\hline Brachystomellidae & Brachystomellidae $s p$ & . Hemi & $1.59 \pm 1.13$ & $1.33 \pm 0.68$ & $0.62 \pm 0.27$ B & $4.6 \pm 2.03$ & $6.04 \pm 2.36$ & $5.78 \pm 2.24 \mathrm{~A}$ \\
\hline \multirow[t]{4}{*}{ Entomobryidae } & Entomobryidae sp. & Hemi & $0.35 \pm 0.25$ & $0 \pm 0$ & $0 \pm 0$ & $0.15 \pm 0.07$ & $0.24 \pm 0.13$ & $0.06 \pm 0.03$ \\
\hline & Lepidocyrtus cyaneus & Hemi & $1.24 \pm 0.8$ & $0 \pm 0$ & $0.35 \pm 0.25$ & $0 \pm 0$ & $0.03 \pm 0.03$ & $0 \pm 0$ \\
\hline & Pseudosinella alba & $\mathrm{Eu}$ & $0 \pm 0$ & $0.09 \pm 0.09$ & $0 \pm 0$ & $0 \pm 0$ & $0 \pm 0$ & $0 \pm 0$ \\
\hline & Total & & $1.59 \pm 1.05$ & $0.09 \pm 0.09$ & $0.35 \pm 0.25$ & $0.15 \pm 0.07$ & $0.27 \pm 0.13$ & $0.06 \pm 0.03$ \\
\hline \multirow[t]{3}{*}{ Hypogastruridae } & $\begin{array}{l}\text { Ceratophysella } \\
\text { succinea }\end{array}$ & Hemi & $0 \pm 0$ & $0.09 \pm 0.09$ & $1.59 \pm 1.17$ & $0 \pm 0$ & $0 \pm 0$ & $0 \pm 0$ \\
\hline & Willemia sp. & $\mathrm{Eu}$ & $1.15 \pm 0.71 \mathrm{~A}$ & $0.18 \pm 0.18$ & $0.53 \pm 0.34$ & $0.12 \pm 0.12$ B & $0.03 \pm 0.03$ & $0.18 \pm 0.11$ \\
\hline & Total & & $1.15 \pm 0.71$ & $0.27 \pm 0.27$ & $2.12 \pm 1.44$ & $0.12 \pm 0.12$ & $0.03 \pm 0.03$ & $0.18 \pm 0.11$ \\
\hline \multirow[t]{8}{*}{ Isotomidae } & Desoria tigrina & Hemi & $15.39 \pm 7.01$ & $11.14 \pm 4.35$ & $31.2 \pm 8.7 \mathrm{~A}$ & $2.65 \pm 1.22$ & $3.45 \pm 0.95$ & $5.78 \pm 1.71 \mathrm{~B}$ \\
\hline & Folsomia fimetaria & $\mathrm{Eu}$ & $1.86 \pm 1.13$ & $0.27 \pm 0.27$ & $1.86 \pm 0.57$ & $0 \pm 0$ & $0 \pm 0$ & $0 \pm 0$ \\
\hline & Isotomiella minor & $\mathrm{Eu}$ & $0 \pm 0$ & $0.09 \pm 0.09$ & $0 \pm 0$ & $0 \pm 0$ & $0.24 \pm 0.24$ & $0.62 \pm 0.54$ \\
\hline & Isotoma sp. & Epe & $0 \pm 0$ & $2.12 \pm 2.12 \mathrm{~B}$ & $0.35 \pm 0.35$ B & $16.7 \pm 10.3$ & $29.6 \pm 7.1 \mathrm{~A}$ & $25.2 \pm 13.9 \mathrm{~A}$ \\
\hline & $\begin{array}{l}\text { Isotomodes } \\
\text { productus }\end{array}$ & Eu & $0.27 \pm 0.27$ & $0 \pm 0$ & $0.97 \pm 0.86$ & $0 \pm 0$ & $0 \pm 0$ & $0 \pm 0$ \\
\hline & Isotomurus sp. & Epe & $0 \pm 0$ & $0 \pm 0$ & $0 \pm 0$ & $1.27 \pm 0.74$ & $0.74 \pm 0.55$ & $1.86 \pm 1.7$ \\
\hline & Parisotoma notabilis & Hemi & $8.8 \pm 4.1 \mathrm{ab}, \mathrm{A}$ & $1.9 \pm 1.2 \mathbf{b}$ & $13.6 \pm 2.9 \mathrm{a}, \mathbf{A}$ & $0.5 \pm 0.3$ B & $1.03 \pm 0.48$ & $2.59 \pm 1.22 \mathrm{~B}$ \\
\hline & Total & & $26.35 \pm 11.63$ & $15.56 \pm 5.08$ & $48.01 \pm 9.53$ & $21.1 \pm 11.9$ & $35.07 \pm 6.75$ & $36.0 \pm 17.0$ \\
\hline Neanuridae & $\begin{array}{l}\text { Micranurida } \\
\text { pygmaea }\end{array}$ & Eu & $0.8 \pm 0.37$ & $0.18 \pm 0.18$ & $2.83 \pm 1.44 \mathrm{~A}$ & $0.12 \pm 0.08$ & $0.3 \pm 0.26$ & $0.27 \pm 0.19 \mathrm{~B}$ \\
\hline Neelidae & $\begin{array}{l}\text { Megalothorax } \\
\text { minimus }\end{array}$ & Eu & $0.09 \pm 0.09$ & $0.09 \pm 0.09$ & $0.09 \pm 0.09$ & $0 \pm 0$ & $0 \pm 0$ & $0 \pm 0$ \\
\hline Symphypleona & Symphypleona & Epe & $1.59 \pm 0.55$ & $1.77 \pm 0.66$ & $3.01 \pm 0.9$ & $0.32 \pm 0.1 \mathbf{b}$ & $0.5 \pm 0.16 b$ & $1.86 \pm 0.47 a$ \\
\hline Tullbergiidae & Tullbergiinae & $\mathrm{Eu}$ & $4.69 \pm 3.05$ & $2.65 \pm 1.48$ & $8.4 \pm 4.68$ & $3.6 \pm 1.82$ & $2.98 \pm 0.92$ & $4.22 \pm 1.09$ \\
\hline Total Collembola & & & $37.8 \pm 15.7$ & $21.9 \pm 6.1$ & $65.4 \pm 10.8$ & $30 \pm 12.8$ & $45.2 \pm 7.8$ & $48.4 \pm 16.9$ \\
\hline $\begin{array}{l}\text { Functional } \\
1 \\
\text { richness }\end{array}$ & & & $0.06 \pm 0.02 a b, A$ & $0.03 \pm 0.01 \mathbf{b}$ & $0.07 \pm 0.0 \mathrm{a}, \mathrm{A}$ & $0.02 \pm 0.00 \mathrm{~B}$ & $0.03 \pm 0.004$ & $0.04 \pm 0.00 \mathrm{~B}$ \\
\hline $\begin{array}{l}\text { Functional } \\
\text { divergence }\end{array}$ & & & $0.78 \pm 0.04$ & $0.74 \pm 0.1$ & $0.77 \pm 0.02$ & $0.71 \pm 0.05$ & $0.73 \pm 0.04$ & $0.71 \pm 0.04$ \\
\hline $\begin{array}{l}\text { Functional } \\
2 \\
\text { evenness }\end{array}$ & & & $0.61 \pm 0.08$ & $0.69 \pm 0.04$ & $0.6 \pm 0.03$ & $0.65 \pm 0.04$ & $0.62 \pm 0.03$ & $0.66 \pm 0.03$ \\
\hline $\begin{array}{l}{ }^{1} \text { May 2012: Roots } \\
{ }^{2} \text { May 2012: Shoots } \\
\text { Time x Treatment: }\end{array}$ & $\begin{array}{l}\mathrm{C}: \mathrm{N}: r(33)=-0.52, p=0 \\
\text { s C:N }: r(21)=-0.42, p= \\
\text { Parisotoma notabilis }\end{array}$ & $\begin{array}{l}0.001 ; \\
=0.011 . \\
* ; \text { Fun }\end{array}$ & $\begin{array}{l}\text { Shoots } \mathrm{C}: \mathrm{N}: r(21)= \\
\text { ctional richness * }\end{array}$ & $=-0.47, p=0$ & & & & \\
\hline
\end{tabular}


Food base and functional diversity of Collembola in agricultural grassland

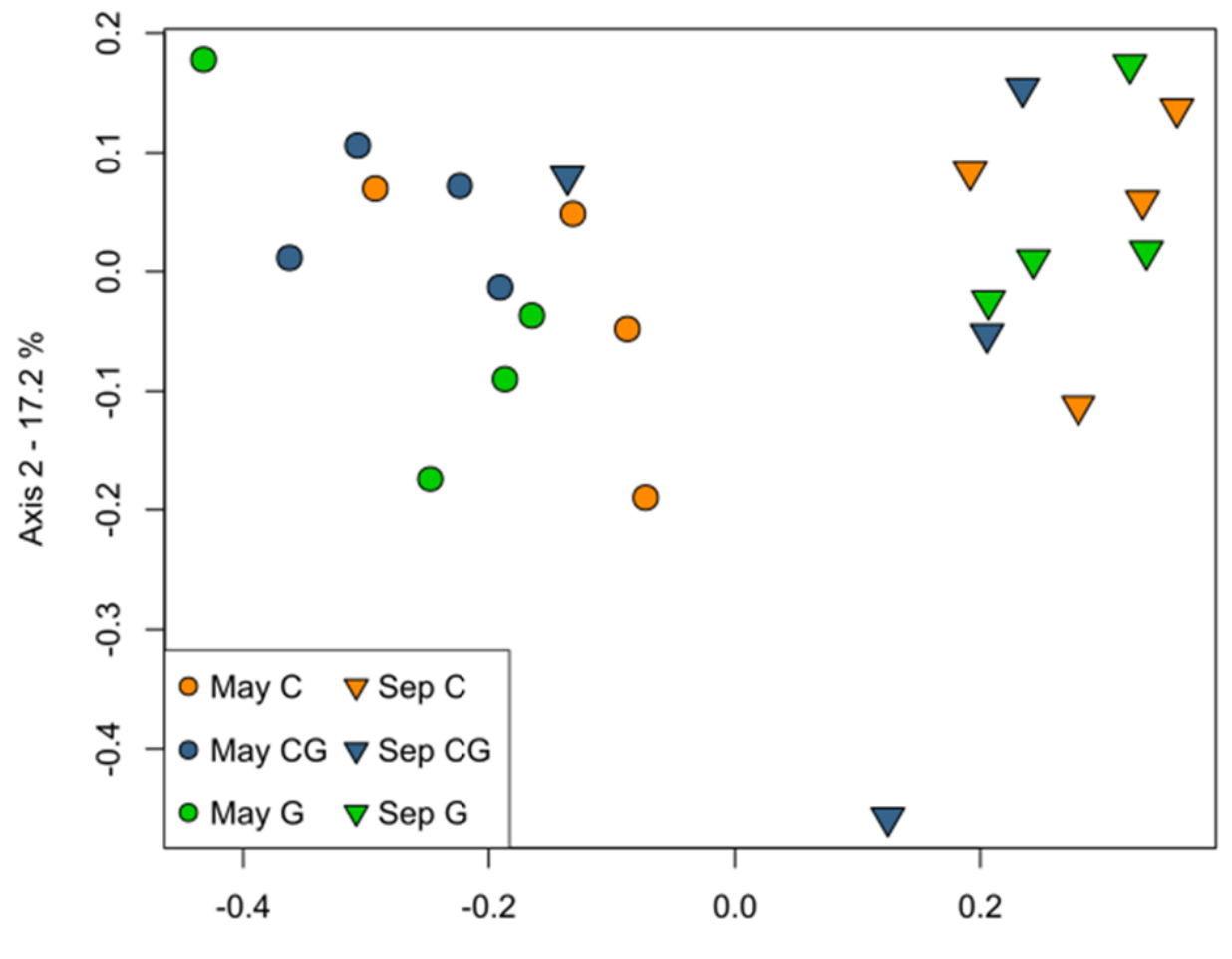

Axis $1-59.4 \%$

Figure 2.2 - Principal Coordinate Analysis on Collembola abundances. The variance explained by each axis is showed in the axis label. Sep: samples from September 2011 (triangles); May: samples from May 2012 (circles); C = white clover (orange); G: ryegrass (green); CG: mixture (blue).

\section{Traits analysis and functional diversity}

Community Weighted Mean (CWM) values for most traits showed significant differences between the two samplings. PCoA also showed that differences between sampling dates prevailed on differences between crops (Fig. 2.3).

Concerning morphological traits, species bigger in size, with long antennae and without a body pigmentation pattern prevailed in May (Table 2.6). All ecological traits showed significant differences between September and May samplings. Epedaphic species were the dominant life-form in May, while in September hemiedaphic species prevailed (Table 2.7). Moreover, the collembolan community developed from September to May towards a narrower habitat preference, significantly under white clover and mixture crop, and had preference for moister environment in all the crops. Sucking mouth parts also prevailed in May compared to September, under white clover and mixture, although Collembola with 
Table 2.6 - Community Weighted Mean (CWM) values and standard error averaged per treatment (ryegrass, mixture, white clover) and sampling date. For quantitative traits (no. of ocelli and body size), the mean values is reported. For qualitative traits (all the rest), the average percentage (\%) of each trait level is reported. Small letters indicate significant differences $(\mathrm{p}<0.05)$ between treatments (ryegrass, mixture and white clover) within the same sampling, and capital letters indicate significant differences between treatments across samplings. Pearson correlation coefficients with plants C:N are reported below the table only for the significant correlations.

\begin{tabular}{|c|c|c|c|c|c|c|c|}
\hline \multirow[b]{2}{*}{ Traits } & \multirow[b]{2}{*}{ Levels } & \multicolumn{2}{|c|}{ September 2011} & \multirow[b]{2}{*}{$\begin{array}{l}\text { White } \\
\text { clover }\end{array}$} & \multicolumn{2}{|l|}{ May 2012} & \multirow[b]{2}{*}{ White clover } \\
\hline & & Ryegrass & Mixture & & Ryegrass & Mixture & \\
\hline \multirow{2}{*}{\multicolumn{2}{|c|}{$\begin{array}{l}\text { No. of ocelli } \\
\text { Body size } \\
\text { (max., in } \mathrm{mm})^{1}\end{array}$}} & $5 \pm 0$ & $6 \pm 1$ & $5 \pm 0$ & $6 \pm 0$ & $7 \pm 0$ & $7 \pm 0$ \\
\hline & & $1.39 \pm 0.06 \mathrm{~B}$ & $1.68 \pm 0.35 \mathrm{~B}$ & $1.46 \pm 0.08$ & $2.14 \pm 0.2 \mathrm{~A}$ & $2.37 \pm 0.17 A$ & $2.08 \pm 0.18$ \\
\hline \multirow{4}{*}{$\begin{array}{l}\text { Body } \\
\text { pigmentation } \\
\text { level (max) }\end{array}$} & white & $23 \pm 4 \%$ & $26 \pm 18 \%$ & $19 \pm 7 \%$ & $22 \pm 6 \%$ & $12 \pm 4 \%$ & $15 \pm 5 \%$ \\
\hline & lightly & $29 \pm 6 \%$ & $11 \pm 6 \%$ & $28 \pm 7 \%$ & $22 \pm 6 \%$ & $26 \pm 5 \%$ & $24 \pm 2 \%$ \\
\hline & intensely & $48 \pm 3 \%$ & $63 \pm 16 \%$ & $52 \pm 7 \%$ & $55 \pm 7 \%$ & $62 \pm 7 \%$ & $60 \pm 5 \%$ \\
\hline & Dominant level & lightly & lightly & lightly & lightly & lightly & lightly \\
\hline \multirow{3}{*}{$\begin{array}{l}\text { Body } \\
\text { pigmentation } \\
\text { pattern }\end{array}$} & absent $^{2}$ & $90 \pm 5 \%$ B & $93 \pm 1 \%$ B & $96 \pm 1 \%$ & $97 \pm 1 \%$ ab,A & $99 \pm 0 \%$ a,A & $94 \pm 1 \%$ b \\
\hline & present $^{3}$ & $10 \pm 5 \% A$ & $7 \pm 1 \% \mathbf{A}$ & $4 \pm 1 \%$ & $3 \pm 1 \% \mathbf{a b}, \mathbf{B}$ & $1 \pm 0 \% \mathbf{b}, \mathbf{B}$ & $6 \pm 1 \% a$ \\
\hline & Dominant level & absent & absent & absent & absent & absent & absent \\
\hline \multirow{3}{*}{$\begin{array}{l}\text { Modified hairs } \\
\text { or scales }\end{array}$} & absent & $97 \pm 2 \%$ B & $99 \pm 1 \%$ & $100 \pm 0 \%$ & $100 \pm 0 \% \mathbf{A}$ & $100 \pm 0 \%$ & $100 \pm 0 \%$ \\
\hline & present & $3 \pm 2 \% A$ & $1 \pm 1 \%$ & $0 \pm 0 \%$ & $0 \pm 0 \% \mathbf{B}$ & $0 \pm 0 \%$ & $0 \pm 0 \%$ \\
\hline & Dominant level & absent & absent & absent & absent & absent & absent \\
\hline \multirow[t]{5}{*}{$\begin{array}{l}\text { Furca } \\
\text { development }\end{array}$} & absent & $20 \pm 5 \%$ & $22 \pm 15 \%$ & $19 \pm 7 \%$ & $23 \pm 6 \%$ & $12 \pm 4 \%$ & $16 \pm 6 \%$ \\
\hline & reduced & $2 \pm 2 \% A$ & $0 \pm 0 \%$ & $1 \pm 1 \% \mathrm{~A}$ & $0 \pm 0 \% \mathrm{~B}$ & $0 \pm 0 \%$ & $0 \pm 0 \% \mathbf{B}$ \\
\hline & $\begin{array}{l}\text { fully developed } \\
\text { short }\end{array}$ & $4 \pm 2 \%$ & $5 \pm 2 \%$ B & $4 \pm 2 \%$ & $16 \pm 5 \%$ & $20 \pm 6 \% A$ & $16 \pm 3 \%$ \\
\hline & $\begin{array}{l}\text { fully developed } \\
\text { long }\end{array}$ & $74 \pm 5 \%$ & $73 \pm 13 \%$ & $76 \pm 6 \%$ & $61 \pm 7 \%$ & $68 \pm 7 \%$ & $68 \pm 6 \%$ \\
\hline & Dominant level & f.d. long & f.d. long & f.d. long & f.d. long & f.d. long & f.d. long \\
\hline \multirow{4}{*}{$\begin{array}{l}\text { Antenna } \\
\text { estimated } \\
\text { length }\end{array}$} & short & $24 \pm 5 \%$ & $28 \pm 14 \%$ & $22 \pm 6 \%$ & $39 \pm 7 \%$ & $32 \pm 7 \%$ & $32 \pm 6 \%$ \\
\hline & medium ${ }^{4}$ & $76 \pm 4 \% A$ & $60 \pm 12 \% \mathbf{A}$ & $77 \pm 6 \% A$ & $17 \pm 4 \%$ b,B & $17 \pm 3 \%$ ab, B & $30 \pm 4 \%$ a,B \\
\hline & long ${ }^{5}$ & $1 \pm 1 \%$ B & $12 \pm 12 \%$ B & $1 \pm 1 \%$ B & $44 \pm 8 \% A$ & $51 \pm 8 \% \mathbf{A}$ & $38 \pm 7 \% A$ \\
\hline & Dominant level & medium & medium & medium & long & long & long \\
\hline $\begin{array}{l}\text { May 2012: Sho } \\
{ }_{2} \text { May 2012: Shc } \\
{ }_{3} \text { May 2012: Sh } \\
{ }_{5} \text { May 2012: Ro } \\
\text { May 2012: Shc }\end{array}$ & $\begin{array}{l}\text { ots } C: N: r(22)=0 \\
\text { oots } C: N: r(22)= \\
\text { oots } C: N: r(22)= \\
\text { ots } C: N: r(34)=-0 \\
\text { oots } C: N: r(22)=\end{array}$ & $\begin{array}{l}.40, p=0.015 \\
.51, p=0.002 \\
-0.51, p=0.002 \\
.34, p=0.04 \\
.34, p=0.041\end{array}$ & Shoots $\mathrm{C}: \mathrm{N}: r$ & $(22)=-0.46, p$ & $0=0.005$ & & \\
\hline
\end{tabular}




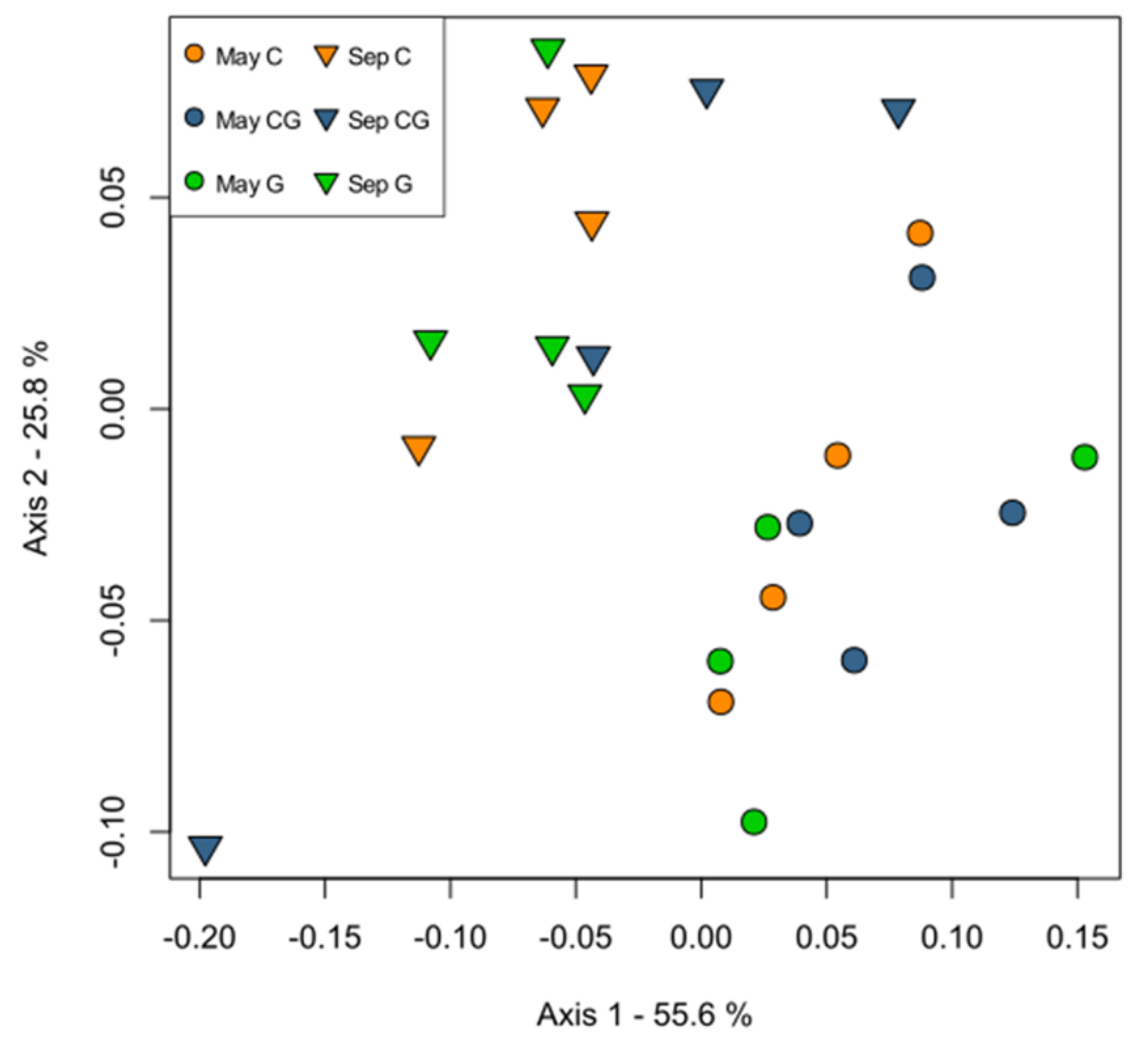

Figure 2.3 - Principal Coordinate Analysis on Collembola Community Weighted Mean (CWM) trait scores. The variance explained by each axis is showed in the axis label. Sep: samples from September 2011 (triangles); May: samples from May 2012 (circles); C = white clover (orange); G: ryegrass (green); CG: mixture (blue).

grinding mouthparts were dominant in both seasons. Statistically significant differences between treatments within the same sampling occurred in May in the antenna trait, being the medium antenna length relatively more present in the community under white clover compared to ryegrass, and in the body pigmentation pattern, where the absence of body pigmentation pattern was relatively more present under mixture compared to white clover plots.

The functional richness of the community was significantly lower in May in the ryegrass and white clover plots compared to September (Table 2.5). It also differed between treatments in September, being significantly higher in the white clover plots compared to the mixture. No differences were detected for the functional evenness, nor for the functional divergence, neither between treatments nor between seasons. 
Table 2.7 - Community Weighted Mean (CWM) values and standard error for the ecological traits averaged per treatment (ryegrass, mixture, white clover) and sampling date. The average percentage (\%) of each trait level is reported. Small letters indicate significant differences $(\mathrm{p}<0.05)$ between treatments within the same sampling, and capital letters indicate significant differences between treatments across samplings.

\begin{tabular}{|c|c|c|c|c|c|c|c|}
\hline \multirow{2}{*}{ Traits } & \multirow[b]{2}{*}{ Levels } & \multicolumn{3}{|c|}{ September 2011} & \multicolumn{3}{|l|}{ May 2012} \\
\hline & & Ryegrass & Mixture & White clover & Ryegrass & Mixture & White clover \\
\hline \multirow{3}{*}{$\begin{array}{l}\text { Habitat } \\
\text { width }\end{array}$} & steno/eury & $4 \pm 2 \%$ & $4 \pm 2 \% B$ & $1 \pm 1 \% B$ & $16 \pm 5 \%$ & $20 \pm 6 \% A$ & $16 \pm 3 \% A$ \\
\hline & $\begin{array}{l}\text { eury and } \\
\text { eury/syn }\end{array}$ & $96 \pm 2 \%$ & $96 \pm 2 \% A$ & $99 \pm 1 \% A$ & $84 \pm 5 \%$ & $80 \pm 6 \% B$ & $84 \pm 3 \%$ B \\
\hline & Dominant level & eury-eury/syn & $\begin{array}{l}\text { eury- } \\
\text { eury/syn }\end{array}$ & $\begin{array}{l}\text { eury- } \\
\text { eury/syn }\end{array}$ & $\begin{array}{l}\text { eury- } \\
\text { eury/syn }\end{array}$ & $\begin{array}{l}\text { eury- } \\
\text { eury/syn }\end{array}$ & eury-eury/syn \\
\hline \multirow{5}{*}{$\begin{array}{l}\text { Moisture } \\
\text { preference }\end{array}$} & xero-mesophilic & $1 \pm 1 \%$ & $0 \pm 0 \%$ & $0 \pm 0 \%$ & $0 \pm 0 \%$ & $0 \pm 0 \%$ & $0 \pm 0 \%$ \\
\hline & Indifferent & $20 \pm 7 \%$ & $30 \pm 16 \%$ & $18 \pm 8 \%$ & $25 \pm 7 \%$ & $12 \pm 5 \%$ & $20 \pm 5 \%$ \\
\hline & Mesophilic & $76 \pm 8 \%$ & $64 \pm 15 \%$ & $78 \pm 7 \%$ & $55 \pm 7 \%$ & $64 \pm 8 \%$ & $61 \pm 5 \%$ \\
\hline & $\begin{array}{l}\text { meso- } \\
\text { hydrophilic }\end{array}$ & $4 \pm 2 \% B$ & $6 \pm 2 \% B$ & $4 \pm 2 \% B$ & $20 \pm 5 \% A$ & $24 \pm 6 \% A$ & $19 \pm 3 \% \mathrm{~A}$ \\
\hline & Dominant level & mesophilic & mesophilic & mesophilic & mesophilic & mesophilic & mesophilic \\
\hline \multirow[t]{4}{*}{ Mouthparts } & Sucking & $4 \pm 2 \%$ & $4 \pm 2 \% B$ & $1 \pm 1 \% B$ & $16 \pm 5 \%$ & $20 \pm 6 \% A$ & $16 \pm 3 \% A$ \\
\hline & Grinding & $95 \pm 1 \%$ & $95 \pm 2 \% A$ & $95 \pm 1 \%$ & $83 \pm 5 \%$ & $80 \pm 6 \% B$ & $82 \pm 3 \%$ \\
\hline & Piercing & $2 \pm 1 \% a b, A$ & $1 \pm 1 \% b$ & $4 \pm 1 \% a, A$ & $0 \pm 0 \% B$ & $0 \pm 0 \%$ & $1 \pm 1 \% B$ \\
\hline & Dominant level & grinding & grinding & grinding & grinding & grinding & grinding \\
\hline \multirow[t]{4}{*}{ Life-form } & Epedaphic & $9 \pm 6 \% B$ & $19 \pm 12 \% \mathrm{~B}$ & $5 \pm 1 \% B$ & $50 \pm 8 \% A$ & $55 \pm 7 \% A$ & $47 \pm 7 \% \mathrm{~A}$ \\
\hline & Hemiedaphic & $66 \pm 7 \% A$ & $54 \pm 15 \%$ & $72 \pm 6 \% A$ & $28 \pm 8 \% B$ & $32 \pm 7 \%$ & $37 \pm 6 \% \mathrm{~B}$ \\
\hline & Euedaphic & $25 \pm 4 \%$ & $27 \pm 18 \%$ & $23 \pm 7 \%$ & $23 \pm 6 \%$ & $12 \pm 4 \%$ & $17 \pm 6 \%$ \\
\hline & Dominant level & hemiedaphic & hemiedaphic & hemiedaphic & epedaphic & epedaphic & epedaphic \\
\hline
\end{tabular}

Some CWM values, functional richness and functional evenness resulted significantly correlated with plants C:N ratios only in May (Table 2.6 and Table 2.7; see Supplementary material for all correlations). Particularly, medium antennae length was negatively correlated with roots and shoots $\mathrm{C}: \mathrm{N}$. Body size, absence of pigmentation pattern and long antennae were positively correlated with shoots C:N. Functional richness was negatively correlated with both roots and shoots $\mathrm{C}: \mathrm{N}$, while functional evenness was negatively correlated only with shoots C:N. 


\section{Discussion}

\section{Changes in stable isotopes values}

Based on isotopic evidence, we confirmed our hypothesis that Collembola rely on recent crop photosynthates but mostly in plots with white clover. This was particularly evident for the lowest trophic group, i.e. Isotoma sp. and Symphypleona, which under ryegrass crop seemed to feed on a broader range of carbon source. In fact, their carbon value in ryegrass crop was positioned in between plant and soil, while under white clover it was very much closer to the one of plant material. The $\delta^{15} \mathrm{~N}$ values of these two epedaphic taxa were significantly more enriched in white clover than ryegrass plots in spite of ryegrass being significantly more $\delta^{15} \mathrm{~N}$ enriched than white clover. Therefore, it is unlikely that ryegrass made a substantial contribution to the epedaphic species considering that the trophic enrichment per trophic level typically is around 3\%o. We suggest that the depleted $\delta^{15} \mathrm{~N}$ values in Collembola compared to plants could be attributed to collembolan feeding on algae or lichens, particularly in the ryegrass plots. Potapov et al. (2014) summarized that depleted ${ }^{13} \mathrm{C}$ and ${ }^{15} \mathrm{~N}$ values can be interpreted as evidence of phycophagy, i.e. feeding on non-vascular plants like algae or lichens (Chahartaghi et al., 2005; Maraun et al., 2011). Algae, lichens and mosses receive the bulk of their nitrogen from atmospheric deposition that usually have depleted $\delta^{15} \mathrm{~N}$ values (Solga et al., 2005). How nutrients were passed on from crops to Collembola is not clear, but microbes associated with litter as well as living roots could have been an important food source for Collembola.

We know from the study of Sechi et al. (2014a), based on a sampling on the same experimental field in September 2011, that Collembola presumably changed diet according to the different crop types, showing a more fungal related diet in ryegrass plots. The analysis of natural abundance of $\delta^{13} \mathrm{C}$ and $\delta^{15} \mathrm{~N}$ in Collembola we ran in May 2012 could not get insights on fungal vs. bacterial based diets, but showed a shift of diets between ryegrass and white clover. In addition to epedaphic species (see above), the two hemiedaphic species L. cyaneus and $B$. parvula showed very distinct isotopes values in reference to the $\delta^{13} \mathrm{C}$ and $\delta^{15} \mathrm{~N}$ values of each crop. Following A.A. Potapov et al. (2016), this would suggest different trophic roles of these two species in ryegrass vs. white clover plots, being primary decomposers in the former 
and secondary decomposers in the latter. Moreover, they were closer to each other in terms of $\delta^{15} \mathrm{~N}$ in white clover plots compared to other treatments. This suggests that they fed on similar diets, which could probably be driven by a different availability or palatability of the food sources in the habitat created by the presence of white clover. Nevertheless, their $\delta^{13} \mathrm{C}$ values were distinct, meaning that the carbon source they fed on was different. We suggest that future research could disentangle details about taxon-specific diets, possibly combining natural abundances stable isotopes analyses with e.g. compound-specific isotope analysis of ${ }^{13} \mathrm{C}$ in amino acids and phospholipid fatty acid analysis, in order also to characterize the soil microbial pool.

\section{Changes according to plant cover}

We did not confirm our hypothesis that a mixture of white clover and ryegrass would increase collembolan densities although several studies have shown that soils with mixtures of grasses and legumes result in positive effects on soil structure and availability of plant nutrients (e.g. Nyfeler et al., 2011; van Eekeren, 2009). Likewise, a concomitant field study performed in the same plots as ours, concluded that a grass-clover mixture increased soil $\mathrm{N}$ fertility (Kušlienè et al., 2014). Moreover, our data showed a significantly lower functional richness in the mixture plots compared to white clover plots in September. Functional richness, which measures the amount of niche space filled by the species, is independent of abundance (analogously as a species counts for species richness even if it occurs in small amounts) (Mason et al., 2005). On the other hand, we did not detect changes in the functional evenness, which does instead relate to species abundances, as it is the "degree to which the biomass of a community is distributed in niche space to allow effective utilisation of the entire range of resources available to it" (Mason et al., 2005). This indicates that the functional traits were homogeneously distributed within the community. We suggest that, some abiotic factors or soil structure changes - which we did not measure in our study might have had an influence on our results. However, the fact that we detected these differences between treatments only in autumn, i.e. six months after plots establishment, could suggest that also particular climatic conditions or even plant-growth related conditions could have affected the results. 
Ryegrass differs from white clover by having a higher C:N ratio and a higher root density. Plots with higher root density are likely to have a higher microbial biomass and higher soil fungal:bacterial ratio, as previously shown in the same experimental plots by Kušlienė et al. (2014) and Sechi et al. (2014a). However, the lower C:N ratio of clover compared to ryegrass means that the litter quality and protein content are higher (van Eekeren et al., 2007), and that root exudates are turned over faster owing to their higher nutritional value. In our study, plants litter quality, resembled by the C:N ratio of shoots, resulted to be correlated with some Collembola morphological traits and with functional richness and evenness, but this occurred only for the sampling in May. At this time, the difference in litter quality between ryegrass and white clover was double compared to September suggesting that litter quality was a driving factor for the community functionality especially in May. Salamon et al. (2004) found higher densities of Isotomidae and Symphypleona in the presence of legumes, and ascribed this result to a high litter quality and microbial biomass in the rhizosphere under legumes. These findings were partially confirmed by the higher abundance of Symphypleona we found in white clover plots compared to the other treatments, although this was statistically significant only in May. In contrast, we did not sample significantly more Isotomidae specimens in white clover plots, compared to other treatments. However, other studies found little or no effects of legumes on collembolan densities (Kooistra, 1964; Milcu et al., 2006; Sabais et al., 2011) highlighting that the abiotic and biotic controls of Collembola are complex and intricate. In our study, the high abundance of Symphypleona in white clover plots was likely linked directly to the higher nitrogen content of plant-derived material in this treatment as indicated by our isotopic results. Symphypleona are epedaphic springtails known to be herbivorous (Christiansen, 1964) and feed on algae and lichens (Chahartaghi et al., 2005).

Supposing that ryegrass and white clover hosted a different microbial community with different fungal:bacterial ratio, we expected to find more Collembola bacterial feeders in white clover plots, compared to ryegrass, which would have been characterized instead by a higher presence of fungivorous species. We did not confirm this hypothesis, as we did not find significant differences between treatments in terms of abundances of known bacterial or 
fungal feeders, such as e.g. B. parvula and L. cyaneus, respectively. Nor we found evident differences between treatments in terms of functional traits distributions. In addition to the results already mentioned about Symphypleona, $P$. notabilis was the only species showing significant different abundances between treatments, but only in September. This species is known as a secondary decomposer feeding on saprotrophic microorganisms (A.A. Potapov et al., 2016), belonging to the same feeding guild of Lepidocyrtus sp. according to Chahartaghi et al. (2005). Therefore, we should have expected a higher presence of this species in ryegrass plots. On the contrary, our results showed a higher abundance of this species in white clover plots in September, compared to the other treatments. Therefore, further investigations are needed, in order to link Collembola diets under different crops with the available microbialrelated resources.

\section{Seasonal differences}

We primarily detected differences in the community between samplings dates, rather than between treatments. However, we did not confirm our hypothesis of finding greater differences between ryegrass and white clover in September compared to May, as we detected only few cases of crops effects on taxa abundances or traits distribution.

The observed seasonal differences may be explained by plant litter quality as C:N ratios of above-ground plant parts were greater in May compared to September. Particularly, C:N ratio of ryegrass shoots (i.e. resembling litter) in May was three times higher compared to white clover, while in September this was only two times higher. The community in May was characterized by a dominance of epedaphic species, compared to September, as showed by the CWM values. At this time, this group fed probably on algae or lichens in the ryegrass plots, as indicated by our stable isotopes results. Instead, with a higher quality of plant material, as it occurred in September - and analogously in the white clover treatment across seasons epedaphic species seemed to be closer to a plant-derived feeding channel, directly or indirectly through the microbiota decomposing plants material.

Ilieva-Makulec et al. (2006), in their field mesocosm experiment, found higher springtails densities in mesocosms with low quality grass litter. They speculated that this litter could host a greater fungal component in the microbial community, which favoured 
Collembola, contrary to the high quality litter of red clover (Trifolium pratense), which fuelled an active microbial biomass dominated by bacteria. Applying their findings to our study, we suppose that a bacteria-dominant microbial community could have characterized the soil in September, when we found more specimens of some euedaphic species (though not at a significant level), which fed on bacteria exploiting the high quality of resources available for degradation (Bardgett et al., 2005). On the other hand, the fungal component probably drove the soil microbial community in May, when the more abundant epedaphic species fed possibly on a mixture of fungi and algae or lichens. That could be the case of the epedahic group Isotoma sp., whose densities were much higher compared to September.

In May the community of ryegrass and white clover plots was characterized by a lower functional richness compared to September. The lower functional richness could have been

linked to the high C:N content in the plants, indicating that some of the resources may have not been available to the community (Mason et al., 2005). In fact, we detected the lowest functional richness in the ryegrass plots in May, in correspondence to the highest C:N ratio of above-ground plants detected, and functional richness resulted to be negatively correlated with shoots C:N (i.e. positively correlated with litter quality) in May. Hence, we suggest again that the quality of plant material affected the functionality of the community. Interestingly, although changes in the functional richness occurred across seasons, the two communities maintained a homogenous distribution of the trait abundance composition as no differences were found in the functional evenness.

\section{Conclusions}

In general, our data suggest that differences in plant material quality between two seasons may have affected the collembolan community, although further samplings within one season are needed to validate these results.

Our study demonstrated that the quality of cover crops, here measured as the C:N ratio, influenced the collembolan community in terms of density of specific taxa and their functional diversity. Results from stable isotope analysis indicated that epedaphic species in particular incorporated crop derived $\mathrm{C}$, but to a greater extent in white clover than in 
ryegrass plots. Under conditions with low quality of plant-derived material, epedaphic species were more abundant, indicating that these species are less dependent on recent plant resources than euedaphic species. With high quality of plant-derived material, we found instead greater functional richness and relative higher density of euedaphic species. Against our expectations, the mixture of ryegrass and white clover did not have positive effects on population densities and functional diversity of collembolans. Future studies are needed to reveal if these effects of crop mixtures are due to direct plant interactions or to mixtureinduced changes in the physiochemical soil properties.

In general, the overall functionality of the community changed between seasons and partially between treatments, but the homogeneity of traits abundance distribution (functional evenness) was not affected by these factors. This probably means that different availability and thus different resource utilization occurred in the two seasons, although there was an even utilization of the resources by the community.

\section{Acknowledgements}

We thank curator emeritus Henning Petersen, Mols Laboratory, Natural History Museum of Aarhus, who provided the collembolan traits, the research technicians Zdenek Gavor and Elin Jørgensen at the Department of Bioscience (Aarhus University) for their assistance to the species identification, and the technicians David Croft, Karin Dyrberg and Mette Nielsen at the Department of Agroecology (Aarhus University) for their help in the field work. We are also grateful to Christian Mulder and two anonymous reviewers for their helpful comments. 


\section{Supplementary material}

Table S2.1 - Pearson correlation coefficients and p-values between C:N ratios of plants roots and shoots, and CWM values and FD indices. Significant correlations are highlighted in bold.

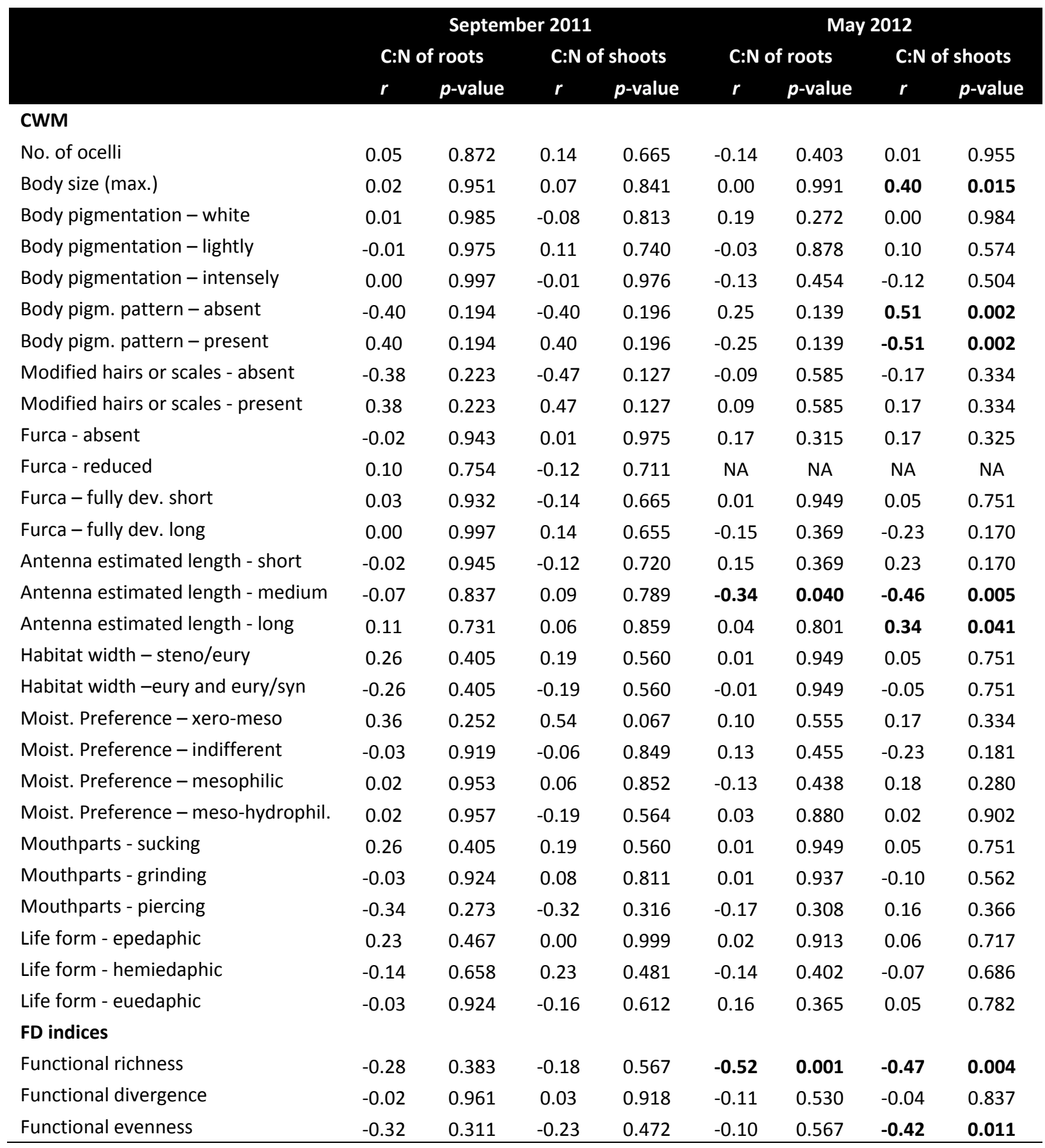


Figure S2.2 - Correlation Matrix showing the significant correlations showed in Table S2.1. On top the (absolute) value of the correlation plus the result of the correlation test as stars. On bottom, the bivariate scatterplots, with a fitted line. FRic: Functional Richness: ant_len_1: Antenna: estimated length - medium; CNroot: C:N ratio of plants roots.

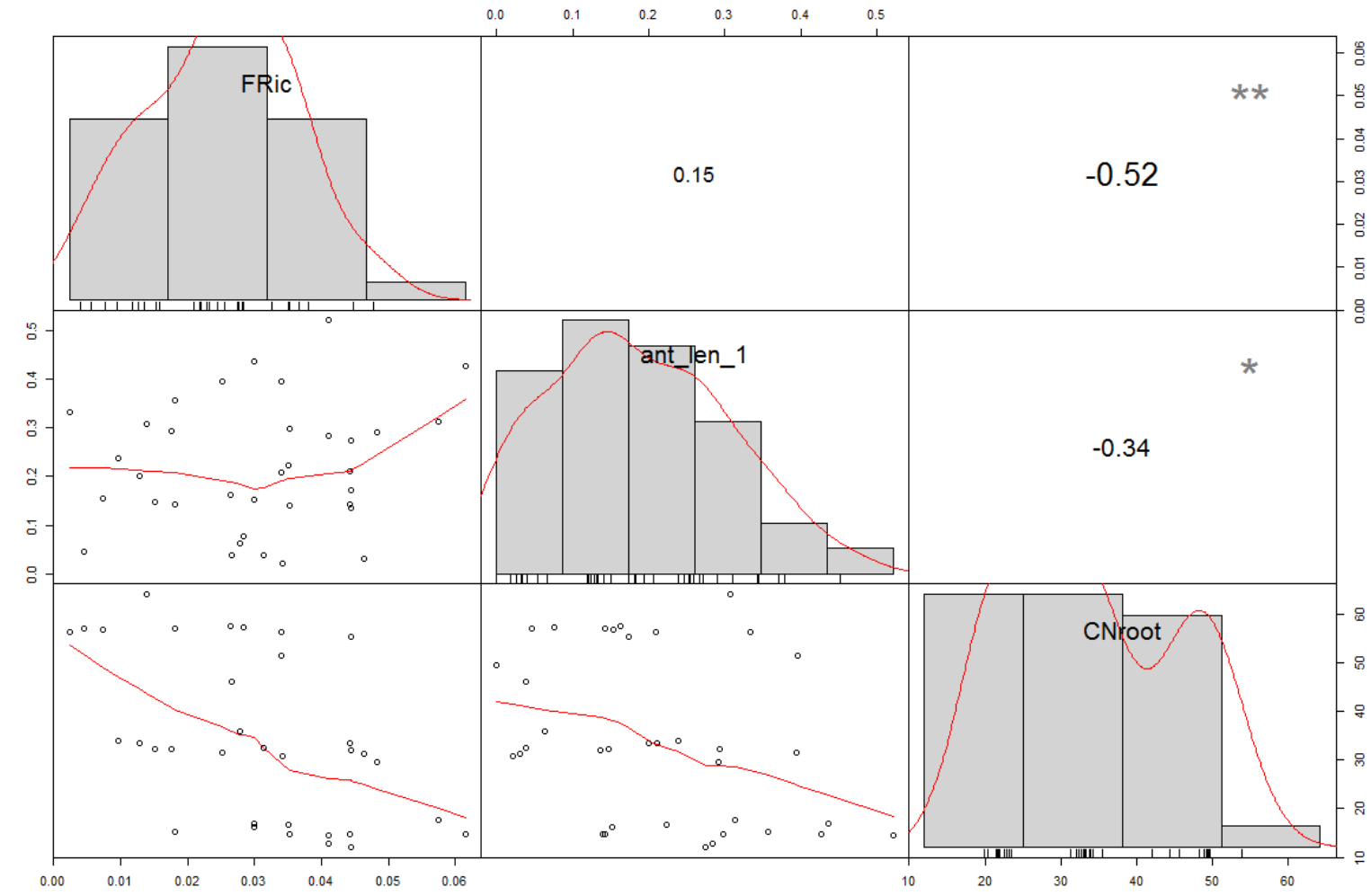


Figure S2.3 - Correlation Matrix showing the significant correlations showed in Table S2.1. On top the (absolute) value of the correlation plus the result of the correlation test as stars. On bottom, the bivariate scatterplots, with a fitted line. FRic: Functional Richness; FEve: Functional Evenness; CNshoot: C:N ratio of plants shoots.

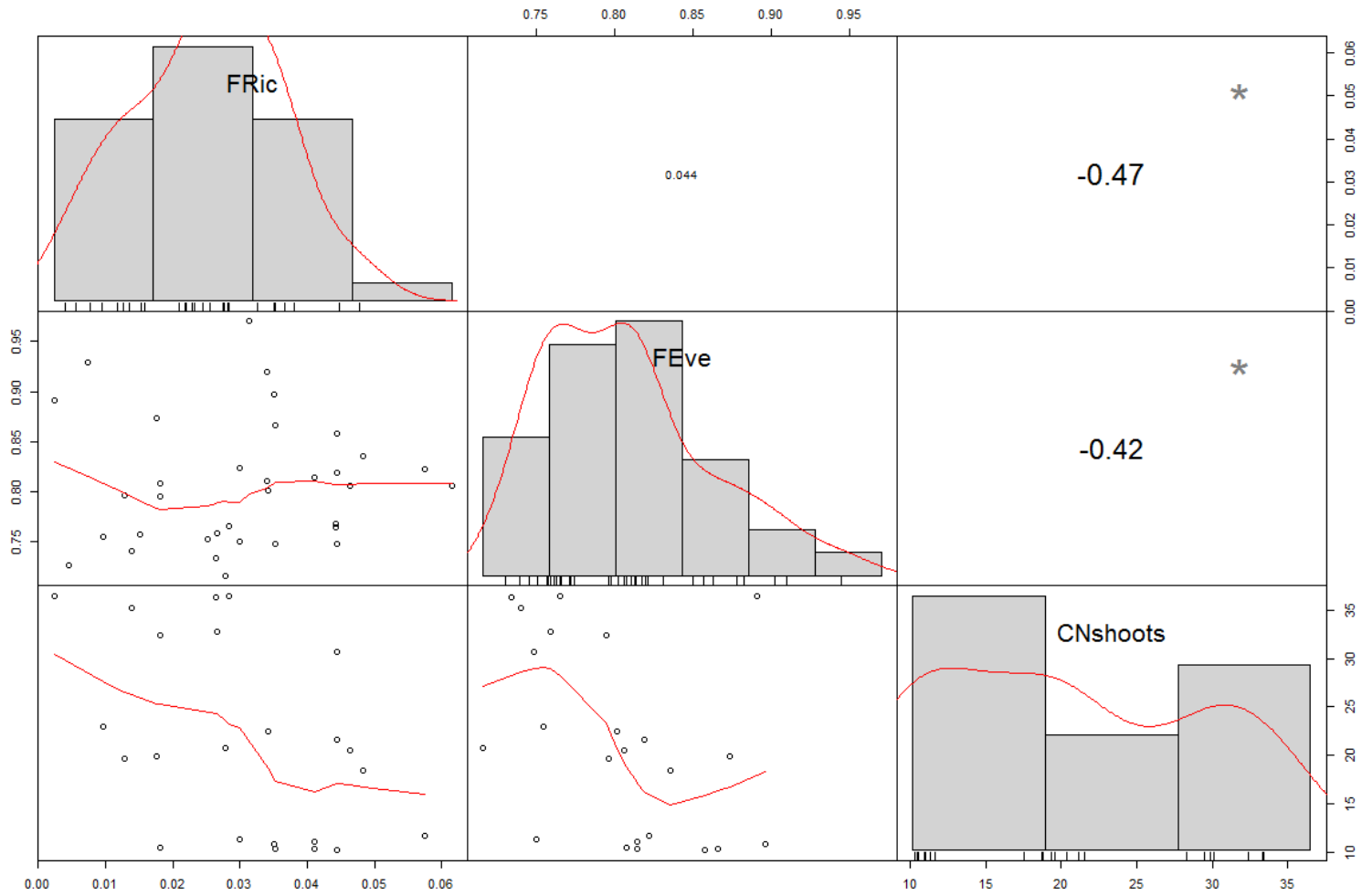


Figure S2.4 - Correlation Matrix showing the significant correlations showed in Table S2.1. On top the (absolute) value of the correlation plus the result of the correlation test as stars. On bottom, the bivariate scatterplots, with a fitted line. length = Body size (max.), pattern_0 = Body pigmentation pattern - absent, pattern_1: Body pigmentation pattern - present; ant_len_1: Antenna estimated length - medium; ant_len_2: Antenna estimated length - long; CNroot: C:N ratio of plants roots.

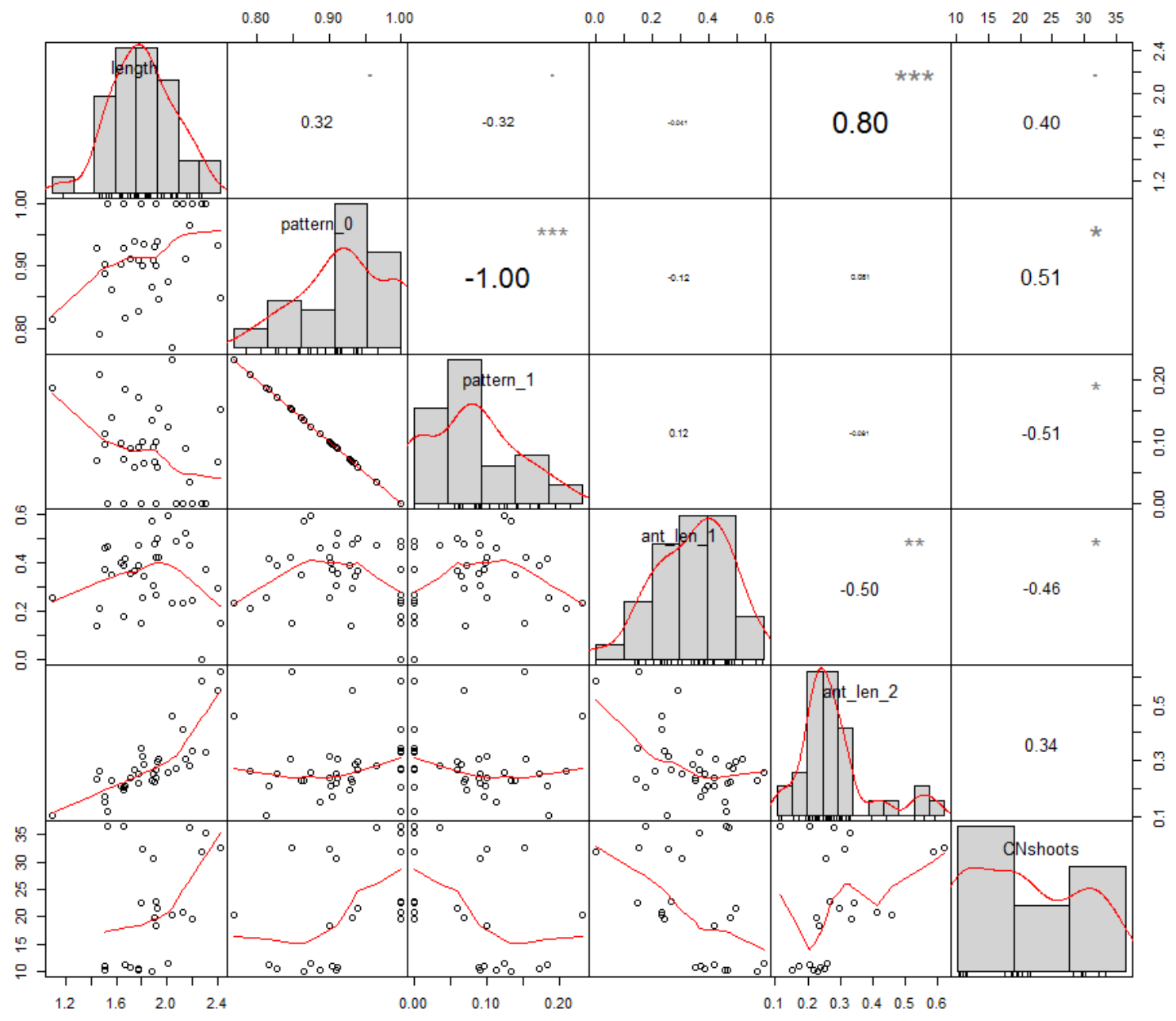


Chapter 3

A community trait-based approach to ecosystem functioning in soil 



\title{
A community trait-based approach to ecosystem functioning in soil
}

Chapter published in Agriculture, Ecosystems and Environment, 2017

239: $265-273$

\author{
Valentina Sechi, Ron G. M. De Goede, Michiel Rutgers, Lijbert Brussaard, \\ Christian Mulder
}

\begin{abstract}
Functional traits capture characteristics of organisms that determine their individual response to environmental pressures, providing a mechanistic understanding of habitat responses and the effects on ecological processes. Trait-based approaches have already been reported for separate soil groups like bacteria, nematodes and collembolans but investigating these groups together could bring better insights in assessing both environmental pressures and state of the systems. Still, selecting a suite of single traits that might encompass the large heterogeneity in soil biota remains a challenge for community trait-based analyses. We sampled arable fields and their adjacent (buffer zone) margins to investigate overall trait-based responses of the soil community to agricultural management. We explored the suitability of three groups of functional traits (i.e. eco-physiological traits, behavioural traits and faunal morphological traits) to analyse how different components of the soil biota (fungi, bacteria, micro- and mesofauna) respond to agricultural management and to what extent the selected traits detect effects on soil functioning. For microbes, we opted for eco-physiological trait proxies due to the difficulties to study these organisms at individual level. Our results showed that ecophysiological traits reflected differences in nutrient cycling dynamics and carbon storage driven by the soil microbial community. The structural organization of micro- and the mesofauna trophic grouping and body mass distribution reflected effects of agricultural management on soil assemblages and revealed differences in the responses of these groups to the environment. We recognize some methodological limitations of our comprehensive community trait-based approach. Yet our analysis reveals characteristics of the soil community structure and belowground ecological processes, as i.e. the partial shift from the bacterial- to the fungal-driven energy channels, that could not be detected by traditional methods, showing the potential of this approach in determining environmental pressures and in evaluating ecosystem services.
\end{abstract}




\section{Introduction}

Trait-based approaches, focusing on the functional characteristics of individuals, provide a mechanistic understanding of habitat responses and ecosystem functioning (Lavorel et al. 2013; Verberk et al. 2013). Functional traits capture characteristics of organisms (i.e. morphological, physiological, phenological or behavioural) that are linked to life-history and ecological functioning, and determine individual response to pressures and subsequent effects on ecological processes (Violle et al. 2007; Díaz et al. 2013). Hence, traits can be used as indicators of specific ecological processes (e.g. Lavorel et al. 1997; Harrington et al. 2010; Lavorel and Grigulis 2012) and changes in means and distributions of trait values within a community can be seen as early warning signals of disturbance (Mulder et al. 2012; Mouillot et al. 2013). Over the last three decades, especially in plant ecology (Violle et al. 2007), and more recently in soil ecology (e.g. Mulder et al. 2005a; Pelosi et al. 2014; Pey et al. 2014), the trait-based approach has been widely used in many studies ranging from organism up to ecosystem levels. Trait-based approaches have already been reported for separate soil groups like bacteria, nematodes and collembolans (e.g. Lennon et al 2012; Vonk et al. 2013; Widenfalk et al. 2015 respectively), but investigating these groups together could bring better insights in assessing both the environmental pressures and the state of the systems. Still, such a community trait-based approach is challenging in representing the enormous diversity of soil life across microbial and faunal groups (Pey et al. 2014). Moreover, little is known regarding the distribution of microbial functional traits in nature (Green et al. 2008) and it is still difficult to study microbial communities at individual or species level.

Therefore, for microbes, we selected 'eco-physiological trait proxies' correlated with microbial metabolism that determine most of the primary consumption in soil systems (Mulder et al. 2006a). For the rest of the soil groups, we analysed two key behavioural and morphological traits (feeding guild and body mass) that determine most of the decomposition process in soil, as well as nutrient cycling (Peters 1983; Calder 1984; Hendriks and Mulder 2008).

Hence, here we wish to explore the suitability of the three groups of functional traits, i.e. eco-physiological, behavioural, and morphological traits, in detecting the effects of 
environmental pressures across different groups of soil biota. We used a suite of these traits to analyse how different components of the soil biota (fungi, bacteria, micro- and mesofauna) respond to agricultural management. In particular, we hypothesized that:

i) The values of the selected eco-physiological traits will reflect differences in the nutrient cycling and carbon storage driven by the soil microbial community;

ii) Trophic grouping will reflect the environmental filtering acting on soil organisms and hence will reveal potential shifts between the bacterial and the fungal-driven energy channels;

iii) Trophic grouping, together with the body-mass distribution, will reveal differences in the responses of the micro- and the mesofauna to the environment;

iv) The structural organization of basal resources and consumer guilds will reflect the effects of agricultural management on soil community assemblages.

\section{Materials and Methods}

\section{SAMPLING AND EXPERIMENTAL DESIGN}

\section{Locations and sampling}

The sampling took place in 2012, September 22 $2^{\text {nd }}-2^{\text {th }}$ in Hoeksche Waard (The Netherlands) and was spread over an area of about $55 \mathrm{~km}^{2}$ (from $51^{\circ} 43^{\prime} 54^{\prime \prime} \mathrm{N}$ to $51^{\circ} 48^{\prime} 21^{\prime \prime} \mathrm{N}$ and from $4^{\circ} 25^{\prime} 45^{\prime \prime} \mathrm{E}$ to $4^{\circ} 36^{\prime} 21^{\prime \prime} \mathrm{E}$ ). This area has been investigated in many projects which facilitated the access to the farms (Heijting et al. 2011; Rutgers et al. 2012) and holds the promise to contribute to transdisciplinary approaches for improving agro-environmental management schemes (Alebeek et al. 2006). Four farms were selected to be comparable in terms of type of crop, rotation scheme and presence of adjacent field margins as buffer zones (Mulder et al. 2017). All the arable fields were under conventional management (Crittenden et al. 2015) whereas their field margins, always between the investigated arable field and a ditch, were not seeded, ploughed, or manured at least since four years. At each farm, we sampled eight spots: four spots in the arable field $\left(1 \times 1 \mathrm{~m}^{2}\right)$ and four spots $\left(1 \times 1 \mathrm{~m}^{2}\right)$ in the field margin. The distance between each sampling spot was close to $20 \mathrm{~m}$. We considered this distance sufficient to ensure independence between each spot within the same management 
(field margins and arable fields), and between the two habitats in terms of, for instance, movements of the soil fauna. For each sampling spot, 50 soil cores $(\varnothing 2.3 \mathrm{~cm}$, depth $10 \mathrm{~cm})$ were collected and mixed to measure soil abiotics and microbial parameters, and to extract nematodes. Three larger intact soil cores $(\varnothing 5.8 \mathrm{~cm}$, depth $10 \mathrm{~cm})$ were used for analysis of mesofauna (collembolans and mites).

\section{Soil parameters}

Soil characterisation and chemical analysis of soil samples were performed according to the standard methods used in the Netherlands Soil Monitoring Network (Rutgers et al. 2009): the soil $\mathrm{pH}$ was measured in $1 \mathrm{M} \mathrm{KCl}$ solution at a soil to solution ratio of 1:1 (weight:volume). Total soil C (C-tot: $\mathrm{mg} \cdot \mathrm{Kg}^{-1}$ ) was determined by thermogravimetric analysis while total soil $\mathrm{N}$ (N-tot: $\mathrm{mg} \cdot \mathrm{Kg}^{-1}$ ) was determined by a titrimetric method after distillation using Kjeldahl destruction. Total soil P (P-tot) was determined by Automated Ion Analyzer after sample digestion. Pore water-extractable phosphorus $\left(\mathrm{P}_{\mathrm{w}}\right)$ was determined as $\mathrm{mg} \mathrm{P} \mathrm{L}^{-1}$, after extraction at a soil to water ratio 1:60 (volume:volume). Soil organic matter (OM\%) was measured by loss on ignition and hot water extractable carbon (HWC) was analysed according to Sparling et al. (1998). Clay percentage (Clay\%) was estimated after sieving by granulometric analysis. Bulk density was measured in the 5-10 cm layer below the soil surface in ring samples containing $100 \mathrm{~cm}^{3}$ of soil.

\section{Microbial parameters}

Bacterial biomass was estimated from numerical abundance and biovolume using a

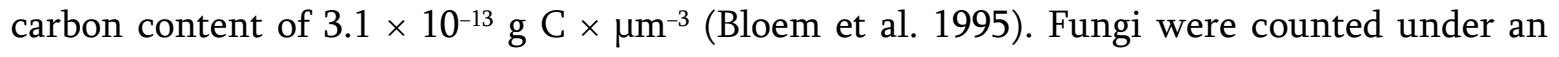
epifluorescence microscope at 400× magnification and the biomass was calculated assuming a

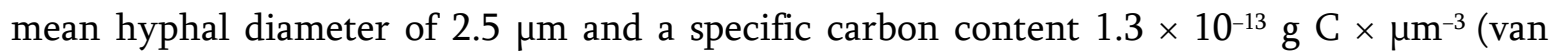
Veen and Paul 1979; Bakken and Olsen 1983). The potential C mineralization (based on $\mathrm{O}_{2}$ consumption) was measured between week 1 and week 6 by soil incubation at $20^{\circ} \mathrm{C}$ and $50 \%$ water holding capacity (Bloem et al. 1994). Potentially mineralizable $\mathrm{N}$ was determined by anaerobic incubation of soil samples in slurry for 1 week at $40^{\circ} \mathrm{C}$ (Keeney and Nelson 1982). The metabolic quotient $\left(\mathrm{qCO}_{2}\right)$ was calculated by dividing the basal respiration rate by the 
amount of microbial carbon (Anderson and Domsch 1993). The growth response of the bacterial community on a range of carbon and energy substrates was analysed in Biolog EcoPlates ${ }^{\mathrm{TM}}$ through the measurement of colour formation in the plates. The multiwell plates were incubated in the dark at $20^{\circ} \mathrm{C}$ and $85 \%$ relative humidity (Rutgers et al. 2006). Colour development was measured daily during 7 days using a semi-automatic sampler and a spectrophotometer (Spectra MAX250; Molecular Devices, Oxford, UK). The amount of inoculum that caused $50 \%$ of the maximum theoretical response for one specific substrate conversion (individual well colour development) was compared with the amount of inoculum that caused $50 \%$ of the maximum average response of all 31 substrates, resulting in a value for the relative abundance of catabolic units (heterotrophic bacteria) for that specific substrate.

\section{Soil fauna}

Nematodes were extracted from $100 \mathrm{~g}$ of fresh soil using funnel elutriation complemented by sieving and cottonwood extraction (Oostenbrink 1960). For each nematode sample, the individuals were counted. A subsample of 150 randomly chosen individuals was identified to genus; body length and width were measured using a microscope. Lengths and widths were used to estimate body mass using a regression according to Andrássy (1956). Per sample, the average body mass of identified taxa was derived from estimated weights. The total abundance of each taxon was derived as a proportion of the number of taxon identified within the 150 individuals. Enchytraeids were extracted from soil cores by wet-funnel extraction (O'Connor 1955) and counted. Adults were identified at genus level. Based on visual observation, each enchytraeid was allocated to one body size class with known body length and width. We used length-weight regressions to convert the body size parameters to body-mass averages as described by Abrahamsen (1973). Soil microarthropods (i.e. collembolans and mites) were extracted with Tullgren funnels. All individuals were counted and identified to species afterwards; if identification to species level was not possible (juveniles or damaged specimens), identification was made on a higher taxonomic level (genus or family). Due to technical limitation, the weight of the individuals could not be measured. A species-specific body-length average was assigned to each individual according to the identification keys; body-mass average was estimated using mass-length regression as 
previously done in Sechi et al. (2015). Differences in methods for body-size determination between groups are justified, because we analyse differences within a taxonomic group, not between taxonomic groups (i.e. nematodes, enchytraeids and microarthropods).

\section{FUNCTIONAL TRAITS}

\section{Eco-physiological traits}

As eco-physiological traits, we selected four parameters that can be seen as proxy of community-weighted means (CWM). Although these parameters are not measured at individual level they can be linked to the microbial activities and are able to assess the "metabolic" state of a system driven by the microbial community (Mulder et al. 2006b, 2007). We therefore measured: potential $\mathrm{C}$ mineralization, potentially mineralizable $\mathrm{N}$, metabolic quotient, and bacterial growth on a range of substrates in EcoPlates (relative coloring development).

\section{Behavioural traits: feeding guilds}

Trophic grouping allows a synthetic functional approach to assessing the potential effects of management on soil assemblages and may provide information on ecosystem functioning (Clough et al. 2007). For each identified taxon, we assigned a feeding habit using the same guilds as in Mulder et al. (2008). We then calculated the feeding guilds Community Weighted Mean value $\left(\mathrm{CWM}_{\mathrm{fg}}\right)$ for each soil group (nematodes, enchytraeids and microarthropods) separately. In general, the CWM is calculated as the mean trait values of all species present in the community weighted by their relative abundances. In the case of categorical traits, such as feeding guild, we used the relative abundance of each class of traits (Laliberté and Legendre 2010).

\section{Morphological traits: body mass}

Body mass is correlated with many life-history traits (Peters 1983; Calder 1984; Hendriks and Mulder 2008). Variation in body mass reflects the effect of environmental filters on individuals. Being body mass a continuous trait, the CWM $\mathrm{Mgg}_{\log }$ was calculated as the mean trait values of all species present in the community weighted by their relative 
abundances (Laliberté and Legendre 2010). We calculated the CWM $\mathrm{Mogm}_{\log }$ for each soil group (nematodes, enchytraeids and microarthropods) and for each feeding guild.

We also studied Kernel density-distributions to analyse the variation in the body-mass distribution of the soil fauna. This technique permits to estimate the precise location of modes and the most likely number of modes in a distribution (Leaper et al. 2001; Sechi et al. 2015), enabling to visualize possible structural compensations between the microfauna grazing on bacteria and the mesofauna browsing on fungi (Mulder et al. 2005b).

\section{TRAIT-DERIVED PARAMETERS: BIOMASS}

The biomass was considered here an aggregated parameter obtained from our selected behavioural and morphological traits (i.e. feeding group and body mass). Furthermore, by definition the biomass encompasses the abundance of the individuals $(B=N \times M)$ and therefore, it is according to us a fundamental parameter to consider when studying community response to environmental drivers. We therefore calculated the biomass for each identified feeding guild; fungal and bacterial biomasses were included in the analysis as two different resources. Furthermore, we studied the biomass Kernel density-distributions to describe the structure of the faunal community in relation to agricultural management (Mulder and Elser 2009; Trebilco et al. 2013).

\section{STATISTICAL ANALYSIS}

We performed the ANOVA to test the effect of management (arable field vs. field margin), farm and their interaction on soil and trait-based parameters using generalized least squares regression model (GLS) with a compound- symmetric structure to include correlation between observations within the same farm. Data were log-transformed to reach normality of variance before analysis. Feeding groups that were detected no more than twice in each management and farm category were excluded from the analysis to avoid bias. CWMs were calculated using "FD" R-package (Laliberté and Legendre 2010). Differences in Kernel density-distributions between the management (field margins vs. arable fields) and between farms were investigated using Kolmogorov-Smirnov test. All analyses were performed using R software 3.0.1 (R Core Team 2013). 


\section{Results}

\section{SOIL PARAMETERS}

Most of the measured soil parameters were found to be dependent on location (farm) and management (Table 3.1). Field margins were characterized by higher amounts of organic matter and nutrients (C-tot, N-tot, P-tot, $\mathrm{P}_{\mathrm{w}}$ and HWC) and by a lower clay content and pHкCl in comparison to the arable fields (Table 3.1).

\section{FUNCTIONAL TRAITS}

\section{Eco-physiological traits}

In the field margins the potential $\mathrm{C}$ mineralization and the potentially mineralizable $\mathrm{N}$ were higher and the metabolic quotient $\left(\mathrm{qCO}_{2}\right)$ was lower than in the arable fields (ANOVA, $\mathrm{p}<0.05$, Fig. 3.1, upper panel).

Table 3.1- Means and standard deviations (SD) per parameter and per agricultural management (i.e. Manag. effect: arable fields vs. field margins). Significant effects of the experimental factors (management, farm and their interaction) on soil parameters are also shown. Asterisks $\left(^{*}\right)$ indicate significant effect $\left({ }^{*} \mathrm{p}<0.05,{ }^{* *} \mathrm{p}<0.01,{ }^{* * *} \mathrm{p}<0.001\right)$. Symbols $(\wedge ; \vee)$ qualify the effect of the agricultural management on the analysed variable: $\wedge$, higher in the field margins, $\vee$, lower in the field margins. OM: organic matter; HWC: Hot Water extractable Carbon; C-tot: total Carbon; N-tot: total Nitrogen, P-tot: Total Phosphorus; $\mathrm{P}_{\mathrm{w}}$ : Water extractable Phosphorus; ns: not significantly difference.

\begin{tabular}{|c|c|c|c|c|c|c|c|c|c|c|}
\hline \multirow{3}{*}{$\begin{array}{l}\text { Soil Parameters } \\
\text { Bulk Density }\left(\mathrm{kg} \mathrm{L}^{-1}\right)\end{array}$} & \multicolumn{3}{|c|}{ Field Margins } & \multicolumn{3}{|c|}{ Arable Fields } & \multicolumn{2}{|c|}{$\begin{array}{l}\text { Manag. } \\
\text { effect }\end{array}$} & \multirow[t]{2}{*}{$\begin{array}{l}\text { Farm } \\
\text { effect }\end{array}$} & \multirow[t]{2}{*}{$\begin{array}{c}\text { Interaction } \\
\text { effect }\end{array}$} \\
\hline & Mean & & SD & Mean & & SD & & & & \\
\hline & 1.45 & \pm & 0.07 & 0.14 & \pm & 0.09 & n.s & & n.s & $*$ \\
\hline Clay (\%) & 18.0 & \pm & 4.53 & 20.25 & \pm & 4.54 & $* * *$ & v & $* * *$ & $* * *$ \\
\hline OM (\%) & 5.41 & \pm & 0.82 & 2.93 & \pm & 0.43 & $* * *$ & $\wedge$ & $* * *$ & $*$ \\
\hline $\mathrm{pH}_{\mathrm{KCl}}$ & 7.31 & \pm & 0.11 & 7.53 & \pm & 0.17 & $* * *$ & v & n.s & n.s \\
\hline $\mathrm{HWC}\left(\mu \mathrm{g} C \mathrm{~g}^{-1}\right)$ & 762 & \pm & 173 & 364 & \pm & 93 & $* * *$ & $\wedge$ & $* * *$ & $* * *$ \\
\hline C-tot $\left(\mathrm{mmol} \mathrm{kg}^{-1}\right)$ & 2911 & \pm & 394 & 1865 & \pm & 190 & $* * *$ & $\wedge$ & $* * *$ & n.s \\
\hline $\mathrm{N}$-tot $\left(\mathrm{mmol} \mathrm{kg}{ }^{-1}\right)$ & 177 & \pm & 21 & 108 & \pm & 18 & $* * *$ & $\wedge$ & $* * *$ & n.s \\
\hline P-tot $\left(\mathrm{mmol} \mathrm{kg}^{-1}\right)$ & 30.68 & \pm & 1.8 & 27.14 & \pm & 3.82 & $* * *$ & $\wedge$ & $* * *$ & $* * *$ \\
\hline $\mathrm{P}_{\mathrm{w}}\left(\mathrm{mmol} \mathrm{L}^{-1}\right)$ & 26.06 & \pm & 10.9 & 20.87 & \pm & 9.53 & $* *$ & $\wedge$ & $* * *$ & $* * *$ \\
\hline
\end{tabular}




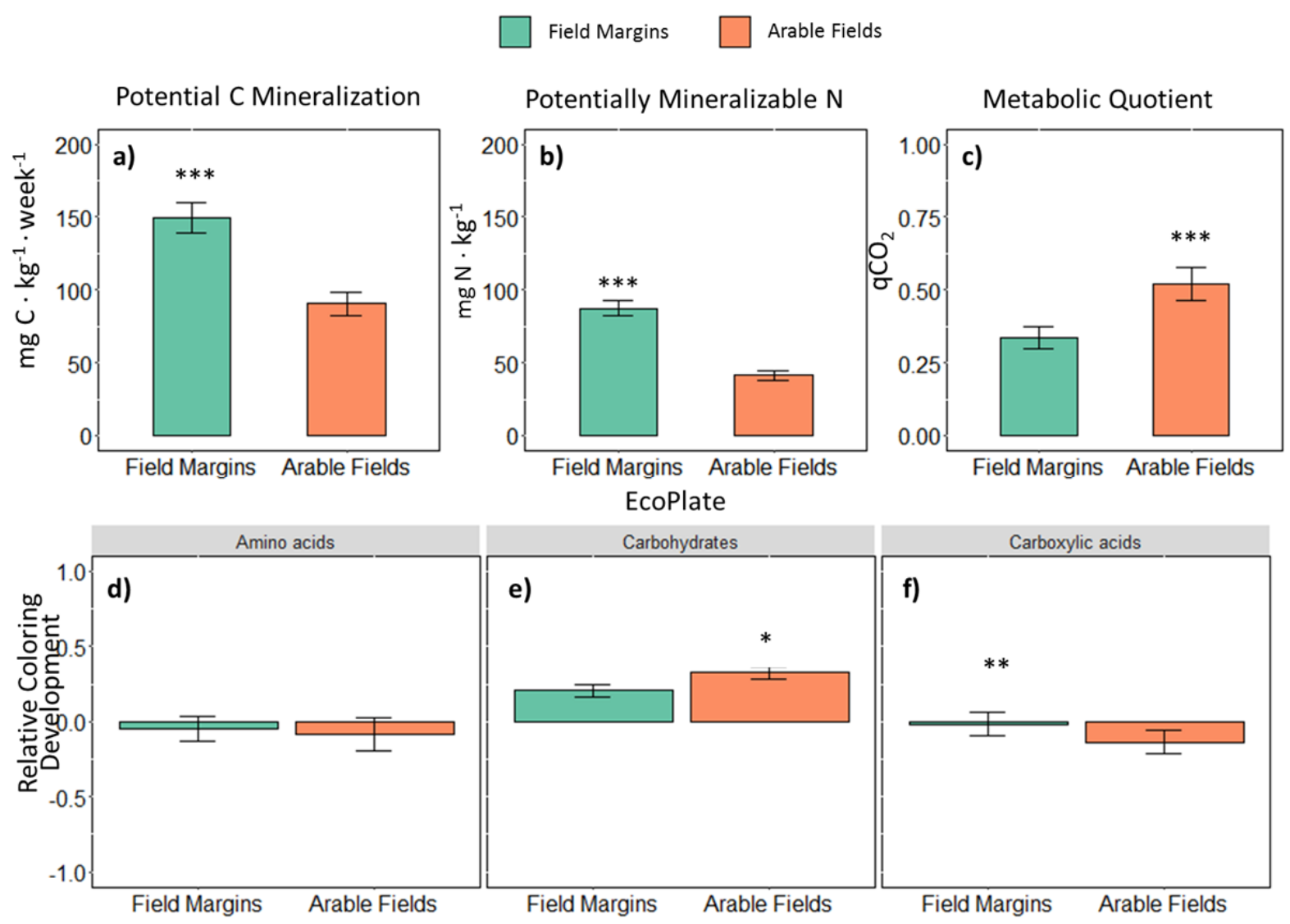

Figure 3.1 - Eco-physiological traits per management (field margins vs. arable fields): Potential C mineralization (based on $\mathrm{O}_{2}$ consumption) (a), potentially mineralizable $\mathrm{N}(\mathrm{b})$, metabolic quotient (c), and EcoPlate bacterial responses (d-f). Error bars depict standard errors. Asterisks $\left(^{*}\right)$ indicate management effects $\left({ }^{*} \mathrm{p}<0.05 ;{ }^{* *} \mathrm{p}<0.01 ;{ }^{* * *} \mathrm{p}<0.001\right)$.

In the field margins, the bacterial communities were less responsive to carbohydrates and more responsive to carboxylic compounds in comparison to the bacterial communities of the arable fields (ANOVA, $\mathrm{p}<0.05$, Fig. 3.1, lower panel).

No statistically significant differences in amino acid utilization were detected between field margins and arable fields or between farms (ANOVA, p>0.05). For details on farm and interaction effects on the eco-physiological trait see Table S3.1 in the Supplementary Material. 


\section{Behavioural traits: feeding guilds}

Both the $\mathrm{CWM}_{\mathrm{fg}}$ values of bacterial-feeding nematodes (including dauerlarvae) and enchytraeids were lower in the field margins (ANOVA, p<0.05, Fig. 3.2), whereas the CWM $\mathrm{fg}_{\mathrm{f}}$ of both plant-feeding nematodes and microarthropods, omnivorous mites and substrate feeding enchytraeids was higher in the field margins compared to arable fields (ANOVA, $\mathrm{p}<0.05$, Fig. 3.2). No consistent pattern was found in the effect of field margins in predators and fungal-feeding soil biota. The fungal feeding enchytraeids had a higher $\mathrm{CWM}_{\mathrm{fg}}$ while the fungal feeding microarthropods had a lower $\mathrm{CWM}_{\mathrm{fg}}$ in the field margins than in the arable fields (ANOVA, $\mathrm{p}<0.05$, Fig. 3.2); no statistically significant difference was found for the fungal feeding nematodes (Fig. 3.2).

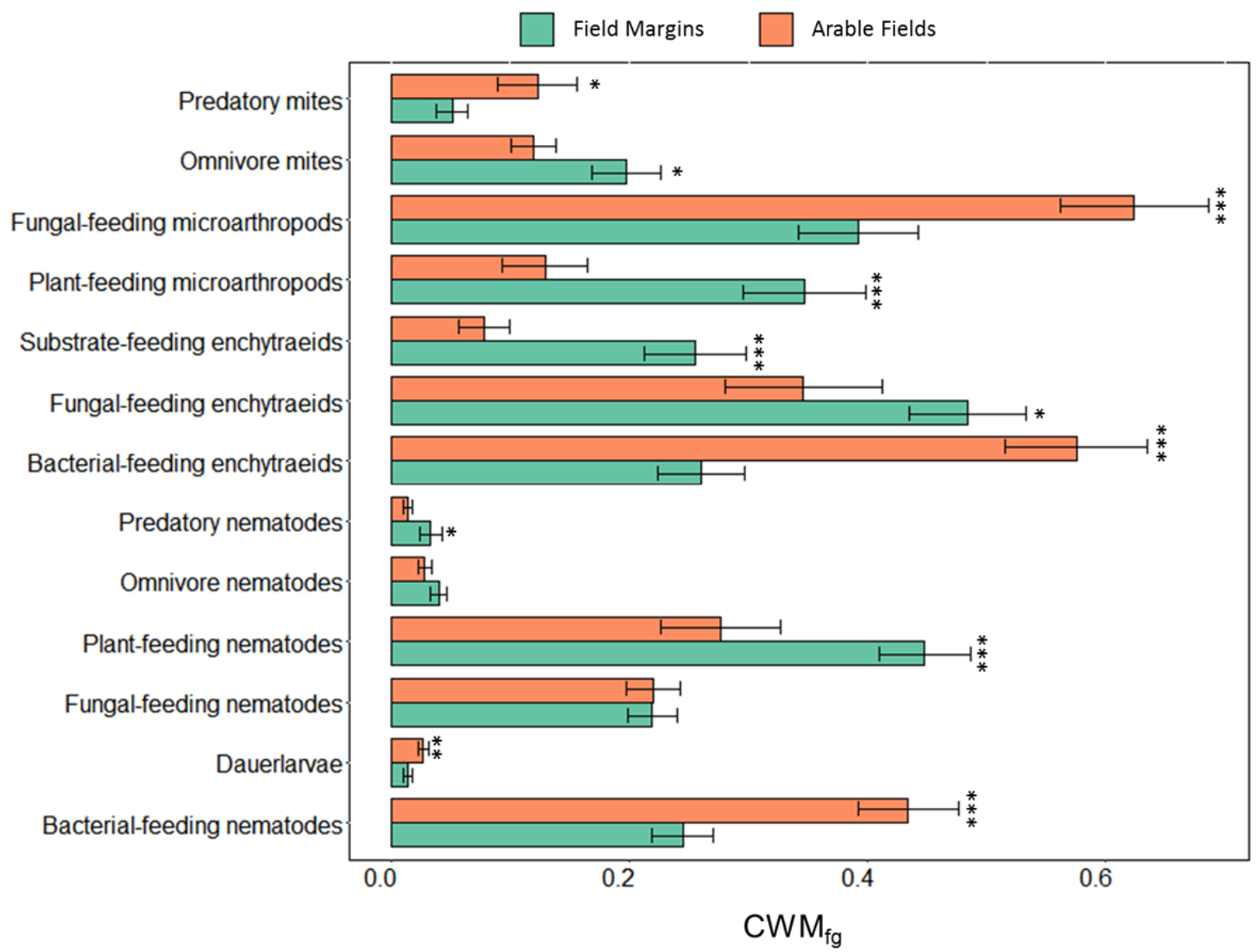

Figure 3.2 - Community-weighted mean $\left(\mathrm{CWM}_{\mathrm{fg}}\right)$ values of behavioural traits (feeding guilds) per management (field margins vs. arable fields). Error bars depict standard errors. Asterisks $\left(^{*}\right)$ indicate management effects $\left({ }^{*} \mathrm{p}<0.05 ;{ }^{* *} \mathrm{p}<0.01 ;{ }^{* * *} \mathrm{p}<0.001\right)$. 
The $\mathrm{CWM}_{\mathrm{fg}}$ of predatory nematodes was higher while the $\mathrm{CWM}_{\mathrm{fg}}$ of predatory mites was lower in the field margins compared to arable fields. See Table S3.2 in the Supplementary Material for farm and interaction effects.

\section{Morphological traits: body mass}

The analysis of the $\mathrm{CWM}_{\log M}$ values per soil groups showed that the enchytraeids and nematodes had higher $\mathrm{CWM}_{\log \mathrm{M}}$ values in the field margins compared to the arable fields (ANOVA, p<0.05, Fig. 3.3), whereas no difference was found for the microarthropods (Fig. 3.3).

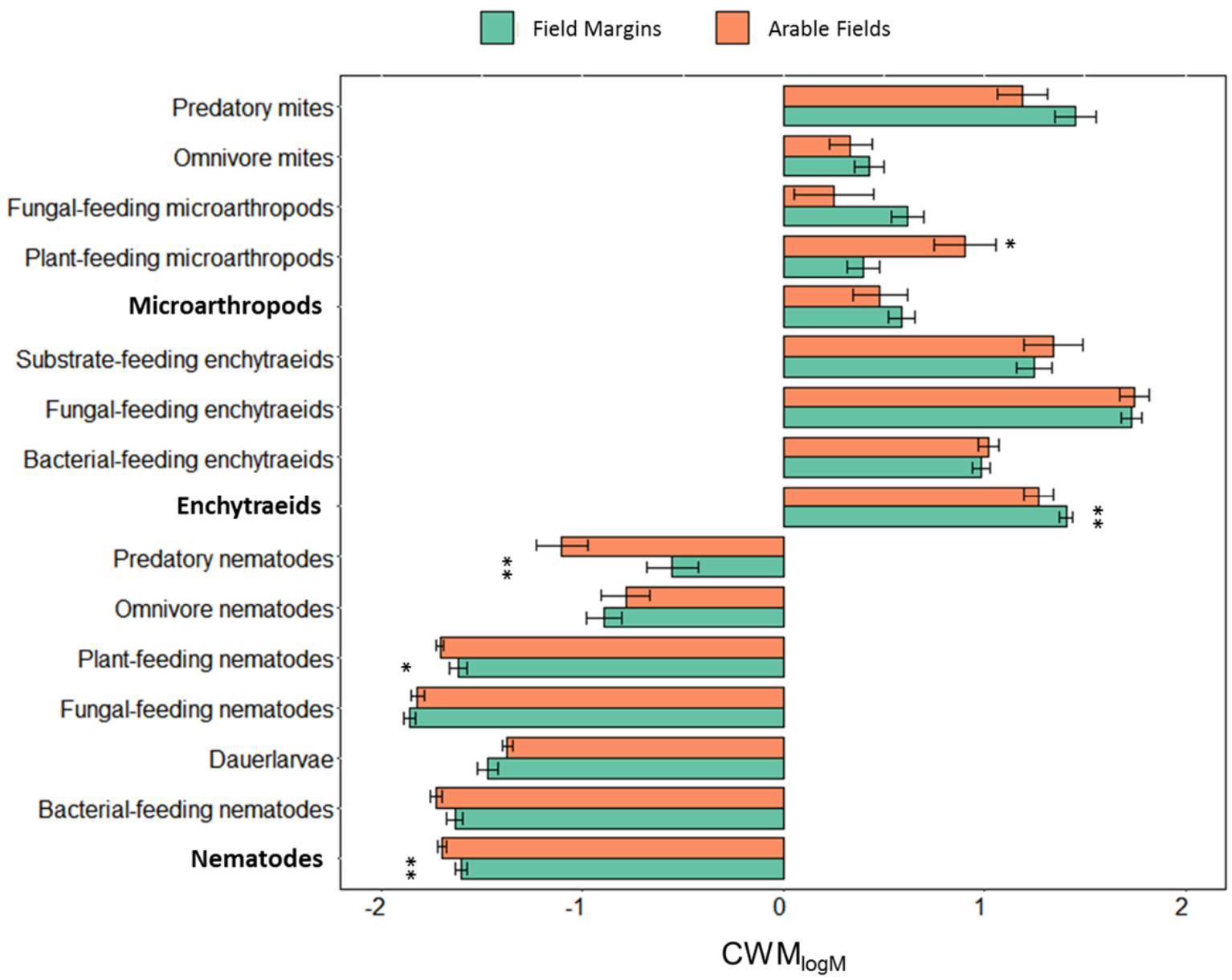

Figure 3.3 - Community-weighted mean $\left(\mathrm{CWM}_{\log \mathrm{M}}\right)$ of morphological trait (body mass) per management (field margins vs. arable fields) for each soil group (in bold) and per feeding guild. Error bars depict standard errors. Asterisks $\left({ }^{*}\right)$ indicate management effects $\left({ }^{*} \mathrm{p}<0.05 ;{ }^{* *} \mathrm{p}<0.01 ;{ }^{* * *} \mathrm{p}<0.001\right)$. 
The analysis of the CWM $\mathrm{M}_{\log \mathrm{M}}$ values per feeding group showed that predatory and plant feeding nematodes had higher $\mathrm{CWM}_{\log \mathrm{M}}$ values in the field margin, whereas plant-feeding microarthropods had lower values (ANOVA, $\mathrm{p}<0.05$, Fig. 3.3). Details on farm and interaction effects are shown in Table S3.3 (Supplementary Material).

The Kernel density-distributions of body mass $(\mathrm{M})$ of field margins and arable fields were affected by management (Kolmogorov-Smirnov test, $\mathrm{p}<0.01$, Fig. 3.4, left panel). The $\log$-scaled $\mathrm{M}$ distribution showed two peaks: a higher peak at $\approx-2 \log \mathrm{M}$ corresponding to the body mass range of soil microfauna (0.01-0.3 $\mu$ g dry weight) and a lower peak at $\approx 1.0 \log \mathrm{M}$ corresponding to the body mass range of soil mesofauna (0.5-32 $\mu \mathrm{g}$ dry weight). The $\log \mathrm{M}$ distribution in the field margins indicated lower density of microfauna and higher density of mesofauna compared to the arable fields. Interestingly, the $\mathrm{M}$ distributions in the field margins differed between farms, (Kolmogorov-Smirnov test, $\mathrm{p}<0.05$, Fig. S3.1, upper panel,

Supplementary Material), whereas we did not find any difference between farms in the arable fields.

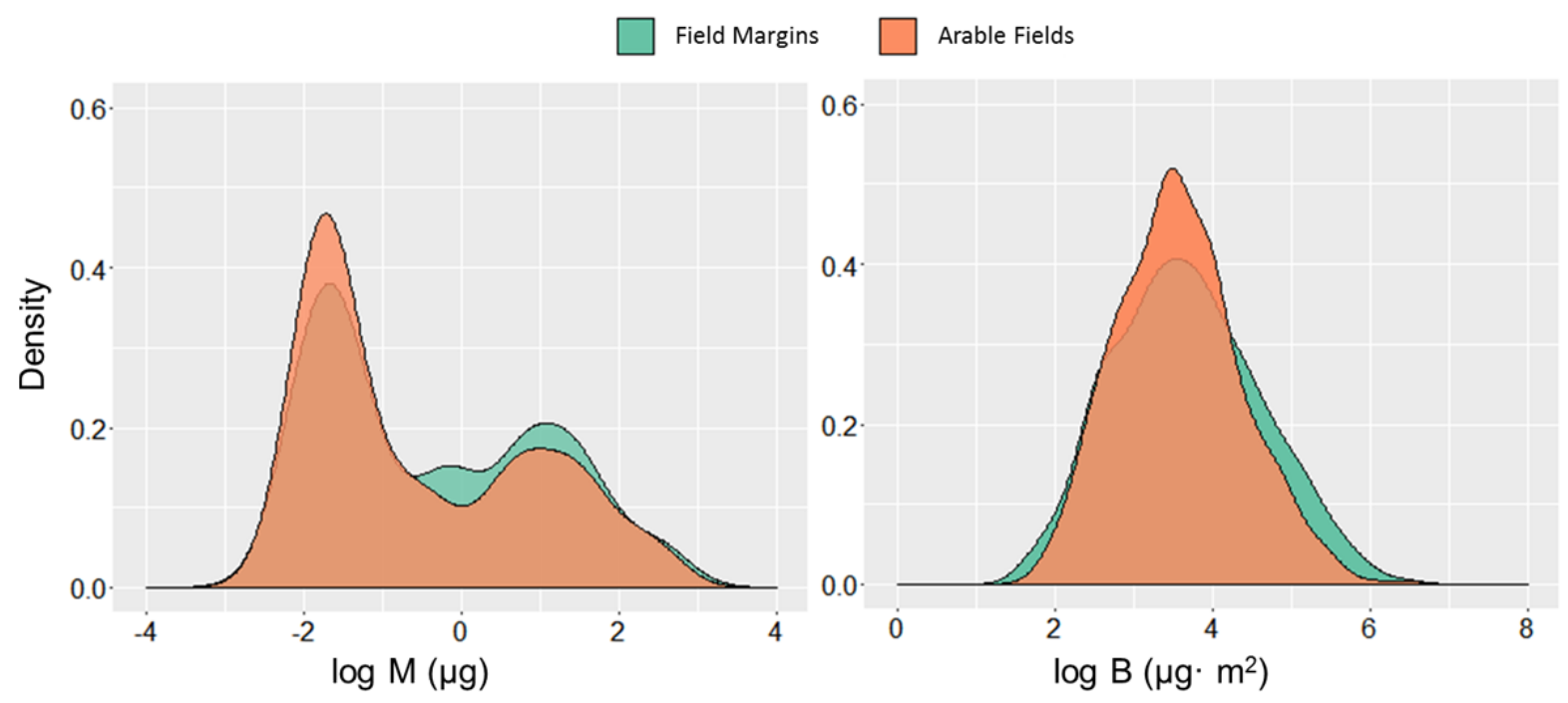

Figure 3.4 - Kernel density-distributions of body-mass (left panel), and biomass (right panel). Different colours indicate different field management (field margins vs. arable fields). 


\section{Trait-derived parameters: biomass}

In the cases where statistically significant differences were detected, the biomass of the soil biota was higher in the field margins than in the arable fields with the only exception for dauerlarvae biomass that was higher in the arable fields (ANOVA, $\mathrm{p}<0.05$, Fig. 3.5). No biomass differences were observed for the active stages of bacterial-feeding nematodes and enchytraeids, whereas the biomass of non-feeding stages of bacterial-feeding nematodes (dauerlarvae) was higher in arable fields (ANOVA, p<0.05, Fig. 3.5).

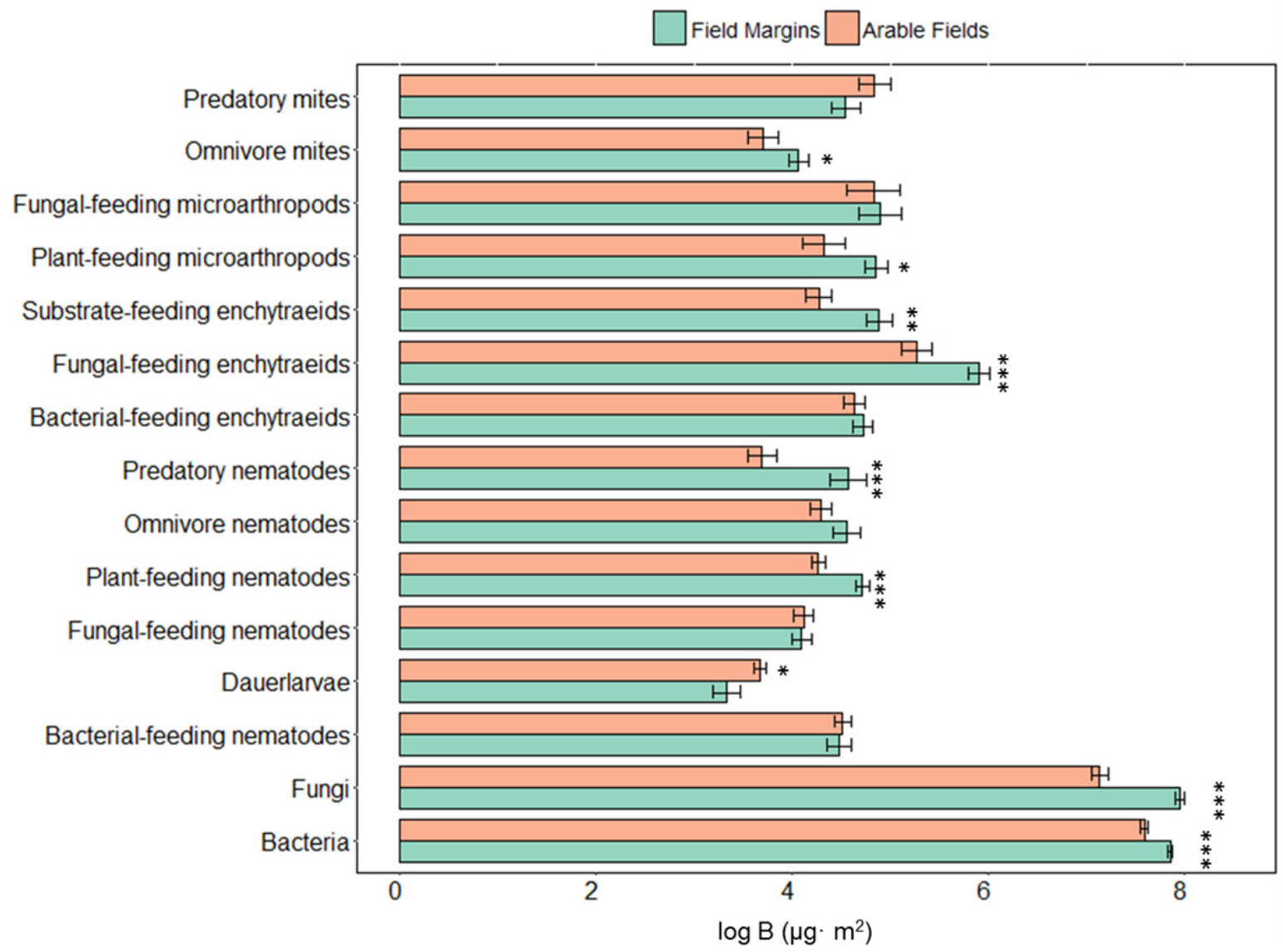

Figure 3.5 - Feeding guild biomass distributions per management (field margins vs. arable fields). Error bars depict standard errors. Asterisks $\left({ }^{*}\right)$ indicate management effects $\left({ }^{*} \mathrm{p}<0.05\right.$; $^{* *} \mathrm{p}<0.01$; ${ }^{* * *}$ $\mathrm{p}<0.001)$.

Fungal-feeding enchytraeids showed higher biomass values in the field margins (ANOVA, p<0.05, Fig. 3.5), but no significant differences were observed between arable fields 
and field margins in the biomasses of fungal-feeding nematodes or microarthropods (ANOVA, $\mathrm{p}>0.05$ ). In the field margins, biomass values of predatory nematodes, omnivorous mites, substrate-feeding enchytraeids and all plant-feeders were higher than in arable fields (ANOVA, $\mathrm{p}<0.05$, Fig. 3.5). Details on farm and interaction effects on feeding guilds biomass can be seen in Table S3.4 (Supplementary Material).

The Kernel density-distributions of biomass (B) of field margins and arable fields were affected by management (Kolmogorov-Smirnov test, p<0.01, Fig. 3.4 right panel). The logscaled B distribution had a sharper curve in the arable fields than in the field margins: the peak of the density distribution reached $50 \%$ around the biomass value of $3.5 \log \mathrm{B}$ in the arable fields while it reached $40 \%$ in the field margins. As for the body masspanel, the difference in the biomass distributions was significant between fields margins but not between arable fields (Kolmogorov-Smirnov test, $\mathrm{p}<0.05$; Fig. S3.1 lower panel, Supplementary Material).

\section{Discussion}

\section{Soil parameters}

Despite the fact that the farms were all under conventional management and located in a relatively homogeneous area with respect to the soil type (calcaric fluvisol), local climate and hydrology, variation in the soil parameters at farm level was evident. This is supported by previous studies in the same area (Heijting et al. 2011; Rutgers et al. 2012). However, the analysis of the soil parameters showed a clear distinction between arable fields and field margins.

Field margins were characterized by higher nutrient contents. The organic matter content was higher in the field margins, and as a consequence, the extractable carbon was higher indicating a higher mineralizable amount of available carbon. The lower clay content in the field margins (in all farms situated next to a ditch) can be explained by the periodical ditch management (Crittenden et al. 2015). 


\section{Functional traits and trait derived parameters}

In line with our hypothesis, eco-physiological traits differed between field margins and arable fields. The $\mathrm{qCO}_{2}$ reflects the environmental conditions (Fließbach et al. 1994; Anderson and Joergensen 1997) and land use (Dilly and Munch 1998; Mulder et al. 2005a). The lower $\mathrm{qCO}_{2}$ in the field margins, together with the observation of a stronger increase of microbial biomass (especially fungal biomass) than of microbial respiration $\left(\mathrm{O}_{2}\right.$ consumption), indicated that the microbial communities in the margins were metabolically less active than in the arable fields. Similarly, the higher eco-physiological response of the bacterial community to carbohydrates in the arable fields could be related to faster bacterial reaction rates to changing environmental conditions. Such higher temporal dynamics in microbial activity can be especially expected to occur in soils of the arable fields as response to flushes in nutrient availability generated by nutrient input and ploughing (Bender and Van der Heijden 2015). Hence, this suggests that the carbon transformation in the arable fields is more efficient than in the field margins.

The analysis of the distribution of basal resources (i.e. bacterial and fungal biomass) and in particular of the feeding guilds (CWMs and biomass) reflected the effects of agricultural management and demonstrated the different effect of environmental filters on soil biota. For example, we observed higher bacterial and fungal biomass in the field margins that probably enhanced the CWMgg and biomass values of fungal and substrate-feeding enchytraeids. Interestingly, at the same time the higher microbial biomass in the field margins did not result in higher biomass of bacterial- and fungal-feeding nematodes. This can be due to a higher top-down pressure in the soil food web in the field margins that could limit the proliferation of the relatively small bacterial- and fungal-feeding nematodes, as supported by the higher biomass of predatory nematodes and omnivorous mites. On the other hand, in the arable fields, the higher $\mathrm{CWM}_{\mathrm{fg}}$ values of bacterial-feeding nematodes and bacterial-feeding enchytraeids (Fig 3.2) were probably driven by nutrient fluctuations characterizing most crop fields. This is confirmed by the relatively higher $\mathrm{CWM}_{\mathrm{fg}}$ values and biomass of dauerlarvae in the arable fields than in the field margins. Dauerlarvae are a remnant of an active population of opportunistic bacterial-feeding nematodes (Ferris et al. 2001, Ferris 2010). 
The field margins were also characterized by a higher $\mathrm{CWM}_{\mathrm{fg}}$ values and higher biomass of plant-feeders and of omnivorous mites, likely enhanced by higher and continuous availability of plant material in these systems. Furthermore, the feeding guilds confirmed our hypothesis that micro- and mesofauna respond differently to environmental pressure. The analyses of body mass distribution showed also differences between micro- and mesofauna, reflecting agricultural management; in the field margins, we observed a difference in the area under the kernel curve corresponding to the micro- and mesofauna body-mass distribution that was smoother than in the arable fields. This indicates a more even distribution of the body-mass classes which reflects a likely higher number of ecological niches in the field margins in comparison to the arable fields (cf. Mason et al. 2005, Villéger et al. 2008).The same holds for the wider shape of the biomass distribution. The higher incidence of mesofaunal biomass in the field margins can be related to lower soil $\mathrm{pH}$ and higher occurrence of phosphorus in these margins as compared to the arable fields. This agrees with observations by Mulder and Elser (2009) and Mulder et al. (2011), who showed that an improved chemical soil quality (overall defined by a $\mathrm{C}: \mathrm{N}: \mathrm{P}$ ratio of $98: 5.2: 1$ in mass units), and not per se the absolute amount of phosphorus, enhances the mesofauna more than the microfauna, which corroborates to the $\mathrm{C}: \mathrm{N}: \mathrm{P}$ ratios we found in our margins $(\mathrm{C}: \mathrm{N}: \mathrm{P}$ ratio was overall $95: 5.8: 1)$ and arable fields $(69: 4.0: 1)$. Furthermore, the relatively high heterogeneity in the Kernel density-distribution in the field margins of either body mass or biomass (Fig A3.1 in Supplementary Material) underlines that these systems allow the preservation of a higher trait variability compared to the arable fields. This is also showed by the more homogeneous distribution of the $\mathrm{CWM}_{\mathrm{fg}}$ values in the field margins with no dominance of one feeding guild over the other (cf. Fig 3.2), especially in the case of mesofauna, when compared with the arable fields. Based on the Kernel density, CWMfg and feeding guild biomass distributions, we conclude that the mesofauna was enhanced in the field margins probably as result of a higher food availability and/or better food quality. 


\section{Conclusions}

Field margins have been broadly established in the last years to enhance the ecosystem functioning and their importance in supporting above-ground biodiversity is broadly recognized (Marshall 2002, Meek et al. 2002, Marshall et al. 2006). However, their role for belowground diversity is still poorly understood.

For the first time for soil biota, we analysed simultaneously traits to detect functional responses across the soil community. Our results showed that in the field margins can be considered as semi-natural systems where soil biotic interactions are much less influenced by human activity. Because field margins showed higher variability in both biomass and bodymass distribution compared to the arable fields, we may infer that field margins contribute to the heterogeneity and enhance stability of the landscape.

The eco-physiological traits differentiated microbial diversity in field margins and arable fields, reflecting the differences in nutrient cycling and carbon storage driven by the soil microbial community. The structural organization of the trophic grouping and body-mass distribution reflected the effects of agricultural management on soil assemblages and revealed differences in the responses of the micro- and the mesofauna to the environment, with a partial shift from the bacterial- to the fungal-driven energy channels that especially affected the mesofauna (Fig. 3.2). The structural organization of feeding guilds of invertebrates appeared to be linked at local level to one or more environmental filters (here: clay, $\mathrm{pH}$, soil organic matter, and carbon, phosphorus, and nitrogen). However, changes at local level of body-mass averages reflected less than expected the environmental filtering of soil biota, as shown in aquatic ecosystems (mesocosm etc.) or at landscape level (Mulder et al. 2016). The apparent lack of evidence for trait-based hypotheses at local scale in comparison to large, macroecological gradients could well be the most relevant limitation to terrestrial trait-based approaches and more work is needed to express the potential of a trait-based approach in understanding the community response to environmental filters acting on soil systems.

Although some studies on microbial traits at individual level have been done in the last few years (Martiny et al. 2006, Bryant et al. 2012, Lennon et al. 2012), it is still difficult to find suitable traits for microorganism due to their extraordinary metabolic and physiological 
diversity, and to the inability to culture most of them (Green et al. 2008). In our case, we were not able to use microbial traits that could be measured at individual level. Moreover, it remains unresolved how to compare microorganisms and soil fauna at a specific functional level, in analogy to the long-standing debate on species definition (Martiny et al. 2006). Another aspect to consider is the use of qualitative instead of quantitative traits. Although the use of categorical (a priori) traits (here: feeding guilds) revealed changes in the community structure, it could lead to some loss of information by imposing a discrete structure on functional differences between taxa and ignoring intraspecific differences (Fonseca et al. 2001, Villéger et al. 2008).

Moreover, measuring body mass of each individual (instead of using an average measurement per species as we did for microarthropods), could increase the accuracy in detecting effects of environmental filtering on the biological community. For this reason, we definitely would advise to consider the possibility of using traits measured at the individual level for future trait-based studies. Nevertheless, we conclude that our whole-soil community trait-based approach (eco-physiological, behavioural, and morphological traits) revealed functionally important relationships between soil biota community structure, ecological processes, and agricultural management.

\section{Acknowledgments}

We thank Aad Klompe, Henk Scheele, Cees Schelling and NoviFarm for allowing access to their farms for sampling. The technical and scientific contributions of Tamas Salanki (Wageningen University), Wim Dimmers, An Vos, Jaap Bloem (Alterra), Erik Steenbergen, Marja Wouterse (RIVM) and Harm Keidel (LIOS) are highly appreciated. This study was performed within the RIVM-project QESAP (Quantification of Ecosystem Services for environmental Assessment and Planning; S/607022) and our work was supported by the RIVM project BEO (M/607406). 


\section{Supplementary Material}

Table S3.1 - Means and standard deviations (SD) for eco-physiological trait (proxies) values per management (field margins vs. arable fields); the number of entries $(n)$ are provided. On the right effects of the experimental factors (Management, Farm and interaction of those) are indicated. Asterisks $\left({ }^{*}\right)$ indicate significant effect $\left({ }^{*} \mathrm{p}<0.5,{ }^{* *} \mathrm{p}<0.01,{ }^{* * *} \mathrm{p}<0.001\right)$. Symbols $(\wedge ; \vee)$ qualify the effect of the Management on the analyzed variable: $\wedge$ : higher in the field margins, $\vee$ : lower in the field margins.

\begin{tabular}{lccccccccccccc}
$\begin{array}{l}\text { Eco-physiologicla trait } \\
\text { (proxies) }\end{array}$ & \multicolumn{3}{c}{ Field Margins } & & & Arable Fields & & $\begin{array}{l}\text { Manag. } \\
\text { effect }\end{array}$ & $\begin{array}{l}\text { Farm } \\
\text { effect }\end{array}$ & $\begin{array}{l}\text { Inter. } \\
\text { effect }\end{array}$ \\
& $n$ & Mean & & $S D$ & $n$ & Mean & & $S D$ & & & & \\
\hline Potential C Mineralization & 16 & 149.8 & \pm & 41.8 & 16 & 90.4 & \pm & 31.1 & $* * *$ & $\wedge$ & $* * *$ & $* * *$ \\
Potentially Mineralizable N & 16 & 87.1 & \pm & 20.4 & 16 & 41.3 & \pm & 12.2 & $* * *$ & $\wedge$ & $*$ & $*$ \\
Metabolic Quotient & 16 & 0.34 & \pm & 0.2 & 16 & 0.52 & \pm & 0.2 & $* * *$ & $\vee$ & $* * *$ & $* * *$ \\
Ecoplate & & & & & & & & & & & & \\
$\quad$ Amino acids & 96 & -0.05 & \pm & 0.79 & 96 & -0.09 & \pm & 1.05 & n.s & & n.s & n.s \\
$\quad$ Carbohydrates & 160 & 0.21 & \pm & 0.50 & 160 & 0.32 & \pm & 0.57 & $*$ & $\vee$ & n.s & n.s \\
Carboxilyc acids & 96 & -0.02 & \pm & 0.76 & 96 & -0.14 & \pm & 0.77 & $* *$ & $\wedge$ & n.s & n.s \\
\hline
\end{tabular}


Table S3.2 - Means and standard deviations (SD) of Community Weighted Mean values for feedingguilds (CWMfg) per management (field margins vs. arable fields); the number of entries (n) are provided. On the right, effects of the experimental factors (Management, Farm and interaction of those) are indicated. Asterisks $\left({ }^{*}\right)$ indicate significant effect $\left({ }^{*} \mathrm{p}<0.5,{ }^{* *} \mathrm{p}<0.01,{ }^{* * *} \mathrm{p}<0.001\right)$. Symbols $(\wedge$; $\vee)$ qualify the effect of the Management on the analyzed variable: $\wedge$ : higher in the field margins, $\vee$ : lower in the field margins.

\begin{tabular}{|c|c|c|c|c|c|c|c|c|c|c|c|c|}
\hline \multirow[t]{2}{*}{$\mathrm{CWM}_{\mathrm{fg}}$} & \multicolumn{5}{|c|}{ Field Margins } & \multicolumn{3}{|c|}{ Arable Fields } & \multicolumn{2}{|c|}{$\begin{array}{c}\text { Manag. } \\
\text { effect }\end{array}$} & \multirow[t]{2}{*}{$\begin{array}{l}\text { Farm } \\
\text { effect }\end{array}$} & \multirow[t]{2}{*}{$\begin{array}{l}\text { Inter. } \\
\text { effect }\end{array}$} \\
\hline & $n$ & Mean & & $S D$ & $n$ & Mean & & $S D$ & & & & \\
\hline $\begin{array}{l}\text { Bacterial-feeding } \\
\text { nematodes }\end{array}$ & 16 & 0.43 & \pm & 0.17 & 16 & 0.24 & \pm & 0.10 & $* * *$ & $\wedge$ & $* *$ & $* * *$ \\
\hline Dauerlarvae & 12 & 0.03 & \pm & 0.02 & 13 & 0.01 & \pm & 0.01 & $* *$ & $\wedge$ & $* *$ & n.s \\
\hline $\begin{array}{l}\text { Fungal-feeding } \\
\text { nematodes }\end{array}$ & 16 & 0.22 & \pm & 0.09 & 16 & 0.22 & \pm & 0.09 & n.s & & $*$ & $* * *$ \\
\hline Plant-feeding nematodes & 16 & 0.28 & \pm & 0.20 & 16 & 0.45 & \pm & 0.15 & $* * *$ & v & $* * *$ & $* * *$ \\
\hline Omnivore nematodes & 15 & 0.03 & \pm & 0.02 & 16 & 0.04 & \pm & 0.03 & n.s & & n.s & n.s \\
\hline Predatory nematodes & 12 & 0.01 & \pm & 0.01 & 13 & 0.03 & \pm & 0.04 & $*$ & v & $* *$ & $*$ \\
\hline $\begin{array}{l}\text { Bacterial-feeding } \\
\text { enchytraeids }\end{array}$ & 15 & 0.58 & \pm & 0.24 & 16 & 0.26 & \pm & 0.14 & $* * *$ & $\wedge$ & $*$ & $* *$ \\
\hline $\begin{array}{l}\text { Fungal-feeding } \\
\text { enchytraeids }\end{array}$ & 16 & 0.35 & \pm & 0.26 & 13 & 0.48 & \pm & 0.20 & $*$ & V & $* *$ & $*$ \\
\hline $\begin{array}{l}\text { Substrate-feeder } \\
\text { enchytraeids }\end{array}$ & 15 & 0.08 & \pm & 0.09 & 10 & 0.26 & \pm & 0.17 & $* * *$ & $v$ & n.s & $*$ \\
\hline $\begin{array}{l}\text { Fungal-feeding } \\
\text { microarthropods }\end{array}$ & 16 & 0.62 & \pm & 0.25 & 16 & 0.39 & \pm & 0.20 & $* * *$ & $\wedge$ & $* * *$ & n.s \\
\hline $\begin{array}{l}\text { Plant-feeding } \\
\text { microarthropods }\end{array}$ & 16 & 0.13 & \pm & 0.14 & 14 & 0.35 & \pm & 0.21 & $* * *$ & v & $* * *$ & n.s \\
\hline Omnivore mites & 16 & 0.12 & \pm & 0.08 & 15 & 0.20 & \pm & 0.12 & $*$ & v & $*$ & n.s \\
\hline Predatory mites & 16 & 0.12 & \pm & 0.13 & 12 & 0.05 & \pm & 0.05 & $*$ & & n.s & $*$ \\
\hline
\end{tabular}


Table S3.3 - Means and standard deviations (SD) Community Weighted Mean values for body-mass (CWMlogM) per management (field margins vs. arable fields); the number of entries (n) are provided. On the right, effects of the experimental factors (Management, Farm and interaction of those) are indicated. Asterisks $\left({ }^{*}\right)$ indicate significant effect $\left({ }^{*} \mathrm{p}<0.5,{ }^{* *} \mathrm{p}<0.01,{ }^{* * *} \mathrm{p}<0.001\right)$. Symbols $(\wedge ; \vee)$ qualify the effect of the Management on the analyzed variable: $\wedge:$ higher in the field margins, $v:$ lower in the field margins.

\begin{tabular}{|c|c|c|c|c|c|c|c|c|c|c|c|c|}
\hline \multirow[t]{2}{*}{$C W M_{\log M}$} & \multicolumn{4}{|c|}{ Field Margins } & \multicolumn{4}{|c|}{ Arable Fields } & \multicolumn{2}{|l|}{$\begin{array}{l}\text { Manag. } \\
\text { effect }\end{array}$} & \multirow{2}{*}{$\begin{array}{l}\text { Farm } \\
\text { effect }\end{array}$} & \multirow{2}{*}{$\begin{array}{l}\text { Inter. } \\
\text { effect }\end{array}$} \\
\hline & $n$ & Mean & & $S D$ & $n$ & Mean & & $S D$ & & & & \\
\hline Nematodes & 16 & -1.60 & \pm & 0.12 & 16 & -1.70 & \pm & 0.08 & $* *$ & $\wedge$ & $* * *$ & * \\
\hline Bacterial-feeding nematodes & 16 & -1.64 & \pm & 0.17 & 16 & -1.72 & \pm & 0.12 & n.s & & n.s & n.s \\
\hline Dauerlarvae & 12 & -1.47 & \pm & 0.18 & 13 & -1.37 & \pm & 0.09 & n.s & $v$ & n.s & n.s \\
\hline Fungal-feeding nematodes & 16 & -1.86 & \pm & 0.12 & 16 & -1.82 & \pm & 0.14 & n.s & & n.s & n.s \\
\hline Plant-feeding nematodes & 16 & -1.62 & \pm & 0.18 & 16 & -1.71 & \pm & 0.08 & * & & n.s & n.s \\
\hline Omnivore nematodes & 15 & -0.89 & \pm & 0.34 & 16 & -0.78 & \pm & 0.48 & n.s & & n.s & n.s \\
\hline Predatory nematodes & 12 & -0.55 & \pm & 0.43 & 13 & -1.10 & \pm & 0.47 & $* * *$ & $\wedge$ & n.s & * \\
\hline Enchytraeids & 16 & 1.27 & \pm & 0.29 & 16 & 1.41 & \pm & 0.14 & * & $\wedge$ & $* *$ & * \\
\hline $\begin{array}{l}\text { Bacterial-feeding } \\
\text { enchytraeids }\end{array}$ & 15 & 0.98 & \pm & 0.16 & 16 & 1.02 & \pm & 0.20 & n.s & & * & n.s \\
\hline Fungal-feeding enchytraeids & 16 & 1.73 & \pm & 0.22 & 13 & 1.74 & \pm & 0.26 & n.s & & n.s & n.s \\
\hline $\begin{array}{l}\text { Substrate-feeder } \\
\text { enchytraeids }\end{array}$ & 15 & 1.25 & \pm & 0.34 & 10 & 1.34 & \pm & 0.46 & n.s & & n.s & n.s \\
\hline Microarthropods & 16 & 0.59 & \pm & 0.26 & 16 & 0.48 & \pm & 0.55 & n.s & & n.s & n.s \\
\hline $\begin{array}{l}\text { Fungal-feeding } \\
\text { microarthropods }\end{array}$ & 16 & 0.62 & \pm & 0.32 & 16 & 0.25 & \pm & 0.79 & n.s & & n.s & n.s \\
\hline $\begin{array}{l}\text { Plant-feeding } \\
\text { microarthropods }\end{array}$ & 16 & 0.40 & \pm & 0.31 & 14 & 0.90 & \pm & 0.58 & * & $\mathrm{v}$ & n.s & n.s \\
\hline Omnivore mites & 16 & 0.43 & \pm & 0.30 & 15 & 0.33 & \pm & 0.41 & n.s & & n.s & n.s \\
\hline Predatory mites & 16 & 1.46 & \pm & 0.41 & 12 & 1.19 & \pm & 0.43 & n.s & & n.s & $* *$ \\
\hline
\end{tabular}


Table S4 - Means and standard deviation (SD) of microbes and trophic guild biomasses per management (field margins vs. arable fields); the number of entries ( $n$ ) are provided. On the right, effects of the experimental factors (Management, Farm and interaction of those) are indicated. Asterisks $\left({ }^{*}\right)$ indicate significant effect $\left({ }^{*} \mathrm{p}<0.5,{ }^{* *} \mathrm{p}<0.01,{ }^{* * *} \mathrm{p}<0.001\right)$. Symbols $(\wedge ; \vee)$ qualify the effect of the Management on the analyzed variable: $\wedge$ : higher in the field margins, $\vee:$ lower in the field margins.

\begin{tabular}{|c|c|c|c|c|c|c|c|c|c|c|c|c|}
\hline \multirow[t]{2}{*}{ Biomass } & \multicolumn{4}{|c|}{ Field Margins } & \multicolumn{4}{|c|}{ Arable Fields } & \multirow[t]{2}{*}{$\begin{array}{l}\text { Manag. } \\
\text { Effect }\end{array}$} & & \multirow[t]{2}{*}{$\begin{array}{l}\text { Farm } \\
\text { effect }\end{array}$} & \multirow[t]{2}{*}{$\begin{array}{l}\text { Inter. } \\
\text { effect }\end{array}$} \\
\hline & $n$ & Mean & & $S D$ & $n$ & Mean & & $S D$ & & & & \\
\hline Bacteria & 16 & 7.85 & \pm & 0.11 & 16 & 7.59 & \pm & 0.13 & $* * *$ & $\wedge$ & n.s & ** \\
\hline Fungi & 16 & 7.96 & \pm & 0.19 & 16 & 7.13 & \pm & 0.34 & $* * *$ & $\wedge$ & n.s & $*$ \\
\hline $\begin{array}{l}\text { Bacterial-feeding } \\
\text { nematodes }\end{array}$ & 16 & 4.48 & \pm & 0.48 & 16 & 4.52 & \pm & 0.35 & n.s & & $* * *$ & n.s \\
\hline Dauerlarvae & 12 & 3.33 & \pm & 0.47 & 13 & 3.68 & \pm & 0.23 & * & $\mathrm{v}$ & n.s & n.s \\
\hline $\begin{array}{l}\text { Fungal-feeding } \\
\text { nematodes }\end{array}$ & 16 & 4.10 & \pm & 0.42 & 16 & 4.12 & \pm & 0.40 & n.s & & $*$ & ** \\
\hline Plant-feeding nematodes & 16 & 4.72 & \pm & 0.27 & 16 & 4.27 & \pm & 0.28 & $* * *$ & $\wedge$ & n.s & $* * *$ \\
\hline Omnivore nematodes & 15 & 4.55 & \pm & 0.52 & 16 & 4.30 & \pm & 0.44 & n.s & & n.s & n.s \\
\hline Predatory nematodes & 12 & 4.58 & \pm & 0.66 & 13 & 3.69 & \pm & 0.53 & $* * *$ & $\wedge$ & n.s & n.s \\
\hline $\begin{array}{l}\text { Bacterial-feeding } \\
\text { enchytraeids }\end{array}$ & 15 & 4.72 & \pm & 0.40 & 16 & 4.64 & \pm & 0.43 & n.s & & n.s & n.s \\
\hline $\begin{array}{l}\text { Fungal-feeding } \\
\text { enchytraeids }\end{array}$ & 16 & 5.90 & \pm & 0.44 & 13 & 5.27 & \pm & 0.57 & $* * *$ & $\wedge$ & $* * *$ & n.s \\
\hline $\begin{array}{l}\text { Substrate-feeder } \\
\text { enchytraeids }\end{array}$ & 15 & 4.89 & \pm & 0.51 & 10 & 4.27 & \pm & 0.43 & ** & $\wedge$ & n.s & n.s \\
\hline $\begin{array}{l}\text { Fungal-feeding } \\
\text { microarthropods }\end{array}$ & 16 & 4.90 & \pm & 0.86 & 16 & 4.83 & \pm & 1.10 & n.s & & * & n.s \\
\hline $\begin{array}{l}\text { Plant-feeding } \\
\text { microarthropods }\end{array}$ & 16 & 4.86 & \pm & 0.45 & 14 & 4.32 & \pm & 0.80 & * & $\wedge$ & * & n.s \\
\hline Omnivore mites & 16 & 4.07 & \pm & 0.42 & 15 & 3.70 & \pm & 0.61 & * & $\wedge$ & $* *$ & n.s \\
\hline Predatory mites & 16 & 4.54 & \pm & 0.58 & 12 & 4.84 & \pm & 0.57 & n.s & & n.s & n.s \\
\hline
\end{tabular}



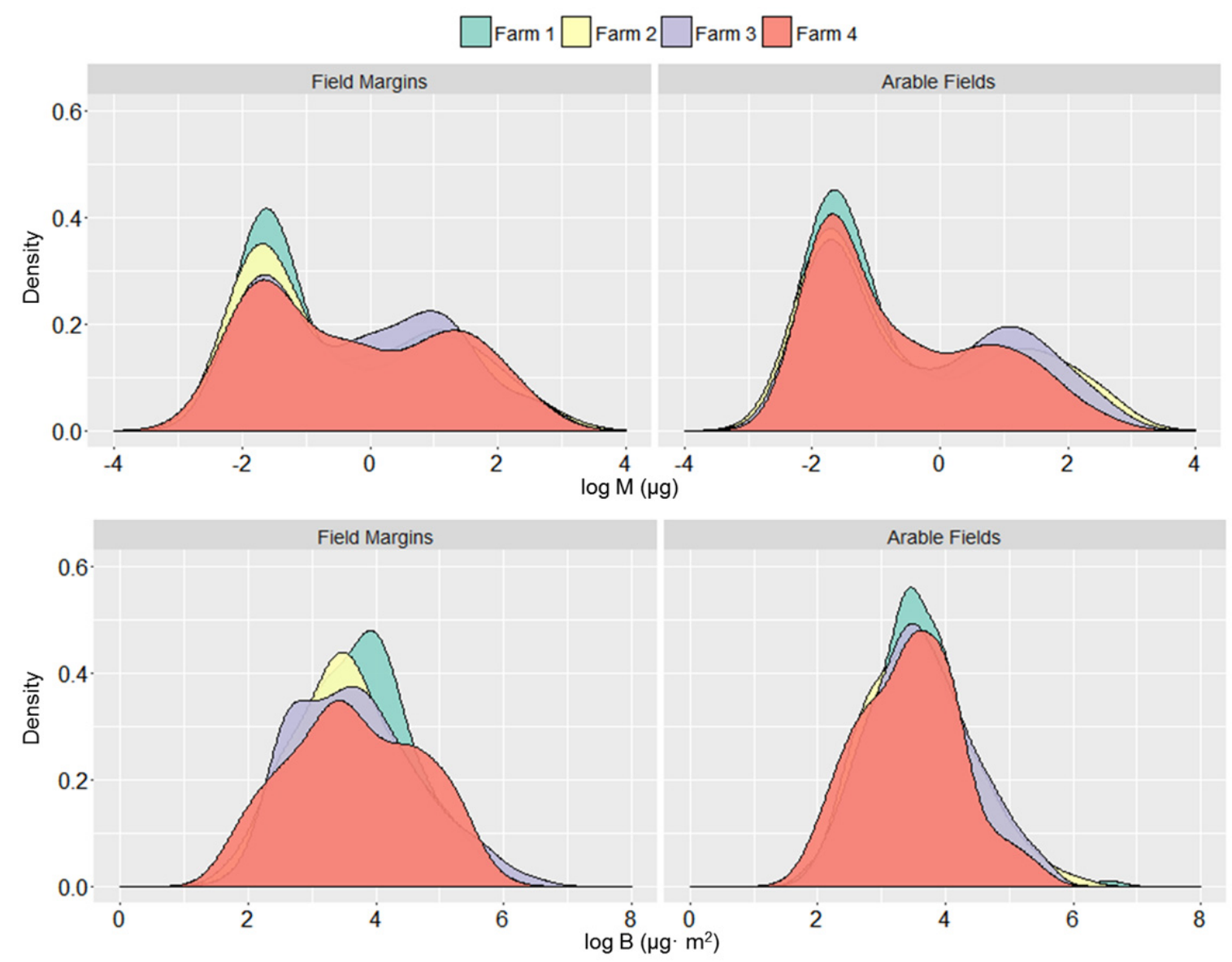

Figure S3.1 - Kernel density-distribution of body-mass (M) and biomass (B) per management (field margins vs. arable fields) and farm (1-4). 



\section{Chapter 4}

Choice of resolution by functional trait or taxonomy affects allometric scaling in soil food webs 



\title{
Choice of resolution by functional trait or taxonomy affects allometric scaling in soil food webs
}

Chapter published in The American Naturalist, 2015

185: $142-149$

Valentina Sechi, Lijbert Brussaard, Ron G. M. De Goede, Michiel Rutgers,

Christian Mulder

\begin{abstract}
Belowground organisms often display a shift in their mass-abundance scaling relationships due to environmental factors such as soil chemistry and atmospheric deposition. Here we present new empirical data that show strong differences in allometric scaling according to whether the resolution at the local scale is based on a taxonomic or a functional classification, whilst only slight differences arise according to soil environmental conditions. For the first time isometry (an inverse 1:1 proportion) is recognized in mass-abundance relationships, providing a functional signal for constant biomass distribution in soil biota regardless of discrete trophic levels. Our findings are in contrast to those from aquatic ecosystems, in that higher trophic levels in soil biota are not a direct function of increasing body mass.
\end{abstract}




\section{Introduction}

The allometric relationships between body mass $(M)$ and population density $(N)$ of organisms are thought to reflect underlying biological and physicochemical constraints in ecosystems (Cohen et al. 2003; Ehnes et al. 2014; Mulder et al. 2005a; Reuman et al. 2008; Turnbull et al. 2014; Yvon-Durocher et al. 2011). Investigations on allometric scaling were mostly performed in aquatic and terrestrial environments, specifically marine, freshwater and aboveground ecosystems, in sharp contrast to soil systems that appear to be a kind of Pandora's Box (Fitter 2005) despite their apparent structural homogeneity.

The body mass distribution of belowground organisms is typically right-skewed, with vastly more individuals of smaller taxa (bacteria and protozoa) than large-sized species (earthworms and fungi). This distribution has implications for ecosystem functioning within the soil system. For instance, the small-sized microfauna may contain much functional redundancy (many species performing the same role) whilst the larger-sized mesofauna has greatest influence on mass-abundance scaling (Mulder and Elser 2009). Depending on how $M$ is estimated (average over the entire population, the average over adults, or the maximum body mass; Cohen and Carpenter 2005), the allometric scaling will be different, fuelling further the debate about the value of the exponent and the metabolic implications (Brown and Gillooly 2003; Kolokotrones et al. 2010).

Numerous previous studies have documented intrinsic properties and variations in food webs, generally arguing for universal scaling laws and these have provided the basis of a general framework for energetic, metabolic and macroecological theories (Brown et al. 2004; Hechinger et al. 2011; West et al. 1997; West and Brown 2005), best illustrated by whole food web studies where $M$ and $N$ are globally known for each population (Cohen et al. 2009; Cohen and Mulder 2014; Mulder and Elser 2009; Woodward et al. 2012). Here we present, for the first time, analyses of complete soil communities based on site-specific $\bar{M}$ data, $N$ data, and biomass $(B=\bar{M} \times N)$ data for bacterial cells, fungal hyphae, protozoa, and soil invertebrates). In particular, $\bar{M}$ data ( $\mu \mathrm{g}$ dry mass) are site-specific measurements of the individual body sizes collected in the study area, as only real field data (as opposed to data 
extrapolated from other studies) for both $M$ and $N$ are likely shed new light on the universality of mass-abundance scaling in soil biota.

\section{Material and Methods}

\section{Field Sampling}

In late September 2012, we sampled three plots in abandoned grasslands on sandy soils within a farm under former organic management in the Netherlands (5209' $\mathrm{N}, 5^{\circ} 18^{\prime} \mathrm{E}$ ), all the plots occurring within a $100 \mathrm{~m}$ radius in one previously investigated by Mulder et al. (2005a). Plots had different management histories and represented a continuum in the soil nutrient contents. Within each of the plots we took three replicate samples of about $5 \mathrm{~m}^{2}$ from the upper $10 \mathrm{~cm}$ of soil for the fauna and soil physico-chemical variables. Bulk samples of 50 soil cores $(\varnothing 2.3 \mathrm{~cm})$ were used to extract the microfauna and to measure soil parameters; two soil cores $(\varnothing 5.8 \mathrm{~cm})$ were used to extract the mesofauna; and a box of $20 \times 20 \times 20 \mathrm{~cm}$ soil samples were used to collect earthworms.

\section{Treatment of Soil Environmental Samples}

Three soil cores were sampled to determine root biomass. Roots were washed-out, dried at $70^{\circ} \mathrm{C}$ for 48 hours, and weighed. Soil samples were oven-dried before soil $\mathrm{pH}$ measurement in potassium chloride solution $(1 \mathrm{M} \mathrm{KCl})$. Total soil carbon $\left(\mathrm{mg} \mathrm{kg}^{-1}\right)$ was determined by thermogravimetric analysis and total soil nitrogen $\left(\mathrm{mg} \mathrm{kg}^{-1}\right)$ was determined by a titrimetric method after distillation using Kjeldahl destruction. Total soil phosphorus was determined by Automated Ion Analyzer after sample digestion. All C, N and P totals were expressed in mmol $\mathrm{kg}^{-1}$ of soil.

\section{Treatment of Soil Fauna and Microbial Taxa}

Numerical abundance and size of bacteria and protozoa were determined by fluorescent staining (Alef and Nannipieri 1995; Bloem et al. 1995). Microbial biomasses were estimated from biovolume using a carbon content of $3.1 \times 10^{-13} \mathrm{~g} \mathrm{C} \times \mu \mathrm{m}^{-3}$ for bacteria and $1.0 \times 10^{-13} \mathrm{~g}$ C $\times \mu \mathrm{m}^{-3}$ for protozoa (Fry 1990 and Alef and Nannipieri 1995, respectively). To convert 
carbon to dry weight we used as conversion factors 2.1 for bacteria and 1.36 for protozoa (Alef and Nannipieri 1995; Bloem et al. 1995; Mulder et al. 2011). Hyphae were counted by epifluorescence microscopy at 400× magnification and their biomass was derived assuming a mean diameter of $2.5 \mu \mathrm{m}$ and a $1.3 \times 10^{-13} \mathrm{~g} \mathrm{C} \times \mu \mathrm{m}^{-3}$ carbon content (Alef and Nannipieri 1995; Mulder et al. 2011). To convert fungal carbon to dry weight we used as conversion factor of 3.75 (Jandl and Sollins 1997).

Free-living nematodes extraction was performed within one week from core sampling using Oostenbrink funnels and all the elutriated nematodes were collected; ecto- and endoparasitic nematodes were recovered with centrifugal flotation. All nematode individuals were counted and approximately 150 randomly-chosen specimens were identified and measured under a light microscope (Mulder and Vonk 2011). Enchytraeid worms (Oligochaeta: Enchytraeidae) were sampled by wet extraction and microarthropods (Acarina and Collembola) by dry extraction (Cohen and Mulder 2014). In both sampling protocols, the heat was increased gradually with incandescent bulbs and the invertebrates escaped the drying by moving downwards. After completing the extraction, enchytraeids and microarthropods were recovered, identified and their lengths were individually measured. Earthworms (Oligochaeta: Lumbricidae) were hand-sorted and fresh-weighed after 3 days to empty their guts. For earthworms, enchytraeids and microarthropods the abundances for 1 $\mathrm{m}^{2} \times 10 \mathrm{~cm}$ depth were derived from the surface of the soil samples. In all the other cases, to estimate the abundance we calculated the soil weight of $1 \mathrm{~m}^{2} \times 10 \mathrm{~cm}$ depth from the soil bulk density as measured at each sampling site.

\section{Data Mining and Modeling}

In contrast to previous investigations, where species-average $M$ data were used (Mulder and Elser 2009; Cohen and Mulder 2014), all site-specific body-mass values $\bar{M}$ of the identified specimens of micro- and mesofauna were derived as dry weight from their observed shape and body-size values (length and width) according to published allometric regressions (Appendix A4). According to Finlay et al. (2000), ciliates are by far the least abundant protozoa and therefore were not taken into account. Still, also without ciliates, all 
the taxa and guilds occurring in the classical detrital soil food web model of Hunt et al. (1987) and Hunt and Wall (2002) were investigated (Appendix B4). OTUs (operational taxonomic units) were as near as possible to real taxa: in general we used data for families or genera, as often species within the same genera share many similar traits (Yeates et al. 1993) and feeding behaviors (Polis and Strong 1996). Some OTUs were comprised of sets of organisms that roughly provide the same resource, like fungi, whose mycelium is considered as a single unit $(N=1$, hence $B=N \times M=1 \times M=M)$. Moreover, bacteria are narrowly defined as a mixture of species and broad taxonomic units, and most protozoa are distinguished as amoebae and flagellates although they do not constitute separate natural groups (Hausmann et al. 2003).

Each OTU was assigned a coarse feeding preference based on the literature (trophic species, as done in Mulder et al. 2008), reflecting the dominant feeding strategy of the individuals belonging to that taxon (Briand and Cohen 1984; Cohen and Mulder 2014). Afterwards, we partitioned the literature-derived feeding preference across each of the phylogenetic groups in a stepwise manner to yield independent groupings to be lumped together (see the Appendix B4 for the identified OTUs and the assigned trophic species). The abundance of each trophic group was then calculated to derive a "functional assemblage" data set for contrasts with the original "taxonomic" data set.

\section{Statistical Analyses}

We performed ANOVA to analyse differences between plots in all the soil parameters estimated. $M$ and $N$ relationships for both the taxonomic and functional data sets were explored using linear regression analysis and slopes compared between sample plots and between the different data sets using ANCOVA. All statistical analyses were performed in R using the version 3.0.1 (R Core Team 2013) and the biomass of soil fauna at different trophic levels represented as pyramids using the R package 'Cheddar' (Hudson et al. 2013).

\section{Results and Discussion}

On average, 97 OTUs $( \pm 2 \mathrm{SE})$ were determined for each sample plot, with a total of 135 OTUs in all samples (Appendix B4). Across the three sample plots, the Coefficient of 
Variation for the OTUs $(\mathrm{CV}=100 \times \mathrm{SD} /$ mean $)$ was only $3 \%$, suggesting similar species-area relationships. $N$ and $M$ values span about 14 orders of magnitude (Figure 4.1 ) and the regressions are all significant (for each plot $R^{2} \geq 0.76$ and $R^{2} \geq 0.85$ for taxonomic and functional data sets respectively). There were no between-plot differences (ANCOVA, $p>$ 0.05). Protozoa perfectly filled the size gap between nematodes and bacteria, increasing the significance of the linear regression models for both taxonomic and functional data sets (Figure 4.1 and Table 4.1).

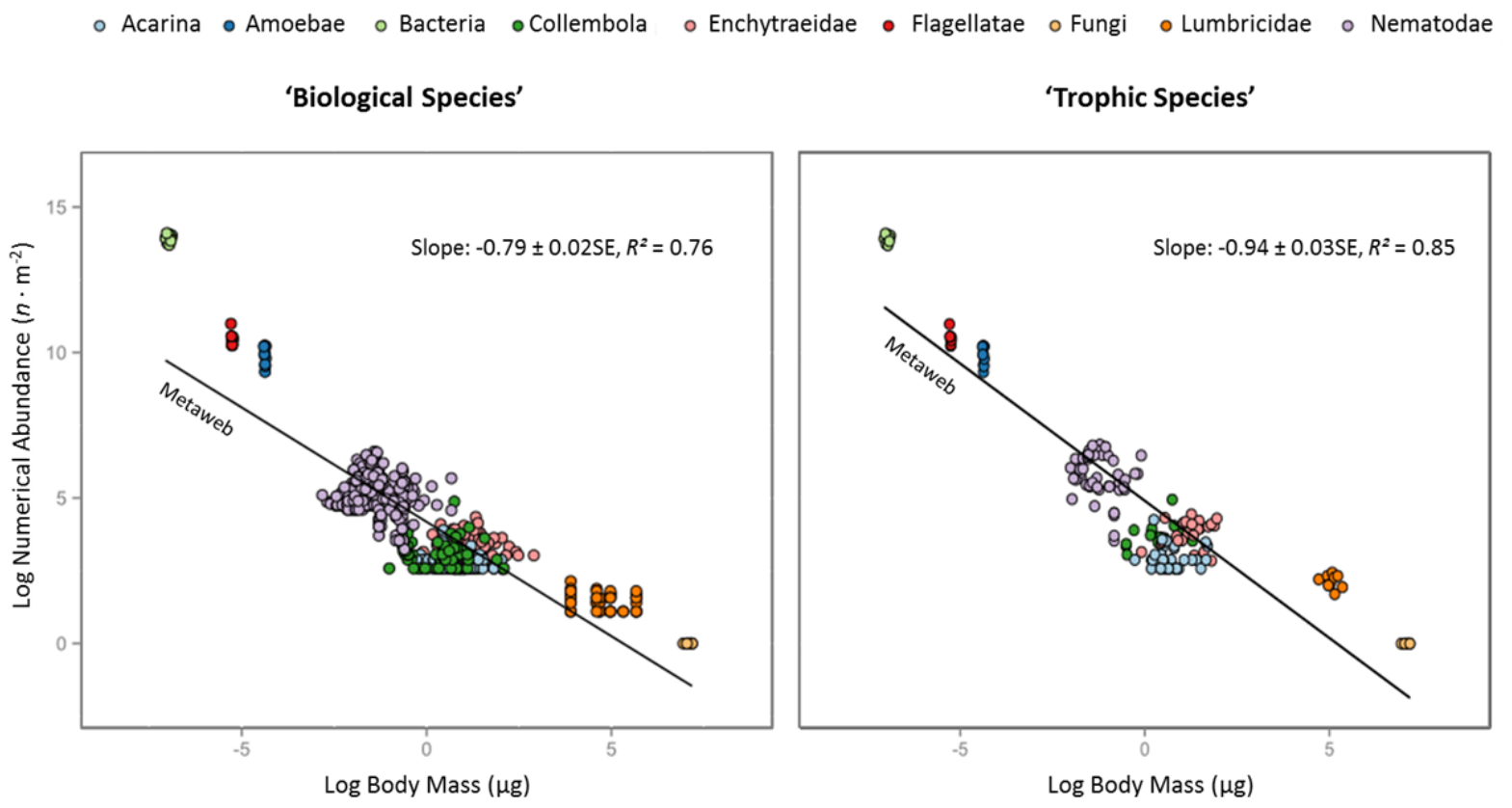

Figure 4.1- Metaweb mass-abundance scalings for 'biological species' and 'trophic species'. Regardless of the different aggregation of the organisms occupying the middle of the $(\mathrm{M}, \mathrm{N})$ cloud, both the linear regression slopes of the estimates of $\mathrm{N}$ on $\mathrm{M}$ remained significant $(\mathrm{p}<0.0001)$. At taxonomic level, the mass-abundance linear regression slopes per plot were more close to the expected three-quarter scaling, whereas at functional level the slopes were steeper (see Figs. S4.1 and S4.2 in Supplementary Material). Excluding the eukaryotes with low taxonomic resolution (Fungi, Amoebae and Flagellatae), mass-abundance slopes will equal -0.75 for the biological species and -1.0 for the trophic species (Table 4.1). All the original data can be accessed via the Dryad Digital Repository (Sechi et al. 2014b).

The mass-abundance slopes range per plot from $-0.80 \pm 0.03 \mathrm{SE}$ to $-0.77 \pm 0.03 \mathrm{SE}$ for the taxonomic data and from $-0.95 \pm 0.05 \mathrm{SE}$ to $-0.93 \pm 0.05 \mathrm{SE}$ for the functional data. Only for the taxonomic data did the regression slopes seem to resemble the $-3 / 4$ power law. Even 
though fungal mycelium is treated here as a single OTU, removing fungi from the analysis did not alter significantly the mass-abundance slope $(-0.79 \pm 0.02 \mathrm{SE}$ with fungi and $-0.82 \pm$ 0.02SE without). At the functional level, the mass-abundance slopes become $-0.94 \pm 0.03 \mathrm{SE}$ with fungi and $-1.05 \pm 0.03 \mathrm{SE}$ without, both approaching -1 (Figs. S4.1 and S4.2 in Supplementary Material). In other words, with each 10-fold increase in the body-mass average at taxonomic level, the corresponding population density decreases by a factor of 7.5, and with each each 10-fold increase in the body-mass average at functional level, the corresponding guild density decreases by a factor of 10 . Even if the taxonomic data are aggregated into major size-defined groups (bacteria, protozoa, microfauna, mesofauna, macrofauna, and fungi), comparable mass-abundance slopes result $(-0.94 \pm 0.02 \mathrm{SE}$ with fungi, identical to the aforementioned slope for all the trophic species, and $-0.96 \pm 0.02 \mathrm{SE}$ without fungi). Also across the sample plots, shifts from allometric to isometric scaling are detectable with and without fungi (Fig. S4.3 in Supplementary Material).

The confidence intervals (CI) for the regression slopes of the mass-abundance scalings of the taxonomic data and of the functional data never intersect (Table 4.1), confirming that differences are sustained after aggregation regardless of the removed trophic species (Fig. S4.4 in Supplementary Material). Furthermore, the distribution of the quantile pairs of the less-resolved functional data (trophic species and bins) falls closer to the straight line of the theoretical (normal) quantile distribution than in the case of highly-resolved taxonomic data (biological species; Fig. S4.5 in Supplementary Material). Therefore, it seems unlikely that our isometry derives from artifacts. The significant discrepancy between the universal $-3 / 4$ scaling and the particular -1 scaling (ANCOVA, $\mathrm{p}<0.001$ ) has at least six important implications and these are explored below.

First, the belowground relationships are robust and cannot be easily explained by our sampling protocols or environmental factors, as seems to the case for aboveground studies. Plotting soil microorganism data in this way helps to reveal donor-controls within the soil community pathways, in our case, the fungi-driven and the bacteria-driven energy channels. This compartmentalization is an essential difference between aquatic and terrestrial food webs. The general area was sampled in 1999 by Mulder et al. (2005), although not in as much 
detail as here (fungi and protozoa were measured only in 2012). Comparing the massabundance slopes between the sampling events, the confidence intervals (CIs) for the lessresolved community slope in 1999 of $(-0.94,-0.59,95 \%$ CI; 57 OTUs, mostly at genus level) and for our high-resolved community slope in 2012 of $(-0.79,-0.71,95 \% \mathrm{CI} ; 133$ OTUs excluding fungi and protozoa) intersect, implying that the two scalings are undistinguishable $(-0.76 \pm 0.09 \mathrm{SE}$ in 1999 vs. $-0.75 \pm 0.02 \mathrm{SE}$ in 2012) regardless of the number of OTUs, although the higher number of OTUs in 2012 strongly reduced the confidence interval of the regression.

Second, in any food web every species feeding on resources defines elemental flows (nutrients and energy) between the sets of biological species sharing the same predators and the same prey (Garlaschelli et al. 2003; Boit et al. 2012), and can as such illustrate the structure of an assemblage across both the body mass $M$ and the abundance $N$ gradients. For example, according to theory (Cohen 1991), abundance $N$ is negatively correlated with body mass $\bar{M}$, but if food web isometry occurs (log-log linear regression -1 , hence $N \propto \bar{M}^{-1}$ ), biomass $B$ will depend on $\bar{M}$, a particular case where biomasses on average remain roughly comparable between functional averages. Therefore isometry (as for our trophic species) implies a constant biomass distribution along the horizontal axis. In the food web of Tuesday Lake as sampled in 1984 (Cohen et al. 2003, 2009; Cohen and Carpenter 2005) a constant biomass distribution is supposed to remain constant also across trophic levels (Cohen et al. 2003), but in our soil systems the biomass distribution remains constant only along the gradient of $\bar{M}$ and not across trophic levels. This can be explained because in soil food webs the trophic levels are not as strongly linked to $M$ as in aquatic food webs because in soil biota the feeding behavior (the diet roughly determines the trophic level of heterotrophic organisms) is much less a function of body size than in aquatic ecosystems.

Third, this novel case of empirical mass-abundance isometry is unexpected and should be taken into account in metabolic ecology. Metabolic rates of simple and complex organisms have been extensively investigated and unraveled (Brown et al. 2004; West and Brown 2005; Hirst et al. 2014). West et al. (1997) already wrote that as living organisms are threedimensional, that should explain the universal ' 3 ' as numerator of the $3 / 4$ power law, and made 
further a plea to examine nearly two-dimensional organisms like bryozoans. Nakaya et al. (2003) provided evidence that nearly two-dimensional colonial organisms exhibit metabolic isometry during a particular phase where all zooids simultaneously give rise to their offspring, but scale allometrically in their ordinary state. We might speculate on the coarse $(M, N)$ component of a conceptual 'trophic species' in comparison to real three-dimensional 'biological species', but as far as we know, no model explains any scaling difference between biological and trophic species.

Fourth, given that overall the numerical abundance $N$ relates to body-mass average $\bar{M}$ as $N \propto \bar{M}^{-0.79}$ and that the energy use $E$ relates to soil invertebrates' body-mass average $\bar{M}$ as $E \propto \bar{M}^{0.77}$ (an overall exponent for springtails, oribatids and spiders as by Meehan 2006), we obtain $E_{t o t} \propto \bar{M}^{0.77} \times \bar{M}^{-0.79}=\bar{M}^{-0.02}$. Being the exponent -0.02 very close to 0 , it appears that the energy use $N \times E$ is almost independent of $\bar{M}$. Hence, at a coarse functional level each 'trophic species' reflects its energy flux regardless of $\bar{M}$. However, seen that overall abundances decrease with the trophic level, a kind of resource-thinning appears to be plausible regardless of the existence of energetic equivalence or not (compare the forest soils in Meehan et al. 2006 with Ehnes et al. 2014). As a matter of fact, populations of smaller-sized soil and litter invertebrates seem to process comparable energy amounts as many populations of large-sized invertebrates.

Fifth, mass-abundance regressions obtained using OTUs are unaffected by the density distribution of body-mass values (upper panel of Fig. 4.2). This occurs despite a hump in the data from sample plot $C$ corresponding to the range of the mesofauna body-mass average, indicating a more homogenous $M$ distribution between micro- and mesofauna in the data from sample plots A and B (upper panel of Fig 4.2). The conversion from body-size to trophic level of each OTU, which usually requires an additional step to build a trophic pyramid (Elton 1927; Trebilco et al. 2013), was in our case resolved for each plot by aggregating the taxonomic species together according to their corresponding trophic level (lower panel of Fig. 4.2). Whilst generalists like those occurring in the upper two trophic levels might defy such discretization of trophic levels, the classical Eltonian distribution remains recognizable, with 
significantly different biomass distributions between resources and consumers (ANOVA, $p<$ 0.001).

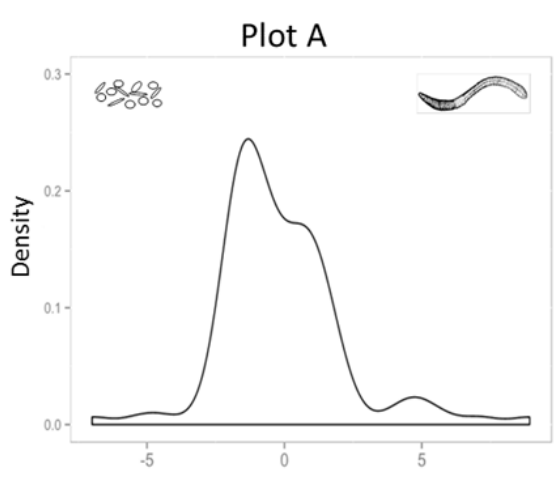

Plot B

Plot C
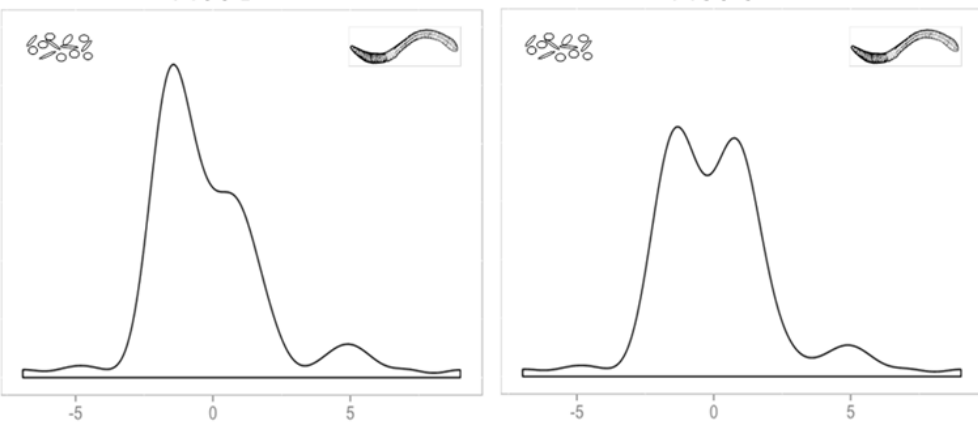

$\log _{10}(M) \mu g$

$\log _{10}(M) \mu \mathrm{g}$

$\log _{10}(M) \mu g$
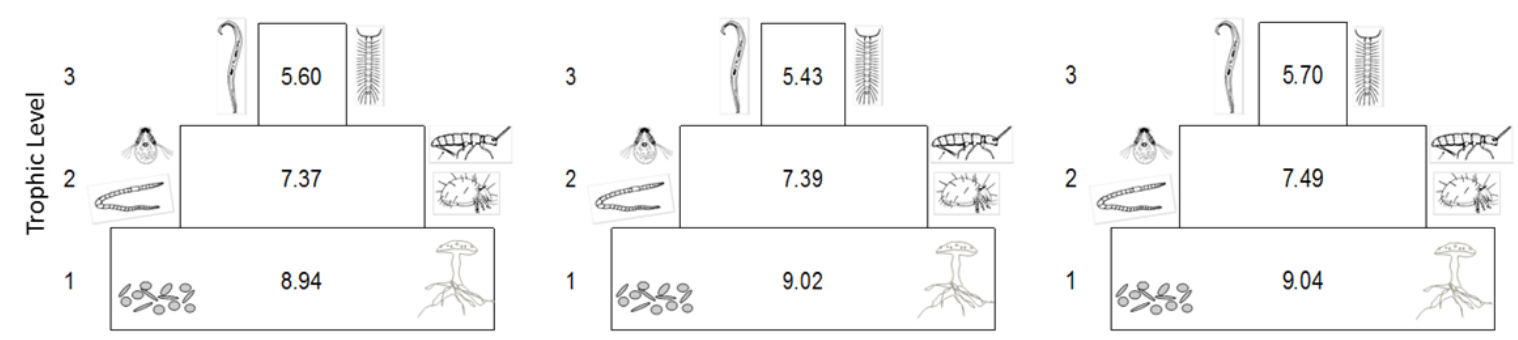

$\log _{10}\left(\sum B\right)\left(\operatorname{ug~m}^{-2}\right)$

$\log _{10}\left(\sum B\right)\left(\right.$ ug m$\left.^{-2}\right)$

$\log _{10}\left(\sum B\right)\left(u_{g ~ m}{ }^{-2}\right)$

$\mathrm{C}: \mathrm{N}: \mathrm{P}$

$141: 10: 1$

$122: 10: 1$

$105: 6: 1$

Figure 4.2 - Body-mass density distributions and Eltonian biomass pyramids for each plot. Upper part of the figure, density functions derived by kernel estimation analysis of the body-size distributions; lower part, biomass pyramids with the main trophic levels. Trophic Level 1 encompasses all the living resources of any soil food web (including fungi and plant roots, and all the other "basal species"), Trophic Level 2 the specialized bacterivore, fungivore and herbivore invertebrates ("intermediate species"), and Trophic Level 3 the predating and omnivore invertebrates ("top species" sensu Briand and Cohen 1984. Molar soil C : N : P ratios are provided at the base of each biomass pyramid to characterize the three plots. These shifts are possibly due to subtle changes in chemical composition that are likely to have enhanced the microfauna less than the mesofauna (Mulder and Elser 2009; Peñuelas and Sardans 2009). 
Since our soils differed mostly in the phosphorus and carbon contents (ANOVA, $p<$ 0.05; Appendix C), we argue that our scaling is independent (or at least less-dependent than commonly assumed) of the environmental conditions of the investigated plots. Only the aforementioned $M$ kernel distribution revealed a difference between plots in the microfaunal distribution and hence most variation in scaling can be attributed to the range of measured body mass. These shifts are possibly due to subtle changes in chemical composition that are likely to have enhanced the microfauna less than the mesofauna (Mulder and Elser 2009; Peñuelas and Sardans 2009).

Finally, it has been suggested by Meehan et al. (2006) and Ehnes et al. (2014) that allometry could be sensitive to the different estimation techniques required for different taxa. Here, nematodes are the only group that exhibit a significant $(p=0.0392)$ and consistently inverse mass-abundance relationship with an overall slope of -0.11 (99\%CI: $-0.248,0.028$ ), covering more than 3.5 orders of magnitude in $M$. Acarina ( -2.5 orders), Collembola and Enchytraeidae (both covering 3 orders) span a smaller range in body mass than Nematoda, although taken together these large-sized invertebrates cover an overall $M$ range of 4 orders of magnitude and explain the extent to which the ratio between the microfauna and the mesofauna may well force the scaling.

\section{Acknowledgements}

We thank David G. Raffaelli and two anonymous reviewers for providing helpful comments that greatly improved the quality of this work. For assistance in accessing the field, for site sampling and for laboratory analysis we are grateful to A. J. Schouten, H. A. Den Hollander, H. Keidel, W. J. Dimmers, and J. Bloem. Data collection was supported by ERGO grants 838.06.062, 838.06.063, and 838.06.064 of the Netherlands Organization for Scientific Research (NWO). 


\section{Supplementary Material}

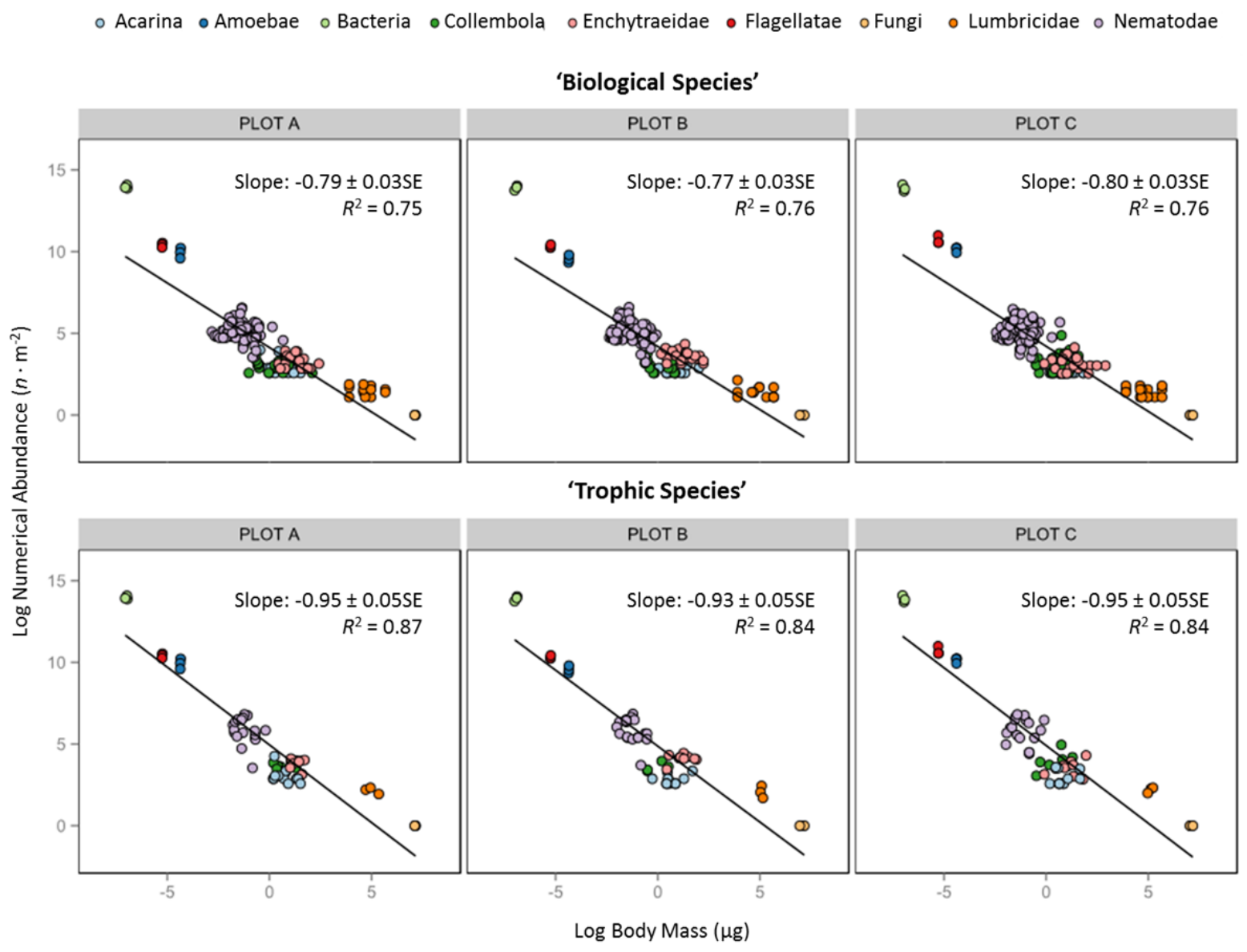

Figure S4.1 - Plot mass-abundance scalings for 'biological species' and 'trophic species' with fungi. 


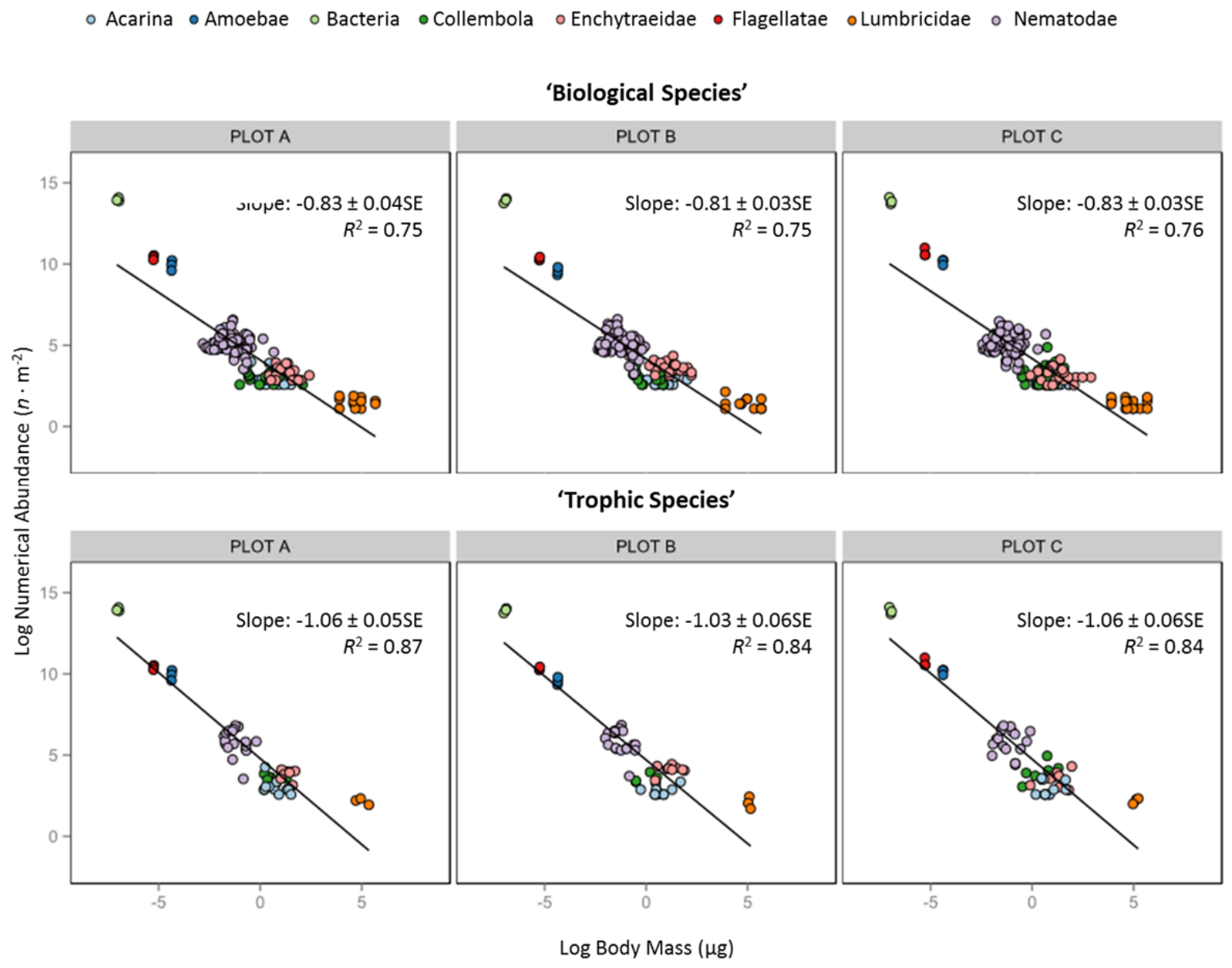

Figure S4.2 - Plot mass-abundance scalings for 'biological species' and 'trophic species' without fungi. 


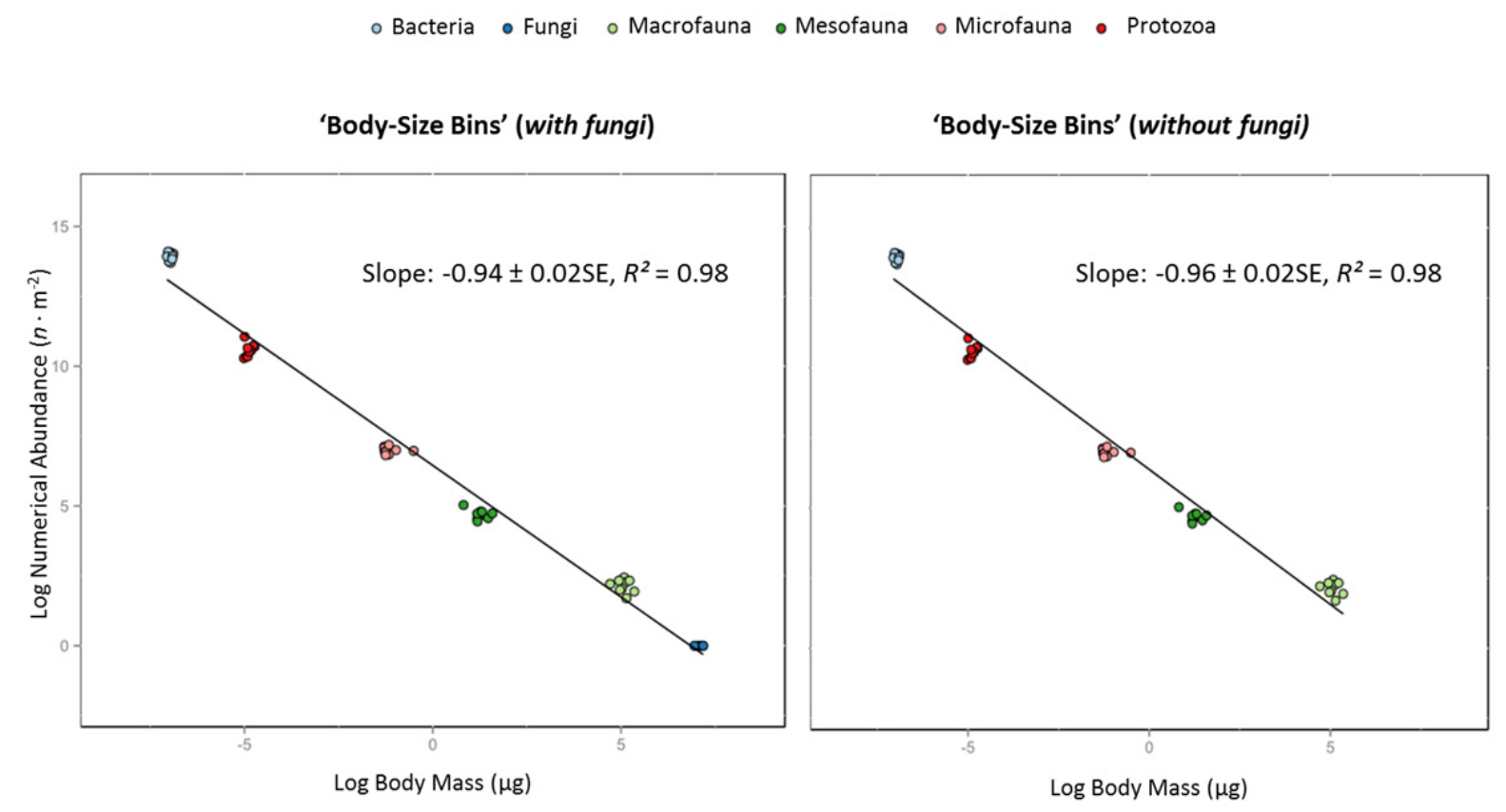

Figure S4.3 - Binned mass-abundance scalings. All the OTUs were aggregated for each replicate $(n=$ 9) into size-defined groups (compare with 'trophic species' in Fig. 4.1 and Fig. S4.1 in Supplementary Material). After aggregation, the Confidence Intervals computed at $99 \%$ per plot are highly overlapping and do not exclude mass-abundance isometry. Including fungi, CIs are for Plot A ( -1.03 , $-0.86)$, Plot $\mathrm{B}(-1.03,-0.84)$, and Plot $\mathrm{C}(-1.02,-0.87)$, and excluding fungi, CIs become for Plot A ($1.10,-0.85)$, Plot B $(-1.09,-0.82)$, and Plot C $(-1.08,-0.85)$. 


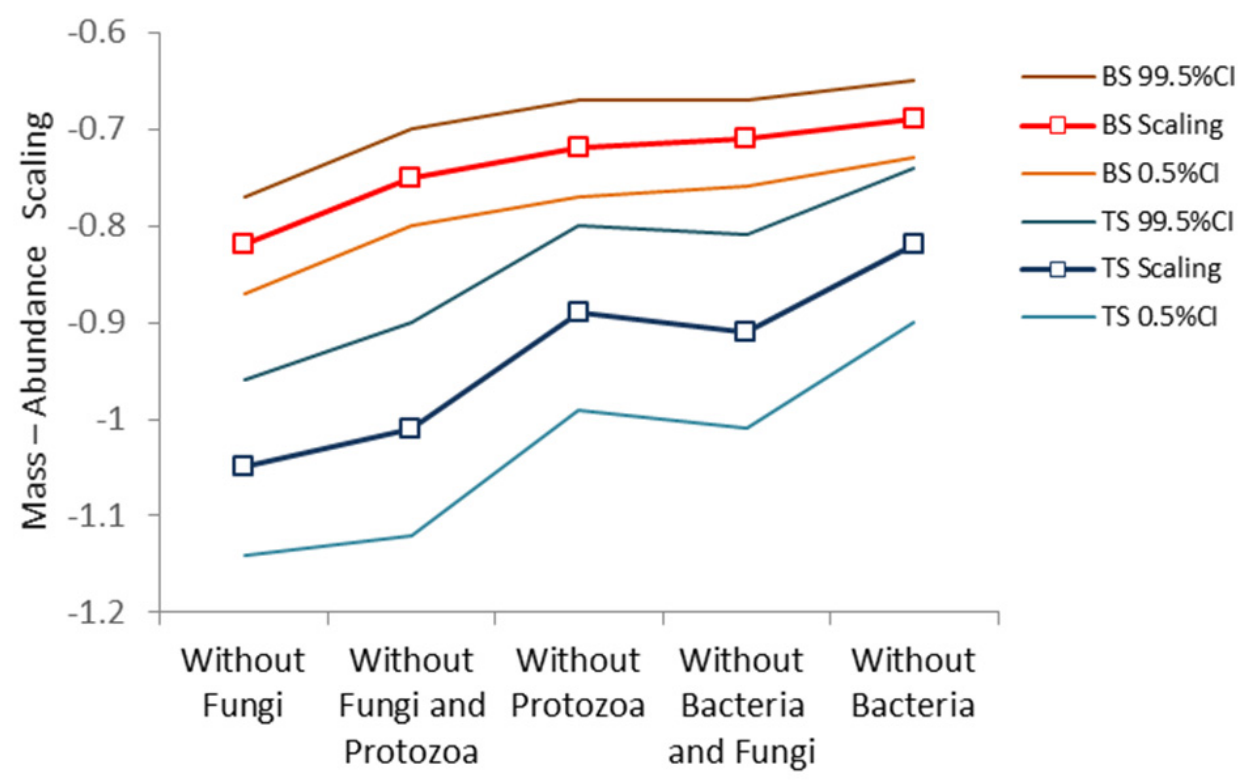

Figure S4.4 - Mass-abundance scalings according to the assembled metawebs. The allometric ranges for trophic species' (TS, upper part of the figure) never intersect the allometric range for biological species' (BS, lower part of the figure). The scaling (i.e., the mass-abundance slope) changes at functional level (TS) more than at taxonomic level (BS). All the linear regressions and the related lower and upper Confidence Intervals were computed at 99\%; see also the Table 4.1. 


\section{'Q-Q Plot 'BS'}
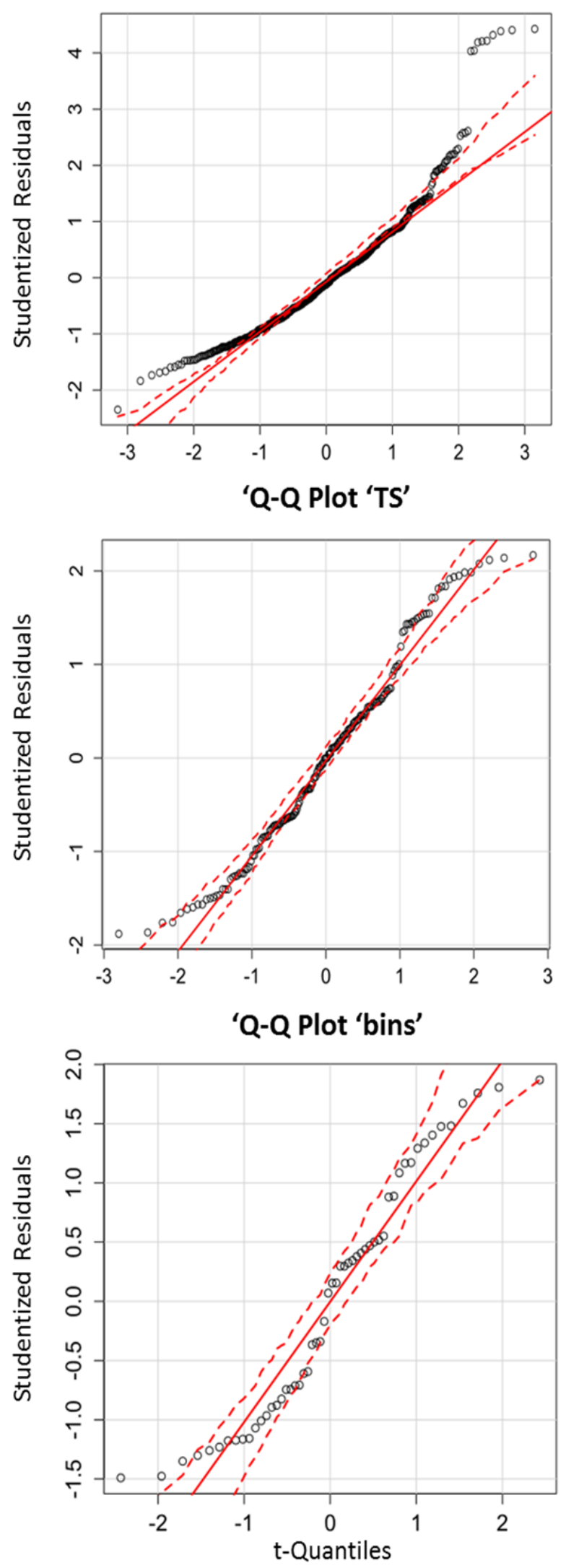

Figure S4.5 - Residuals according to the degree of resolution. From the top to the bottom, Studentized Residual at the taxonomic ('BS'), the functional ('TS') and the binned ('bins') level. As expected, bacteria are more outliers when plotted as biological species (upper right part of the top panel) than as either functional group or size-defined bin (the middle and the lower panel, respecively). Despite a different amount of records for trophic species and bins, the distributions of the residuals at both resolution levels are similar. All data can be accessed via the Dryad Digital Repository at http://dx.doi.org/10.5061/dryad.2sj29 
APPENDIX A4 - Mass-length regressions used to estimate body masses from the measured body size of soil fauna.

\begin{tabular}{|c|c|c|c|c|c|c|}
\hline $\begin{array}{l}\text { Phylogenetic } \\
\text { Group }\end{array}$ & & Mass Unit & Type of Equation & a & b & $\begin{array}{l}\text { Original } \\
\text { Study }\end{array}$ \\
\hline \multicolumn{2}{|l|}{$\begin{array}{l}\text { Nematoda } \\
\text { (all species) }\end{array}$} & fresh mass & $M=\left[L_{\mu m} *\left(D_{\mu m}\right)^{2}\right] /\left(1.6 * 10^{6}\right)$ & & & Andrássy \\
\hline Collembola & $\begin{array}{l}\text { Elongated } \\
\text { specimens: }\end{array}$ & & & & & \\
\hline \multirow[t]{13}{*}{ and } & $\begin{array}{l}\text { Brachystomella } \\
\text { parvula }\end{array}$ & dry mass $[\mu \mathrm{g}]$ & $\log (M)=a+\left[b^{*} \log \left(L_{\mu m}\right)\right]^{i}$ & 0.928 & 3.22 & \multirow{14}{*}{$\begin{array}{c}\text { Petersen } \\
1975 \\
\text { “ }\end{array}$} \\
\hline & $\begin{array}{l}\text { Ceratophysella } \\
\text { denticulata }\end{array}$ & “ & “ & “ & “ & \\
\hline & Folsomia & “ & “ & “ & “ & \\
\hline & Friesea truncata & “ & $"$ & $"$ & “ & \\
\hline & Isotoma & “ & $"$ & $“$ & “ & \\
\hline & Isotomidae & “ & “ & “ & $“$ & \\
\hline & Isotomiella minor & “ & $“$ & $"$ & “ & \\
\hline & Isotomurus & “ & $“$ & $"$ & “ & \\
\hline & Mesaphorura & “ & “ & “ & “ & \\
\hline & Onychiurus & “ & “ & “ & “ & \\
\hline & $\begin{array}{l}\text { Parisotoma } \\
\text { notabilis }\end{array}$ & “ & “ & “ & “ & \\
\hline & $\begin{array}{l}\text { Pseudisotoma } \\
\text { sensibilis }\end{array}$ & “ & “ & “ & “ & \\
\hline & Lepidocyrtus & dry mass $[\mu \mathrm{g}]$ & $\log (M)=a+\left[b^{*} \log \left(L_{\mu m} * 4 / 5\right)\right]^{i}$ & 1.154 & 2.708 & \\
\hline \multirow{4}{*}{ Collembola } & $\begin{array}{l}\text { Globular } \\
\text { specimens }\end{array}$ & & & & & \\
\hline & Symphypleona & dry mass $[\mu \mathrm{g}]$ & $\log (M)=a+\left[b^{*} \log \left(L_{\mu m} * 2 / 3\right)\right]^{i}$ & 1.602 & 2.113 & “ \\
\hline & Sphaeridia & “ & “ & “ & “ & “ \\
\hline & $\begin{array}{l}\text { Sminthurinus } \\
\text { elegans }\end{array}$ & dry mass $[\mu \mathrm{g}]$ & $\log (M)=a+\left[b^{*} \log \left(L_{\mu m}\right)\right]^{i}$ & 2.079 & 3.627 & “ \\
\hline $\begin{array}{l}\text { Acarina } \\
\text { (all species) }\end{array}$ & & dry mass $[\mu \mathrm{g}]$ & $\log (M)=a+\left[b^{*} \log \left(L_{\mu m}\right)\right]^{i i}$ & 2.079 & 3.627 & “ \\
\hline \multirow[t]{2}{*}{ Enchytraeidae } & Achaeta & fresh mass & $\log (M)=a+\left[b * \log \left(L_{m m}\right)\right]^{i i i}$ & 0.627 & 1.855 & \multirow{2}{*}{$\begin{array}{l}\text { Cohen \& } \\
\text { Mulder } \\
2014\end{array}$} \\
\hline & & {$[\mu \mathrm{g}]$} & & & & \\
\hline \multirow{11}{*}{ 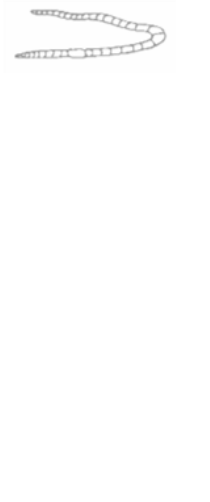 } & Buchholzia & “ & “ & 0.971 & 1.534 & “ \\
\hline & Cognettia & “ & “ & 0.971 & 1.534 & “ \\
\hline & Enchytraeus & “ & “ & 0.658 & 2.038 & “ \\
\hline & Enchytronia & $"$ & $"$ & 0.627 & 1.855 & $“$ \\
\hline & Fridericia & “ & $“$ & 0.798 & 2.011 & “ \\
\hline & Hemienchytraeus & “ & “ & 0.658 & 2.038 & “ \\
\hline & Hemifridericia & “ & “ & 0.627 & 1.855 & “ \\
\hline & Henlea & $"$ & $"$ & 0.837 & 1.980 & $“$ \\
\hline & Marionina & $“$ & “ & 0.658 & 2.038 & “ \\
\hline & Mesenchytraeus & $"$ & $"$ & 0.803 & 2.187 & “ \\
\hline & Unidentified & “ & $"$ & 0.773 & 1.910 & $“$ \\
\hline
\end{tabular}




\section{Chapter 5}

Note: $\mathrm{M}$ is the mass per individual, $\mathrm{L}$ is the body length and $\mathrm{D}$ is the greatest body diameter. Logarithms are base-10, units are provided in the formulae.To convert fresh to dry weight we assumed a water content of $80 \%$ for the nematodes, $82 \%$ for the enchytraeids and $90 \%$ for the earthworms.

${ }^{i}$ Morphotype mass-length regressions were used to estimate the body masses (dry weights) from the measured body lengths of single collembolans. For the allometric parameters provided by Petersen (1975) without considering animal's heads, we used here slightly modified linear regressions to avoid possible overestimation of the body mass.

ii Due to volumetric resemblances with globular collembolans, we used for all mites (Acarina) the same allometric parameters as originally provided by Petersen (1975) for Sminthurinus aureus.

iii Mass-length regression used to compute the enchytraeid's weights and parameters as provided by Wim A. M. Didden (Cohen \& Mulder 2014, their Box 1). 
APPENDIX B4 - Identified Operational Taxonomic Units (OTUs) and assigned Trophic Species

\begin{tabular}{|c|c|c|c|c|c|}
\hline ID & $\begin{array}{l}\text { Phylogenetic } \\
\text { Group }\end{array}$ & OTU & $\begin{array}{l}\text { Taxon } \\
\text { ID }\end{array}$ & $\begin{array}{l}\text { Trophic } \\
\text { ID }\end{array}$ & $\begin{array}{l}\text { TrophicSpecies } \\
\text { (Guild) }\end{array}$ \\
\hline 1 & Fungi & Fungi & 49000 & 49 & $\begin{array}{l}\text { Primary (heterotrophic) } \\
\text { producer }\end{array}$ \\
\hline 2 & Bacteria & Bacteria & 48000 & 48 & $\begin{array}{l}\text { Primary (heterotrophic) } \\
\text { producer }\end{array}$ \\
\hline 3 & Amoebae & Amoebae & 36000 & 36 & $\begin{array}{l}\text { Mostly bacterivore naked } \\
\text { amoebae }\end{array}$ \\
\hline 4 & Flagellatae & Flagellatae & 37000 & 37 & Bacterivore flagellate \\
\hline 5 & Nematoda & Achromadora & 21001 & 21 & Fungivore nematode \\
\hline 6 & Nematoda & Acrobeles ciliatus & 31002 & 31 & Bacterivore nematode \\
\hline 7 & Nematoda & Acrobeloides & 31003 & 31 & Bacterivore nematode \\
\hline 8 & Nematoda & Aglenchus agricola & 11006 & 11 & Plant-feeding nematode \\
\hline 9 & Nematoda & Alaimus & 31008 & 31 & Bacterivore nematode \\
\hline 10 & Nematoda & $\begin{array}{l}\text { Anaplectus } \\
\text { grandepapillatus }\end{array}$ & 31012 & 31 & Bacterivore nematode \\
\hline 11 & Nematoda & Aphelenchoides & 21016 & 21 & Fungivore nematode \\
\hline 12 & Nematoda & Aphelenchus & 21018 & 21 & Fungivore nematode \\
\hline 13 & Nematoda & $\begin{array}{l}\text { Aporcelaimellus } \\
\text { obtusicaudatus }\end{array}$ & 81019 & 81 & Omnivore nematode \\
\hline 14 & Nematoda & Bastiania & 31023 & 31 & Bacterivore nematode \\
\hline 15 & Nematoda & Cephalobidae & 31032 & 31 & Bacterivore nematode \\
\hline 16 & Nematoda & Chromadoridae & 31036 & 31 & Bacterivore nematode \\
\hline 17 & Nematoda & Chronogaster & 31037 & 31 & Bacterivore nematode \\
\hline 18 & Nematoda & Clarkus & 51038 & 51 & $\begin{array}{l}\text { Predating nematode } \\
\text { (consuming nematodes) }\end{array}$ \\
\hline 19 & Nematoda & Coslenchus & 11041 & 11 & Plant-feeding nematode \\
\hline 20 & Nematoda & Dauerlarvae & 41046 & 41 & $\begin{array}{l}\text { Passive lifestage, substrate- } \\
\text { related nematode }\end{array}$ \\
\hline 21 & Nematoda & Diphtherophora & 21048 & 21 & Fungivore nematode \\
\hline 22 & Nematoda & Ditylenchus & 21053 & 21 & Fungivore nematode \\
\hline 23 & Nematoda & Dolichodoridae & 11054 & 11 & Plant-feeding nematode \\
\hline 24 & Nematoda & Dolichorhynchus & 11056 & 11 & Plant-feeding nematode \\
\hline 25 & Nematoda & Dorylaimida & $11171 *$ & 11 & Plant-feeding nematode \\
\hline 26 & Nematoda & Dorylaimoidea & 81058 & 81 & Omnivore nematode \\
\hline 27 & Nematoda & Eucephalobus & 31065 & 31 & Bacterivore nematode \\
\hline 28 & Nematoda & Eudorylaimus & 81066 & 81 & Omnivore nematode \\
\hline 29 & Nematoda & Eumonhystera & 31067 & 31 & Bacterivore nematode \\
\hline 30 & Nematoda & Filenchus & 11070 & 11 & Plant-feeding nematode \\
\hline 31 & Nematoda & Helicotylenchus & 11074 & 11 & Plant-feeding nematode \\
\hline 32 & Nematoda & $\begin{array}{l}\text { Heterocephalobus } \\
\text { elongatus }\end{array}$ & 31076 & 31 & Bacterivore nematode \\
\hline 33 & Nematoda & Heterodera & 11077 & 11 & Plant-feeding nematode \\
\hline 34 & Nematoda & Longidoridae & 11086 & 11 & Plant-feeding nematode \\
\hline 35 & Nematoda & Longidorus & 11087 & 11 & Plant-feeding nematode \\
\hline 36 & Nematoda & Meloidogyne & 11091 & 11 & Plant-feeding nematode \\
\hline 37 & Nematoda & Meloidogyne naasi & 11091 & 11 & Plant-feeding nematode \\
\hline 38 & Nematoda & $\begin{array}{l}\text { Metateratocephalus } \\
\text { crassidens }\end{array}$ & 31095 & 31 & Bacterivore nematode \\
\hline 39 & Nematoda & Monhystera & 31099 & 31 & Bacterivore nematode \\
\hline 40 & Nematoda & Mononchidae & 51102 & 51 & $\begin{array}{l}\text { Predating nematode } \\
\text { (consuming nematodes) }\end{array}$ \\
\hline 41 & Nematoda & Mononchus & 51104 & 51 & Predating nematode \\
\hline
\end{tabular}




\begin{tabular}{|c|c|c|c|c|c|}
\hline 42 & Nematoda & Mylonchulus & 51106 & 51 & $\begin{array}{l}\text { (consuming nematodes) } \\
\text { Predating nematode } \\
\text { (consuming nematodes) }\end{array}$ \\
\hline 43 & Nematoda & Neodiplogasteridae & 81108 & 81 & Omnivore nematode \\
\hline 44 & Nematoda & Odontolaimus & 31113 & 31 & Bacterivore nematode \\
\hline 45 & Nematoda & Panagrolaimus & 31116 & 31 & Bacterivore nematode \\
\hline 46 & Nematoda & Paramphidelus & 31117 & 31 & Bacterivore nematode \\
\hline 47 & Nematoda & Paratrichodorus & 11119 & 11 & Plant-feeding nematode \\
\hline 48 & Nematoda & Paratrichodorus teres & 11119 & 11 & Plant-feeding nematode \\
\hline 49 & Nematoda & Paratylenchus & 11122 & 11 & Plant-feeding nematode \\
\hline 50 & Nematoda & Plectidae & 31126 & 31 & Bacterivore nematode \\
\hline 51 & Nematoda & Plectus & 31127 & 31 & Bacterivore nematode \\
\hline 52 & Nematoda & Pratylenchus & 11129 & 11 & Plant-feeding nematode \\
\hline 53 & Nematoda & Pratylenchus crenatus & 11129 & 11 & Plant-feeding nematode \\
\hline 54 & Nematoda & Prismatolaimus & 31131 & 31 & Bacterivore nematode \\
\hline 55 & Nematoda & Prodorylaimus & 81134 & 81 & Omnivore nematode \\
\hline 56 & Nematoda & Pungentus & 81139 & 81 & Omnivore nematode \\
\hline 57 & Nematoda & Qudsianematidae & 81140 & 81 & Omnivore nematode \\
\hline 58 & Nematoda & Rhabditidae & 31142 & 31 & Bacterivore nematode \\
\hline 59 & Nematoda & Rotylenchus & 11144 & 11 & Plant-feeding nematode \\
\hline 60 & Nematoda & Teratocephalus & 31149 & 31 & Bacterivore nematode \\
\hline 61 & Nematoda & Thornenematinae & $81170 *$ & 11 & Plant-feeding nematode \\
\hline 62 & Nematoda & Trichodoridae & 11154 & 11 & Plant-feeding nematode \\
\hline 63 & Nematoda & Trichodorus & 11155 & 11 & Plant-feeding nematode \\
\hline 64 & Nematoda & Trichodorus similis & 11155 & 11 & Plant-feeding nematode \\
\hline 65 & Nematoda & Tripyla & 51156 & 51 & $\begin{array}{l}\text { Predating nematode } \\
\text { (consuming nematodes) }\end{array}$ \\
\hline 66 & Nematoda & Tylenchidae & 21160 & 21 & Fungivore nematode \\
\hline 67 & Nematoda & Tylenchorhynchus & 11163 & 11 & Plant-feeding nematode \\
\hline 68 & Nematoda & Tylenchorhynchus dubius & 11163 & 11 & Plant-feeding nematode \\
\hline 69 & Nematoda & Wilsonema & 31168 & 31 & Bacterivore nematode \\
\hline 70 & Enchytraeidae & Achaeta & 24001 & 24 & Fungivore enchytraeid \\
\hline 71 & Enchytraeidae & Achaeta abulba & 24001 & 24 & Fungivore enchytraeid \\
\hline 72 & Enchytraeidae & Buchholzia & 44002 & 44 & $\begin{array}{l}\text { Substrate-inhabiting } \\
\text { enchytraeid }\end{array}$ \\
\hline 73 & Enchytraeidae & Enchytraeus & 34004 & 34 & Bacterivore enchytraeid \\
\hline 74 & Enchytraeidae & Enchytraeus buchholzi & 34004 & 34 & Bacterivore enchytraeid \\
\hline 75 & Enchytraeidae & Enchytraeus minutus & 34004 & 34 & Bacterivore enchytraeid \\
\hline 76 & Enchytraeidae & Enchytronia & 34005 & 34 & Bacterivore enchytraeid \\
\hline 77 & Enchytraeidae & Enchytronia parva & 34005 & 34 & Bacterivore enchytraeid \\
\hline 78 & Enchytraeidae & Fridericia & 24006 & 24 & Fungivore enchytraeid \\
\hline 79 & Enchytraeidae & Fridericia alata & 24006 & 24 & Fungivore enchytraeid \\
\hline 80 & Enchytraeidae & Fridericia bisetosa & 24006 & 24 & Fungivore enchytraeid \\
\hline 81 & Enchytraeidae & Fridericia bulboides & 24006 & 24 & Fungivore enchytraeid \\
\hline 82 & Enchytraeidae & Fridericia cylindrica & 24006 & 24 & Fungivore enchytraeid \\
\hline 83 & Enchytraeidae & Fridericia hegemon & 24006 & 24 & Fungivore enchytraeid \\
\hline 84 & Enchytraeidae & Fridericia paroniana & 24006 & 24 & Fungivore enchytraeid \\
\hline 85 & Enchytraeidae & Fridericia perrieri & 24006 & 24 & Fungivore enchytraeid \\
\hline 86 & Enchytraeidae & Henlea perpusilla & 44009 & 44 & $\begin{array}{l}\text { Substrate-inhabiting } \\
\text { enchytraeid }\end{array}$ \\
\hline 87 & Enchytraeidae & Henlea ventriculosa & 44009 & 44 & $\begin{array}{l}\text { Substrate-inhabiting } \\
\text { enchytraeid }\end{array}$ \\
\hline 88 & Enchytraeidae & Marionina & 44010 & 44 & $\begin{array}{l}\text { Substrate-inhabiting } \\
\text { enchytraeid }\end{array}$ \\
\hline 89 & Enchytraeidae & Marionina argentea & 44010 & 44 & $\begin{array}{l}\text { Substrate-inhabiting } \\
\text { enchytraeid }\end{array}$ \\
\hline 90 & Enchytraeidae & Marionina communis & 44010 & 44 & Substrate-inhabiting \\
\hline
\end{tabular}




\begin{tabular}{|c|c|c|c|c|c|}
\hline 91 & Enchytraeidae & Marionina vesiculata & 44010 & 44 & $\begin{array}{l}\text { enchytraeid } \\
\text { Substrate-inhabiting } \\
\text { enchytraeid }\end{array}$ \\
\hline 92 & Acarina & Achipteria coleoptrata & 12001 & 12 & $\begin{array}{l}\text { Macrophytophage and } \\
\text { panphytophage mite }\end{array}$ \\
\hline 93 & Acarina & Alliphis siculus & 52004 & 52 & $\begin{array}{l}\text { Predatory mite (attacking } \\
\text { nematodes) }\end{array}$ \\
\hline 94 & Acarina & Bdellidae & 62015 & 62 & $\begin{array}{l}\text { Predatory mite (attacking } \\
\text { arthropods) }\end{array}$ \\
\hline 95 & Acarina & Cheiroseius & 72026 & 72 & Generalist mite \\
\hline 96 & Acarina & Dendrolaelaps & 72034 & 72 & Generalist mite \\
\hline 97 & Acarina & Epicriopsis & 22040 & 22 & $\begin{array}{l}\text { Microphytophage mite } \\
\text { (feeding on fungi) }\end{array}$ \\
\hline 98 & Acarina & Eupodidae & 82047 & 82 & Omnivore mite \\
\hline 99 & Acarina & Hypoaspis & 72058 & 72 & Generalist mite \\
\hline 100 & Acarina & Liebstadia similis & 22068 & 22 & $\begin{array}{l}\text { Microphytophage mite } \\
\text { (feeding on fungi) }\end{array}$ \\
\hline 101 & Acarina & Lysigamasus & 72071 & 72 & Generalist mite \\
\hline 102 & Acarina & Macrocheles & 72072 & 72 & Generalist mite \\
\hline 103 & Acarina & Oribatida & 82090 & 82 & Omnivore mite \\
\hline 104 & Acarina & Pachygnatidae & 12092 & 12 & $\begin{array}{l}\text { Macrophytophage and } \\
\text { panphytophage mite }\end{array}$ \\
\hline 105 & Acarina & Parasitus & 72096 & 72 & Generalist mite \\
\hline 106 & Acarina & Pergamasus & 72100 & 72 & Generalist mite \\
\hline 107 & Acarina & Prostigmata & 92105 & 92 & $\begin{array}{l}\text { Predatory mite (parasitizing } \\
\text { mites and nematodes) }\end{array}$ \\
\hline 108 & Acarina & Pygmephorus & 22112 & 22 & $\begin{array}{l}\text { Microphytophage mite } \\
\text { (feeding on fungi) }\end{array}$ \\
\hline 109 & Acarina & Rhizoglyphus & 12117 & 12 & $\begin{array}{l}\text { Macrophytophage and } \\
\text { panphytophage mite }\end{array}$ \\
\hline 110 & Acarina & Scutacarus & 82125 & 82 & Omnivore mite \\
\hline 111 & Acarina & Stigmaeidae & 82131 & 82 & Omnivore mite \\
\hline 112 & Acarina & Tydeidae & 12139 & 12 & $\begin{array}{l}\text { Macrophytophage and } \\
\text { panphytophage mite }\end{array}$ \\
\hline 113 & Acarina & Tyrophagus & 22140 & 22 & $\begin{array}{l}\text { Microphytophage mite } \\
\text { (feeding on fungi) }\end{array}$ \\
\hline 114 & Acarina & Uropoda orbicularis & 72142 & 72 & Generalist mite \\
\hline 115 & Collembola & Brachystomella parvula & 23003 & 23 & Fungivore insect (springtail) \\
\hline 116 & Collembola & Ceratophysella denticulata & 23004 & 23 & Fungivore insect (springtail) \\
\hline 117 & Collembola & Folsomia & 23009 & 23 & Fungivore insect (springtail) \\
\hline 118 & Collembola & Friesea truncata & 23010 & 23 & Fungivore insect (springtail) \\
\hline 119 & Collembola & Isotoma $* *$ & 23013 & 23 & Fungivore insect (springtail) \\
\hline 120 & Collembola & Isotomiella minor & 23014 & 23 & Fungivore insect (springtail) \\
\hline 121 & Collembola & Isotomurus & 23015 & 23 & Fungivore insect (springtail) \\
\hline 122 & Collembola & Lepidocyrtus & 23016 & 23 & Fungivore insect (springtail) \\
\hline 123 & Collembola & Mesaphorura & 23018 & 23 & Fungivore insect (springtail) \\
\hline 124 & Collembola & Onychiurus & 23021 & 23 & Fungivore insect (springtail) \\
\hline 125 & Collembola & Parisotoma notabilis & 23024 & 23 & Fungivore insect (springtail) \\
\hline 126 & Collembola & Pseudisotoma sensibilis & 23030 & 23 & Fungivore insect (springtail) \\
\hline 127 & Collembola & Sminthurinus elegans & 13034 & 13 & Plant-feeding insect (springtail) \\
\hline 128 & Collembola & Sphaeridia pumilis & 13036 & 13 & Plant-feeding insect (springtail) \\
\hline 129 & Collembola & Symphypleona & $13042 *$ & 13 & Plant-feeding insect (springtail) \\
\hline 130 & Lumbricidae & Allolobophora chlorotica & 45012 & 45 & Substrate-ingesting earthworm \\
\hline 131 & Lumbricidae & $\begin{array}{l}\text { Aporrectodea caliginosa } \\
\text { adults }\end{array}$ & 45013 & 45 & Substrate-ingesting earthworm \\
\hline 132 & Lumbricidae & $\begin{array}{l}\text { Aporrectodea epilobous } \\
\text { juveniles }\end{array}$ & 45013 & 45 & Substrate-ingesting earthworm \\
\hline
\end{tabular}


Chapter 5

\begin{tabular}{|llllll|}
\hline 133 & Lumbricidae & Lumbricidae undiff. & 45000 & 45 & Substrate-ingesting earthworm \\
134 & Lumbricidae & Lumbricus rubellus adults & 45018 & 45 & Substrate-ingesting earthworm \\
135 & Lumbricidae & $\begin{array}{l}\text { Lumbricus tanylobous } \\
\text { juveniles }\end{array}$ & 45018 & 45 & Substrate-ingesting earthworm \\
\hline
\end{tabular}

* New Taxon_IDs, these three taxa are not mentioned in Mulder et al. (2008) at DOI:

10.1371/journal.pone.0003573.s001

${ }^{* *}$ In two cases, specimens were incomplete or damaged and have been assigned to a higher taxonomic level (Isotomidae)

APPENDIX C4 - Means and standard error ( \pm SE) of environmental parameters: $\mathrm{C}, \mathrm{N}, \mathrm{P}$, and $\mathrm{pH}$. Vertically-different letters indicate differences between plots (post hoc analysis).

\begin{tabular}{|ccccccccccccccccccc|}
\hline Plot & C-tot & & se & & N-tot & & se & & P-tot & & se & & pH & & se \\
\hline A & 2472.22 & \pm & 337.93 & ab & 170.95 & \pm & 1.67 & n.s & 17.55 & \pm & 0.77 & ab & 4.97 & \pm & 0.03 & n.s \\
B & 2027.78 & \pm & 227.37 & a & 166.19 & \pm & 12.18 & n.s & 16.56 & \pm & 0.26 & a & 5.20 & \pm & 0.06 & n.s \\
C & 3388.89 & \pm & 194.45 & b & 203.33 & \pm & 15.83 & n.s & 32.38 & \pm & 0.14 & b & 5.07 & \pm & 0.09 & n.s \\
\hline
\end{tabular}

C-tot: total carbon $\left(\mathrm{mmol} \times \mathrm{kg}^{-1}\right.$ soil), $\mathrm{N}$-tot: total nitrogen $\left(\mathrm{mmol} \times \mathrm{kg}^{-1}\right.$ soil),

P-tot: total phosphorus $\left(\mathrm{mmol} \times \mathrm{kg}^{-1}\right.$ soil). 
Chapter 5

Functional diversity in nematode communities across terrestrial ecosystems 



\title{
Functional diversity in nematode communities across terrestrial ecosystems
}

\author{
Chapter submitted for publication
}

\author{
Valentina Sechi, Ron G. M. De Goede, Giorgio Mancinelli, \\ Michiel Rutgers, Lijbert Brussaard, Christian Mulder
}

\begin{abstract}
Functional diversity has been suggested as indicator of environmental filtering and is widely recognized as reliable predictor of ecosystem functioning. Currently, there is a growing consensus that functional diversity based on continuous traits shows a much higher resolution than when it is based on discrete trait values. However, there is a lack of studies that test how functional diversity responds to different environmental pressures. To fill this gap and to explore the trait distribution in biological communities from real ecosystems, we selected a large online dataset on continuous body-size traits of soil nematodes from three contrasting ecosystem types, i.e. woodlands/shrublands, managed grasslands and arable fields. We analysed i) the three components of functional diversity, i.e. richness, divergence and evenness; ii) the shifts in body size; and iii) the body-mass distributions of five trophic groups and of the entire nematode community. We found low values of functional evenness to be associated with high values of functional richness. The shift in body size revealed environmental filters that could not have been identified by the study of functional diversity indices per se. Body-mass distributions revealed different filtering effects, especially when similarity in the values of functional indices emerged. Moreover, we provide empirical evidence that body-mass distribution within a trophic group mirrors the effects of environmental filtering more than the distribution of the community as a whole. Hence, our trait-based approach, more than the functional diversity itself, disclosed soil food-web structure and identified trait responses.
\end{abstract}




\section{Introduction}

Functional diversity can be defined as the distribution of trait values within a community (Díaz and Cabido 2001) and was commonly assessed by functional group richness (Villéger et al. 2008). It has further been suggested to reflect environmental filtering (Villéger et al. 2008) and ecosystem functioning (Petchey and Gaston 2002). In particular, functional diversity is assumed to be a better predictor of ecosystem functioning than the classical species diversity (Gagic et al. 2015) because competitive interactions and the responses to environmental filtering reflect, at least partly, functional traits (Mouillot et al. 2013). In the last decades, many indices have been proposed to quantify functional diversity and to capture the different aspects of trait distributions within and between species assemblages (Tilman et al. 1997b, Hooper and Dukes 2004). However, gathering species into groups imposes a discrete structure on the data that often results in a loss of information (Petchey and Gaston 2002). More recently, indices based on continuous and/or multiple (discrete and continuous) traits and their abundance have been formulated (Botta-Dukát 2005, Mason et al. 2005, Villéger et al. 2008, Laliberté and Legendre 2010). Here, we follow Mason et al. (2005) who defined the three main components of functional diversity and formulated the related indices, which are in principle independent from each other: functional richness (the amount of functional space, i.e. the range of values of the trait considered, filled by species in a community), functional evenness (i.e. the evenness of abundance distribution in filled functional space) and functional divergence, (i.e. the degree to which abundance distribution in functional space enhances divergence in functional characters within a community). These indices have the additional advantage of considering site-specific trait measurements instead of averaged trait values, hence they can provide higher resolution. Moreover, they are based on one single trait, making their interpretation potentially easier to explain than if based on multiple traits.

Until now, the performance of functional diversity indices has been assessed using artificial data (Mouillot and Wilson 2002, Villéger et al. 2008, Mouchet et al. 2010). Hence, there is a lack of studies testing how these indices of functional diversity change in response to specific environmental pressures in real ecosystems (Pakeman 2011). To explore the 
structure of biological communities and to investigate how functional diversity varies with environmental conditions, we use an online dataset on individual body sizes of nematodes across three contrasting terrestrial ecosystem types, i.e. arable fields, managed grasslands, and shrublands/woodlands (Mulder and Vonk 2011). Body size reflects the adaptation of organisms and, together with taxonomic and functional identity, determines the species interactions that shape community structure (Peters 1983, Calder 1984, Hendriks and Mulder 2008). The aim of our study was to analyse $i$ ) the three components of functional diversity sensu Mason et al. (2005); ii) the shifts in the body size traits length and width; and iii) the differences in body-mass distribution of the nematode community as a whole and of five trophic groups separately. We hypothesized that the functional diversity reflects the land management intensity, assuming that in less disturbed habitats competition will be of higher importance in structuring the community than habitat filtering. Accordingly, we expect to find high functional richness and divergence, and low evenness in such environments (Pakeman 2011). Given that the soil microfauna often seems functionally redundant (i.e. high species richness but low functional richness) and that the body mass only partially reflects single trophic levels (Mulder and Elser 2009, Sechi et al. 2015), we hypothesized that species belonging to different trophic groups overlap along a trait-based functional gradient. Hence, we also hypothesized that individual body-size distribution within each group, more than that of the whole community, will mirror the environmental filtering acting on all the organisms within the soil food web.

\section{Material and Methods}

\section{Dataset}

For our study we used a nematode dataset containing 29,552 individual records collected in The Netherlands (Mulder and Vonk 2011). The dataset comprised physical, chemical, and biological information covering four soil types and three ecosystem types. Although not all cross-combinations were available, the dataset allowed a direct comparison between three ecosystem types (i.e., arable fields, managed grasslands, and shrublands/woodlands) on sand ( $\mathrm{n}=118$ sites). We also compared body-size values between 
arable fields and managed grasslands on clay $(n=41)$ and between soil types (i.e. clay and sandy soils, $\mathrm{n}=137$ sites, being 32 arable fields and 105 managed grasslands). To avoid negative numbers, we multiplied the original mass values (in $\mu \mathrm{g}$ ) times $10^{6}$ before $\log _{10}$ transformation. To enable a direct comparison between ecosystem types despite the different numbers of sites, the frequency of each nematode body-size class was expressed either in percentage or averaged per ecosystem type.

\section{Sampling methods}

In each ecosystem type, 320 randomly taken cores $(\Phi 2.3 \times 10 \mathrm{~cm})$ were collected all over the investigated area (field area ranging from $\approx 8$ to $\approx 100 \mathrm{ha}$ ) and mixed in one sample. A sub-sample of about $500 \mathrm{~g}$ was taken and stored at $4{ }^{\circ} \mathrm{C}$ in glass containers until extraction. Nematodes were extracted from about $100 \mathrm{~g}$ soil using the Oostenbrink method (Oostenbrink 1960). Per site, all the specimens were screened in two clean $10 \mathrm{ml}$ water suspensions and

approximately 150 randomly-chosen specimens were identified and measured under light microscopy. Soil $\mathrm{pH}\left(\mathrm{H}_{2} \mathrm{O}\right)$ was determined using a de-ionized $4: 1$ water : soil vol/vol ratio. Organic carbon (g Corg / kg soil) was measured after oven-combustion of soil using the Van Bemmelen conversion factor 1.72 (pedotransfer function). Total soil nitrogen (g N / kg soil) was determined by a titrimetric method after distillation using Kjeldahl destruction. Total soil phosphorus (g P / kg soil) was determined by automated ion analyzer after sample digestion.

\section{Trait collection}

Body length and width of all identified nematodes were measured to the nearest $1 \mu \mathrm{m}$ with an eyepiece micrometer. Subsequently, the nematode fresh weight (fresh body mass) was derived at the individual level with the volumetric function of Andrássy (1956) and converted to dry body mass using a weight ratio of 0.20 (Petersen and Luxton 1982). For all individual records (193 taxa, mostly at genus level), feeding habits (hence, diet and trophic level) were assigned based on the functional trophic groups as defined in Yeates et al. (1993). 


\section{Functional diversity indices}

For each site, functional diversity estimations were derived from mass distributions of nematodes, calculating the three components as proposed by Mason et al. (2005): (a) functional richness, (b) functional evenness and (c) functional divergence.

(a) Functional richness (hereafter, Fric) represents the quantity of functional space filled by an assemblage $i$. It was estimated by using the total range of functional values present in the assemblage (Mason et al. 2005). This filled amount of functional space must be standardized to enable comparison of different attributes:

$$
\text { Fric }_{i}=\frac{F S_{i}}{R}
$$

with $F S_{i}$ being the functional space (number of mass bins) filled by the species within assemblage $i$ and $R$ the absolute range of the functional trait. Fric varies between 0 and 1 .

(b) Functional evenness (hereafter, Feve) describes to which extent abundance is equitably distributed in the functional space within a community $i$ (Mason et al. 2005). In our case, Feve represents the degree to which the body-mass assemblage (i.e. biomass) is evenly distributed across the size spectrum. It was measured by applying the evenness index by Smith and Wilson (1996) to the total biomass within each mass bin. Feve was estimated using the formula:

$$
\text { Feve }=1-2 / \pi \arctan \left[\sum_{s_{1}=1}^{N}\left(\ln \left(x_{s_{1}}\right)-\sum_{s_{2}=1}^{N}\left(\ln \left(x_{s_{2}}\right) / N\right)\right)^{2} / N\right]
$$

with $N$ being the number of mass bins; xi the total biomass of the $i^{\text {th }}$ bin. This index has the advantage to vary between 0 and 1 , to be able to discriminate assemblages irrespective to their species richness (Mouillot and Wilson 2002) and to meet the statistical requirements listed in Smith and Wilson (1996).

(c) Functional divergence (hereafter, $F d i v$ ) quantifies the extent to which mass distribution enhances the divergence in the spectra within our nematode community (Mason et al. 2005). Fdiv is high if peaks of abundances are located at the edges of a functional axis, but if the 
maximum abundance is close to the mean, Fdiv is low. Fdiv is based on an abundanceweighted sum of squares analogous to a log-transformed variance:

$$
F d i v=\frac{2}{\pi} \arctan \left\{5 \times \sum_{i=1}^{N}\left[\left(\ln C_{i}-\overline{\ln C}\right)^{2} \times A_{i}\right]\right\}
$$

where $C_{i}$ is the value of body mass for the $i^{\text {th }}$ body-mass class, $A_{\mathrm{i}}$ is the proportional abundance of the $i^{\text {th }}$ body-mass class, and $\overline{\ln C}$ is the abundance-weighted mean of the natural logarithm of body mass values for the classes. Also this index ranges between 0 and 1 . Differences in the indices between ecosystem types were tested with ANOVA.

\section{Traits shift and body-size distribution}

Shifts in body size variation were analysed by plotting the body length $\left(\log _{10} \mathrm{~L}\right)$ vs. the body width $\left(\log _{10} \mathrm{~W}\right)$ values averaged per trophic group and ecosystem type both in sandy and clay soils. Body-mass (M) distribution was analysed by discretizing the individual mass measurements into equal size bins. The number of bins was determined according to the Freedman-Diaconis rule for histograms (Freedman and Diaconis 1981) resulting in 94 bins (bin width $=0.05)$.

\section{Results}

\section{Functional diversity indices}

In sandy soils, functional richness of the whole community was higher in managed grasslands than in arable fields and shrublands/woodlands (Table 5.1). Feve did not differ between ecosystems while Fdiv was higher in managed grasslands than in arable fields (Table 5.1). Looking at the functional indices per trophic group, we found that Fric of bacterivores was higher in arable fields and managed grasslands than in shrublands/woodlands. The opposite was found for Feve, which had the lowest value in arable fields, intermediate in managed grasslands, and highest in shrublands/woodlands. Such a contrasting response of functional richness and evenness to the environment was found not only for bacterivores, but also for fungivores and omnivores. Divergence of bacterivores was highest in managed grasslands and 
Table 5.1 - Means and standard deviations (SD) of functional diversity indices for each nematode feeding group (FG) from three main ecosystem type on sandy soils. Numbers of entries $(n)$ are also indicated. Means followed by the same letter do not differ at $\mathrm{p}<0.05$.

\begin{tabular}{|c|c|c|c|c|c|c|c|c|c|c|c|c|c|c|c|c|}
\hline & \multirow[t]{2}{*}{ FG } & \multicolumn{4}{|c|}{ Arable Fields } & \multicolumn{6}{|c|}{ Managed Grasslands } & \multicolumn{5}{|c|}{ Shrublands/Woodlands } \\
\hline & & $\mathrm{n}$ & Mean & & SD & & $\mathrm{n}$ & Mean & & SD & & $\mathrm{n}$ & Mean & & SD & \\
\hline Functional & $\begin{array}{l}\text { Whole } \\
\text { community }\end{array}$ & 20 & 0.476 & \pm & 0.058 & $\mathrm{~b}$ & 76 & 0.537 & \pm & 0.060 & a & 22 & 0.472 & \pm & 0.071 & $b$ \\
\hline \multirow[t]{5}{*}{ richness } & Bacterivores & 20 & 0.474 & \pm & 0.059 & a & 76 & 0.469 & \pm & 0.068 & $\mathrm{a}$ & 22 & 0.365 & \pm & 0.071 & $\mathrm{~b}$ \\
\hline & Fungivores & 16 & 0.106 & \pm & 0.050 & $\mathrm{~b}$ & 76 & 0.140 & \pm & 0.083 & $\mathrm{~b}$ & 22 & 0.395 & \pm & 0.125 & $\mathrm{a}$ \\
\hline & Herbivores & 20 & 0.278 & \pm & 0.079 & $\mathrm{C}$ & 76 & 0.402 & \pm & 0.060 & $\mathrm{a}$ & 22 & 0.338 & \pm & 0.069 & $b$ \\
\hline & Omnivores & 9 & 0.238 & \pm & 0.062 & $b$ & 58 & 0.249 & \pm & 0.099 & $b$ & 18 & 0.341 & \pm & 0.131 & $\mathrm{a}$ \\
\hline & Predators & 12 & 0.211 & \pm & 0.080 & - & 56 & 0.264 & \pm & 0.121 & - & 8 & 0.242 & \pm & 0.107 & - \\
\hline Functional & $\begin{array}{l}\text { Whole } \\
\text { community }\end{array}$ & 20 & 0.650 & \pm & 0.067 & - & 76 & 0.675 & \pm & 0.047 & - & 22 & 0.665 & \pm & 0.077 & - \\
\hline \multirow[t]{5}{*}{ evenness } & Bacterivores & 20 & 0.692 & \pm & 0.079 & C & 76 & 0.748 & \pm & 0.062 & $b$ & 22 & 0.792 & \pm & 0.063 & $\mathrm{a}$ \\
\hline & Fungivores & 16 & 0.981 & \pm & 0.040 & $\mathrm{a}$ & 76 & 0.956 & \pm & 0.055 & a & 22 & 0.810 & \pm & 0.099 & $\mathrm{~b}$ \\
\hline & Herbivores & 20 & 0.859 & \pm & 0.069 & $\mathrm{a}$ & 76 & 0.817 & \pm & 0.061 & a & 22 & 0.758 & \pm & 0.096 & $b$ \\
\hline & Omnivores & 9 & 0.967 & \pm & 0.041 & $\mathrm{a}$ & 58 & 0.946 & \pm & 0.064 & a & 18 & 0.892 & \pm & 0.060 & $\mathrm{~b}$ \\
\hline & Predators & 12 & 0.970 & \pm & 0.060 & - & 56 & 0.959 & \pm & 0.048 & - & 8 & 0.942 & \pm & 0.083 & - \\
\hline Functional & $\begin{array}{l}\text { Whole } \\
\text { community }\end{array}$ & 20 & 0.027 & \pm & 0.009 & $b$ & 76 & 0.039 & \pm & 0.011 & a & 22 & 0.035 & \pm & 0.015 & $a b$ \\
\hline \multirow[t]{5}{*}{ divergence } & Bacterivores & 20 & 0.025 & \pm & 0.010 & $\mathrm{~b}$ & 76 & 0.031 & \pm & 0.010 & $\mathrm{a}$ & 22 & 0.029 & \pm & 0.012 & $a b$ \\
\hline & Fungivores & 16 & 0.011 & \pm & 0.011 & $\mathrm{~b}$ & 76 & 0.021 & \pm & 0.023 & $a b$ & 22 & 0.027 & \pm & 0.010 & a \\
\hline & Herbivores & 20 & 0.021 & \pm & 0.006 & $\mathrm{~b}$ & 76 & 0.034 & \pm & 0.012 & $\mathrm{a}$ & 22 & 0.025 & \pm & 0.017 & $\mathrm{~b}$ \\
\hline & Omnivores & 9 & 0.019 & \pm & 0.015 & - & 58 & 0.021 & \pm & 0.017 & - & 18 & 0.021 & \pm & 0.015 & - \\
\hline & Predators & 12 & 0.028 & \pm & 0.023 & - & 56 & 0.032 & \pm & 0.025 & - & 8 & 0.021 & \pm & 0.013 & - \\
\hline
\end{tabular}

lowest in arable fields (Table 5.1). Fungivores had highest richness and divergence, but lowest evenness in shrublands/woodlands (Table 5.1). Herbivores showed higher richness and divergence in managed grasslands while evenness was higher in managed grasslands and arable fields compared to shrublands/woodlands (Table 5.1). Omnivores had higher richness and lower evenness in shrublands/woodlands as compared to arable fields and managed 
grasslands (Table 5.1), but divergence did not differ between ecosystem types (Table 5.1). For predators we did not find differences in the functional indices between ecosystems (Table $5.1)$.

\section{Trait shifts and body size distribution}

In sandy soils, four out of five trophic groups were relatively large (i.e. high width/length ratio) in arable fields (Table S5.2), while width/length (W/L) ratios did not differ between managed grasslands and shrublands/woodlands. An exception was shown by fungivores that were relatively large (i.e. high $\mathrm{W} / \mathrm{L}$ ratio) in shrublands/woodlands and did not differ between arable fields and managed grasslands (Tukey-test, $\mathrm{p}<0.05$, Table S5.2).

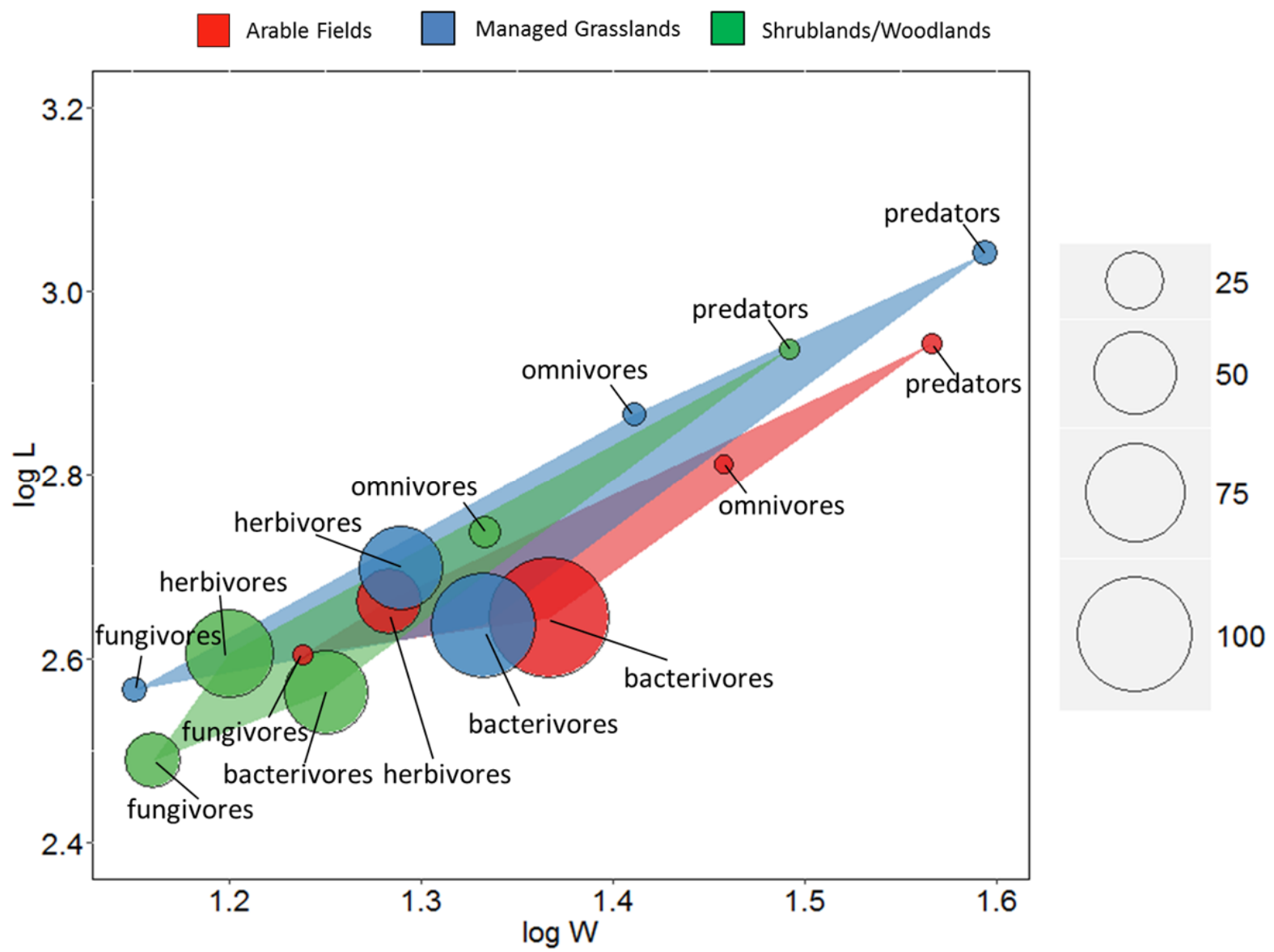

Figure 5.1 - Shift in trait values (L: length, W: width) between ecosystem types and trophic groups in sandy soils. The area occupied by each dot is proportional to the averaged frequency per site of each trophic group within each ecosystem type. 
In general, shrublands/woodlands were characterized by the lowest values of body size traits (Fig. 5.1). The convex hull area of the managed grasslands (0.032) was almost two times larger than for arable fields (0.017) and shrublands/woodlands (0.018) (Fig. 5.1).

In clay soils, fungivores were relatively larger (higher W/L ratio) in arable fields than in managed grassland (Table 5.2). Omnivores were bigger (both longer and wider) in arable fields compared to managed grasslands (ANOVA, p<0.05, Table 5.2 and Fig. 5.2), although their W/L ratio did not differ. In contrast, predators were relatively longer (lower W/L ratio) in arable fields than in managed grassland (ANOVA, $\mathrm{p}<0.05$, Table S5.2).

Within arable fields, bacterivores, fungivores and herbivores were longer in sandy than in clay soils (ANOVA, $\mathrm{p}<0.05$, Table 5.2 and Fig. 5.2). In managed grasslands, most nematodes, regardless of their trophic group, were longer (i.e. higher length) and/or relatively longer (i.e. low W/L ratio) in sandy soils than in clay soils (Fig. 5.2 and Table 5.2).

We found statistically differences in the body-size patterns between arable fields and managed grassland; overall, differences were most evident in sandy soils (Table 5.2).

Managed grasslands exhibited the widest range of body-mass values while body-mass distribution in arable fields covered the greatest area in comparison to the other ecosystem types (Kolmogorov-Smirnov test, $\mathrm{p}<0.05$, Fig. 5.3). The mass distribution in shrublands/woodlands exhibited a mode shifted to the left i.e. to individuals lower in body mass, in comparison to the other two ecosystem types (Fig. 5.3): these patterns were recognizable both in juvenile and adult body-size distributions.

The three ecosystem types differed from each other in the proportion of bacterivores: arable fields contained the highest proportion and shrublands/forests the lowest (Tukey-test, $\mathrm{p}<0.05$, Fig. 5.3).

However, shrublands/forests had a higher proportion of fungivores and omnivores compared to arable fields and managed grasslands (Tukey-test, $\mathrm{p}<0.05$ ), while the latter did not differ from each other (Fig. 5.3). Furthermore, shrublands/forests as well as managed grasslands had a higher proportion of herbivores in comparison to arable fields (Tukey-test, $\mathrm{p}<0.05$, Fig. 5.3). 
节营造

范范㤩令

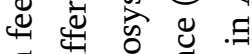

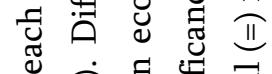

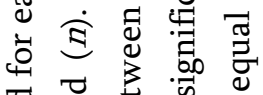

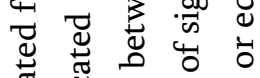

焉

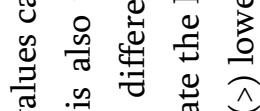

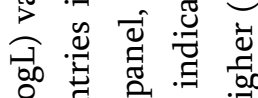

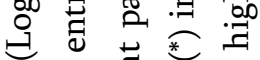

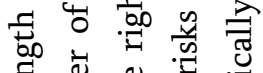

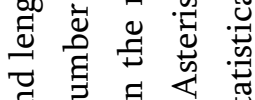

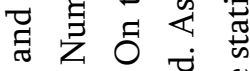

ß

宛䎡

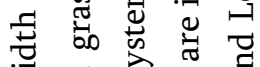

उ च के

今ิ

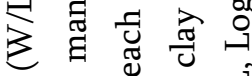

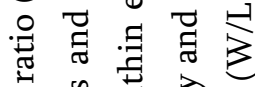

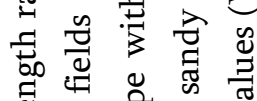

ब

売苟

薄.

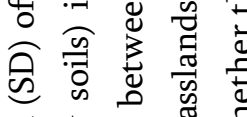

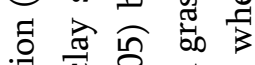

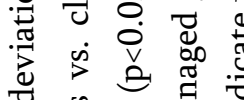

च

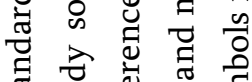

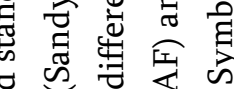

䒕

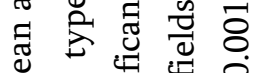

$\sum_{1}^{\infty} \overline{0} \stackrel{a}{0}$

กั

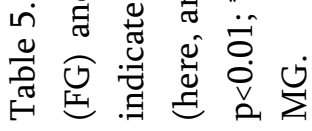

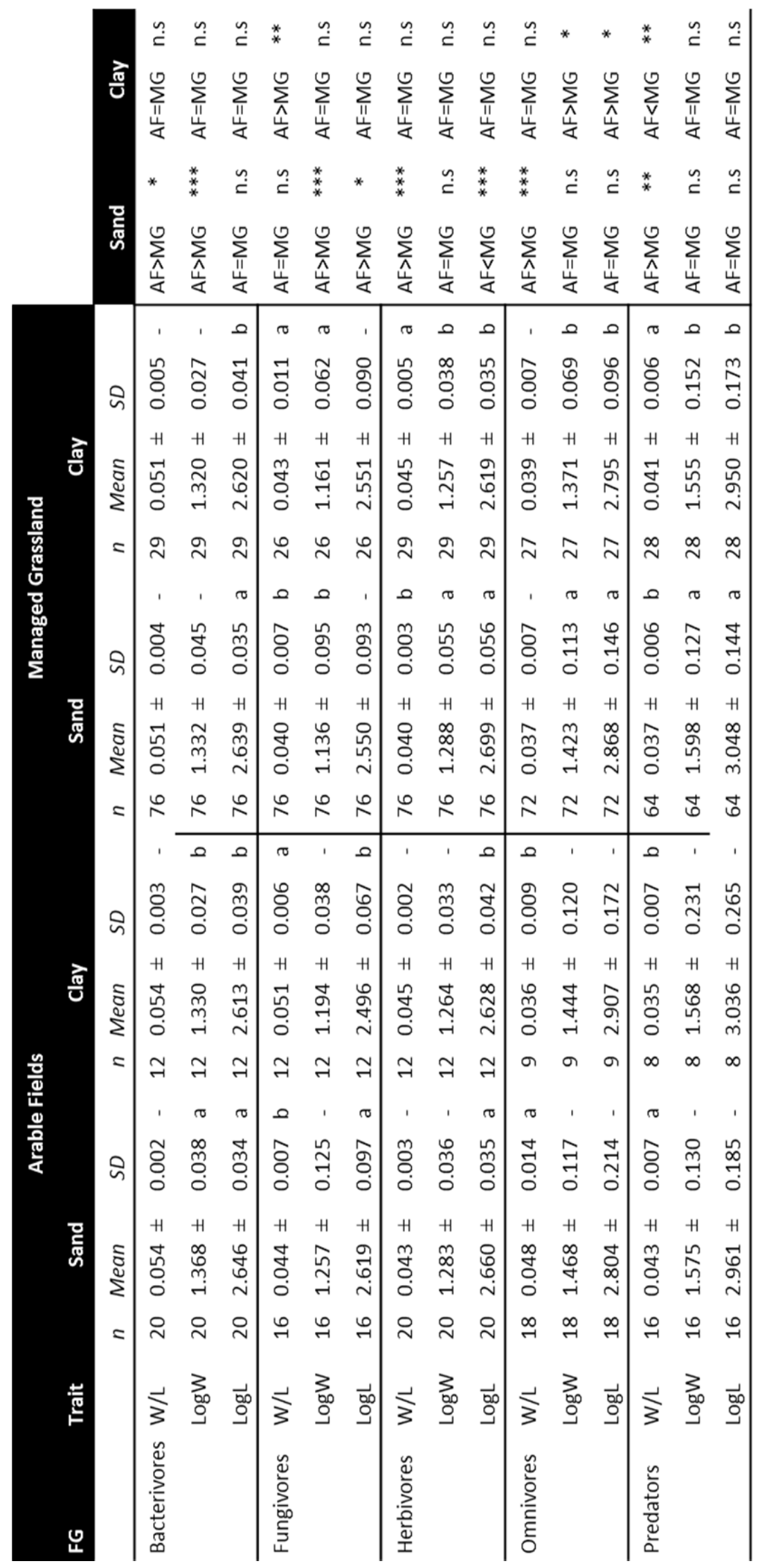




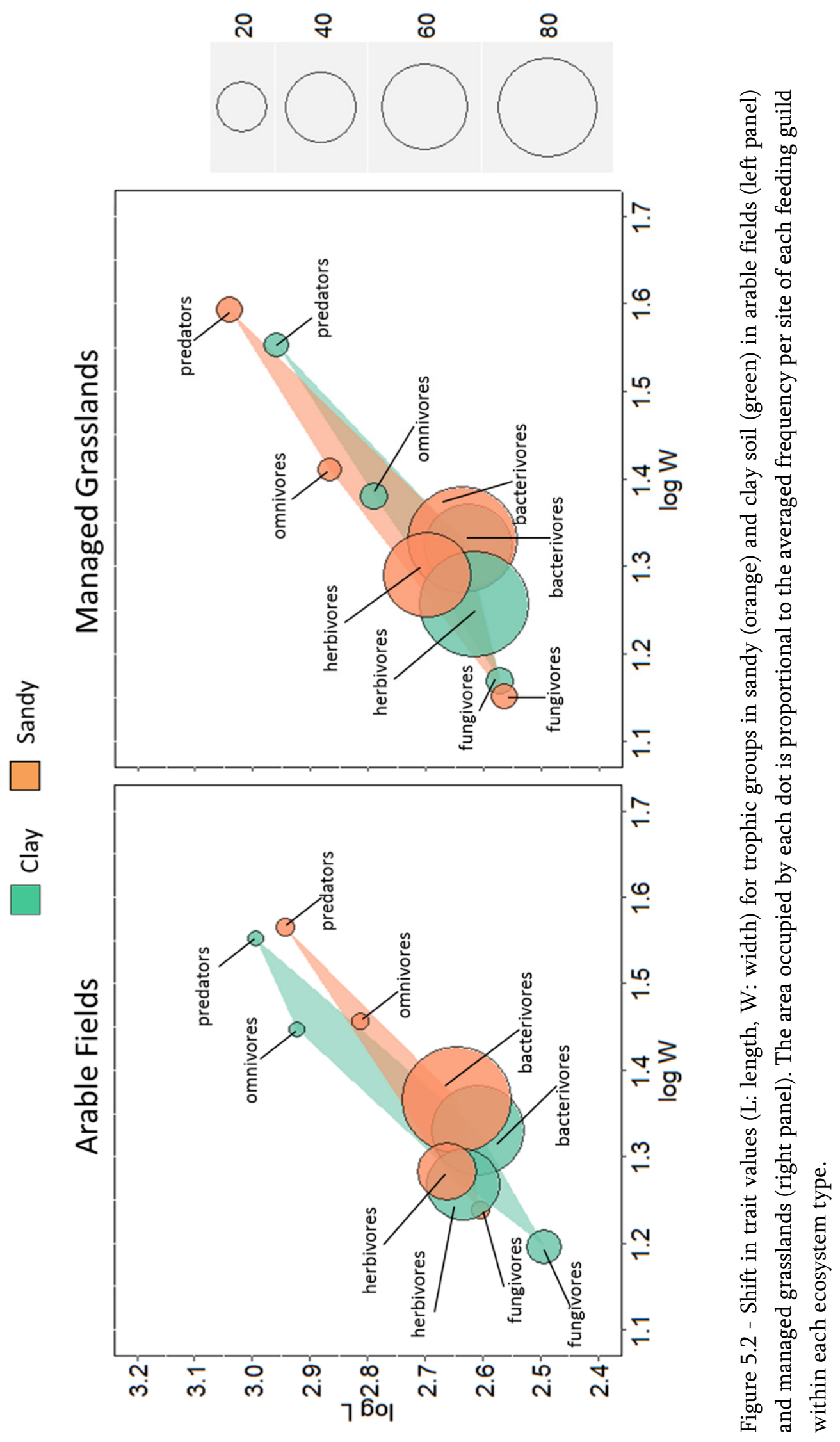




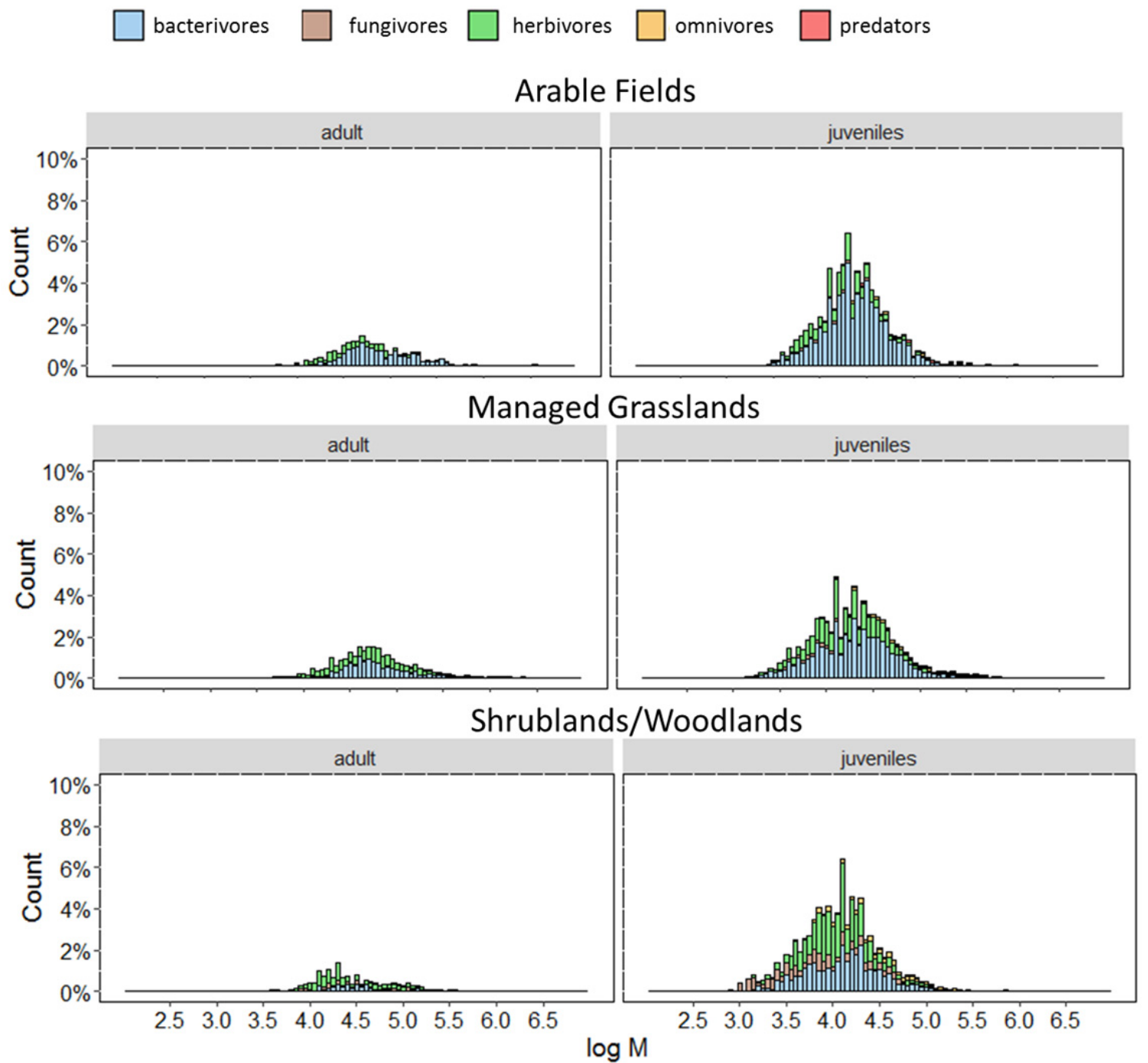

Figure 5.3 - Distribution of body-mass classes for life stage (juveniles and adults) and for ecosystem types in sandy soils. Different colors within each bar indicate the relative occurrence of each feeding guild within each body-mass class.

In general, the kurtosis per single trophic group combined for adults and juveniles showed that at the lower trophic level the distribution of body mass was sharper than at the upper trophic level: the body-mass distributions of omnivores and predators were much wider in all three ecosystem types compared to bacterivores, fungivores and herbivores (Fig. 5.4). At the lower trophic level, however, shrublands/forests had a much wider density distribution of fungivores and a sharper one of herbivores than in the other two ecosystem types (Fig. 5.4). Furthermore, in shrublands/forests the shape of the distribution of omnivores was inverted compared to arable fields and managed grasslands: shrublands/forests exhibited 
a small peak of relatively small omnivores followed by a high peak of large omnivores, whereas in arable fields and managed grasslands this body-mass distribution showed the opposite pattern. Finally, the mode of the predators' mass distribution in shrublands/grasslands was lower than in arable fields and managed grasslands $(\approx 5.0, \approx 5.25$ and $\approx 5.5$, respectively; Fig. 5.4).

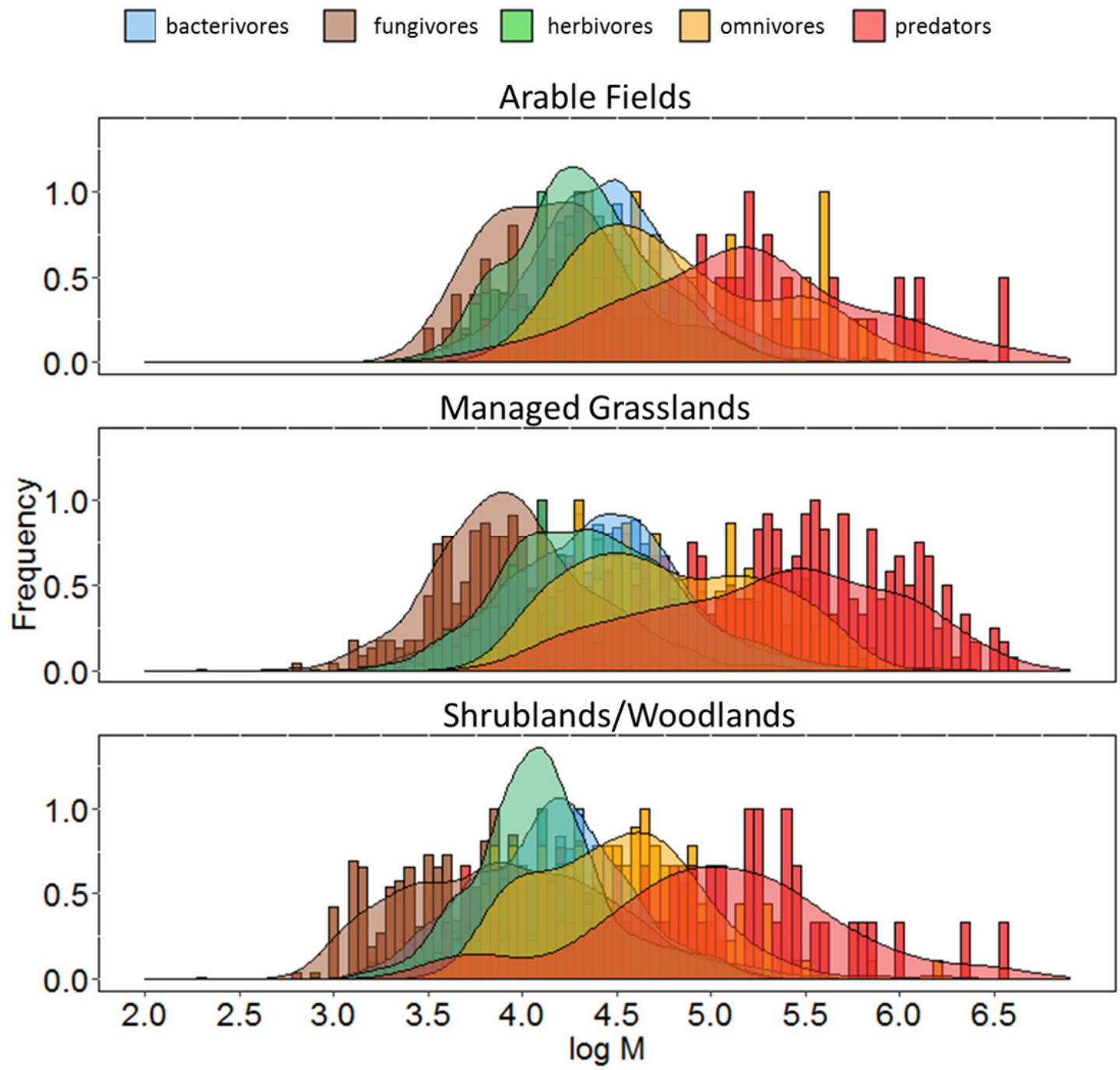

Figure 5.4 - Distribution of body-mass classes for trophic groups (scaled to 1) and ecosystem types in sandy soils. 


\section{Discussion}

Functional richness represents the amount of niche space filled by species in the community according to Mason et al. (2005) and can indicate the degree of habitat filtering (Mouchet et al. 2010). In managed grassland, richness was overall higher compared to arable fields and shrublands/woodlands (Table 5.1), suggesting a kind of ecological niche optimum (Grime 1973) at intermediate level of disturbance. The apparent similarity in the relatively low richness in arable fields and shrublands/woodlands is likely the result of completely different types of habitat filtering. In fact, arable fields and shrublands/woodlands showed opposite trends when comparing richness per trophic group. Only predatory richness did not differ between these two systems (Table 5.1). In arable fields, we observed relatively low Fric values for fungivores, herbivores and omnivores, but high Fric values for bacterivores. Arable fields are characterized by temporarily high inputs of nutrients, often provided as organic manures with high fractions of readily available nutrients, which are well known to enhance fast-reproducing bacterial feeding nematodes (Ferris et al. 2001), although they apparently did not contribute to increase the complexity of structure of the nematofauna. Moreover, crop harvest, mono-cropping, and soil tillage hamper the establishment of stable, diverse rhizosphere communities which might explain the low richness of herbivores found in these systems. Instead, in the acidic shrublands/woodlands, both the most stable conditions and the relatively high presence of hyphae (Mulder et al. 2005b) likely enhanced nematode richness (i.e. niche specialization) for herbivores and fungivores. At the same time, the lower nutrient availability in shrublands/woodlands (cf. Vonk et al. 2013) enhances omnivory (high omnivore richness) and constrains bacterial feeders (low bacterivores richness).

These poor nutrient conditions can have been the driver of the smaller body-size traits (length and width) in shrublands/woodlands, further endorsing differences in habitat filtering between the three ecosystem types. Similarly, nutrient availability might also explain the larger body-size values found in arable fields, and partially in managed grasslands. The relative high external input of nutrients in such managed ecosystems enhances bacterial growth and a possible higher energy transfer towards the higher levels of the soil food web. 
When comparing the managed ecosystems, all trophic groups, except fungivores, exhibited in arable fields higher W/L ratios than in managed grasslands, although Mulder and Vonk (2011) found that the stoichiometry of these two ecosystem types was quite comparable. Soil particles and porosity can affect the speed and efficiency of nematode movement in soil (Wallace 1958a, b). Therefore, in compacted and fine-structured soils, relatively large nematodes were probably limited in their access to food resources. This hypothesis is indirectly supported by the small body size of the nematodes in both fields and grasslands on clay soils, and the large body size of the nematodes in the arable fields on sandy soils (Fig. 2 and Table S2). Schrama et al. (2013) found that cattle is correlated with increasing bulk density in clay, although soil porosity was unaffected. We speculate that cattle compaction of coarse-textured soils like Pleistocene sand could have acted in grasslands as additional environmental filter on nematode's body-size traits.

Functional evenness is the degree to which the biomass of a community is equally distributed in functional space to allow effective utilization of the entire range of resources available while divergence indicates the degree to which the abundance distribution in functional space enhances divergence in body mass within the community. High Fdiv values can indicate a high degree of niche differentiation, and thus low resource competition (Mason et al. 2005). At the community level, evenness did not differ between ecosystems (Table 1), although differences in evenness were detectable at the level of single trophic groups, as hypothesized. Overall, relatively low Feve values were associated with high values of richness for each trophic group (Table 1). For example, in shrublands/woodlands the fungivores showed lower evenness but higher richness (and divergence) in comparison to arable fields and managed grassland. The body-mass distributions (Fig. 4) indicate that at high evenness, species abundances are restricted to relatively small ranges along the body-mass gradient (i.e. low richness). Pakeman (2011) hypothesized that in less disturbed habitats, low evenness in combination without (or with positive) variation in divergence indicate less habitat filtering but more competition, structuring the community in comparison to disturbed ecosystems. Therefore, the relatively high Fric, low Feve and high Fdiv values in shrublands/woodlands may be explained by an increased competition between fungivores. 
Likewise, bacterivores in arable fields and in managed grassland had relatively higher richness and relatively lower evenness in comparison to shrublands/woodlands. However, the bacterivore divergence in arable fields and in managed grassland did not differ from that in shrublands/woodlands. In this case, it is unlikely that the bacterivore community was shaped by competition given the high nutrient availability that characterizes arable fields. The uneven distribution of body-size classes in this group is probably due to differences in the species-specific reproduction rate. Compared to managed grasslands, arable fields had lower evenness in combination with lower divergence, further indicating that other habitat filtering than competition distinguished these two systems.

Functional divergence calculated for the entire nematode community was the highest in grasslands, showing higher differentiation in comparison to fields, while shrublands/woodlands did not differ from arable fields and managed grassland. In this case, the body-mass distribution highlights divergence differences between ecosystem types (Fig. 3). In arable fields, bacterivores dominated the body-mass distribution which contributed to the concentration of individuals with a body size in the middle of the body-mass range, thereby reducing divergence. In contrast, in managed grasslands, the co-dominance of bacterivores and herbivores widened the distribution and at the same time increased divergence (Fig. 3). In shrublands/woodlands fungivores and herbivores were dominant and larger body-size classes of bacterivores were absent, resulting in a narrower body mass distribution which reduced divergence, as in arable fields.

\section{Conclusion}

We empirically showed how functional indices change across environmental conditions and how available resources likely affect the average size of soil nematodes. The indices proposed by Mason et al. (2005) applied to body mass are therefore a promising tool to link trait-based observations to ecological processes and ecosystem functioning in soil. As hypothesized, the study of body-size distribution combined with trophic grouping allowed to identify trait-mediated responses to environmental filters in different ecosystem types. Such combination, more than the functional diversity per se, disclosed soil food-web structure and 
identified differences in the position of trophic groups along the body-mass gradient related to abiotic and biotic factors. 


\section{Supplementary Material}

Table S5.1 - Means and standard deviations (SD) of functional diversity indices for each trophic group (FG) and ecosystem type in clay soils. Number of entries are also indicated (n). Different letters indicate significant differences between arable fields and managed grasslands.

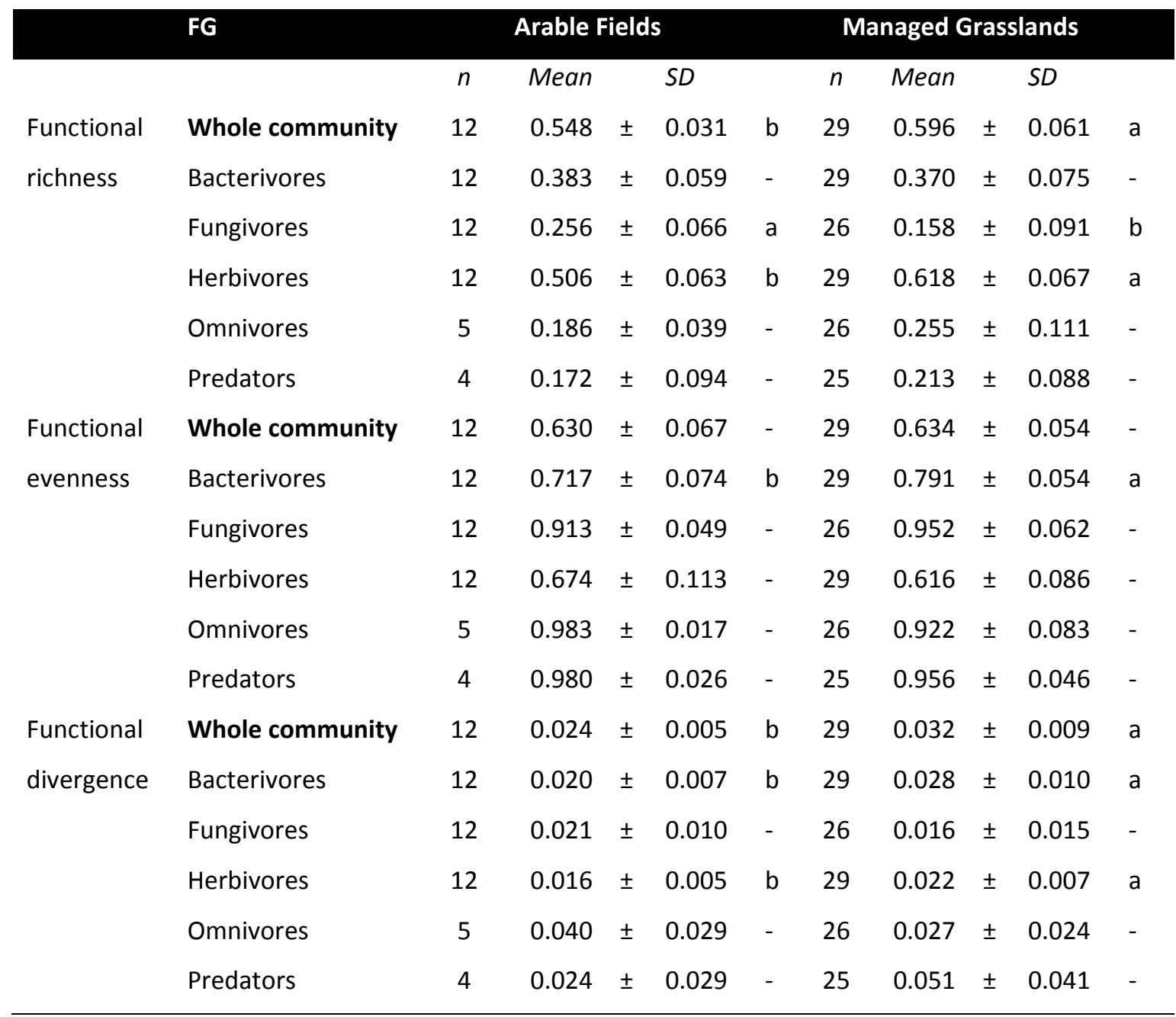


Table S5.2 - Means and standard deviations (SD) of width length ratio (W/L), width (LogW) and length (LogL) values calculated for each trophic guild (FG) and ecosystem type in sandy soils. Number of entries is also indicated $(n)$. Means followed by the same letter indicate no differences $(\mathrm{p}>0.05)$ between ecosystem types.

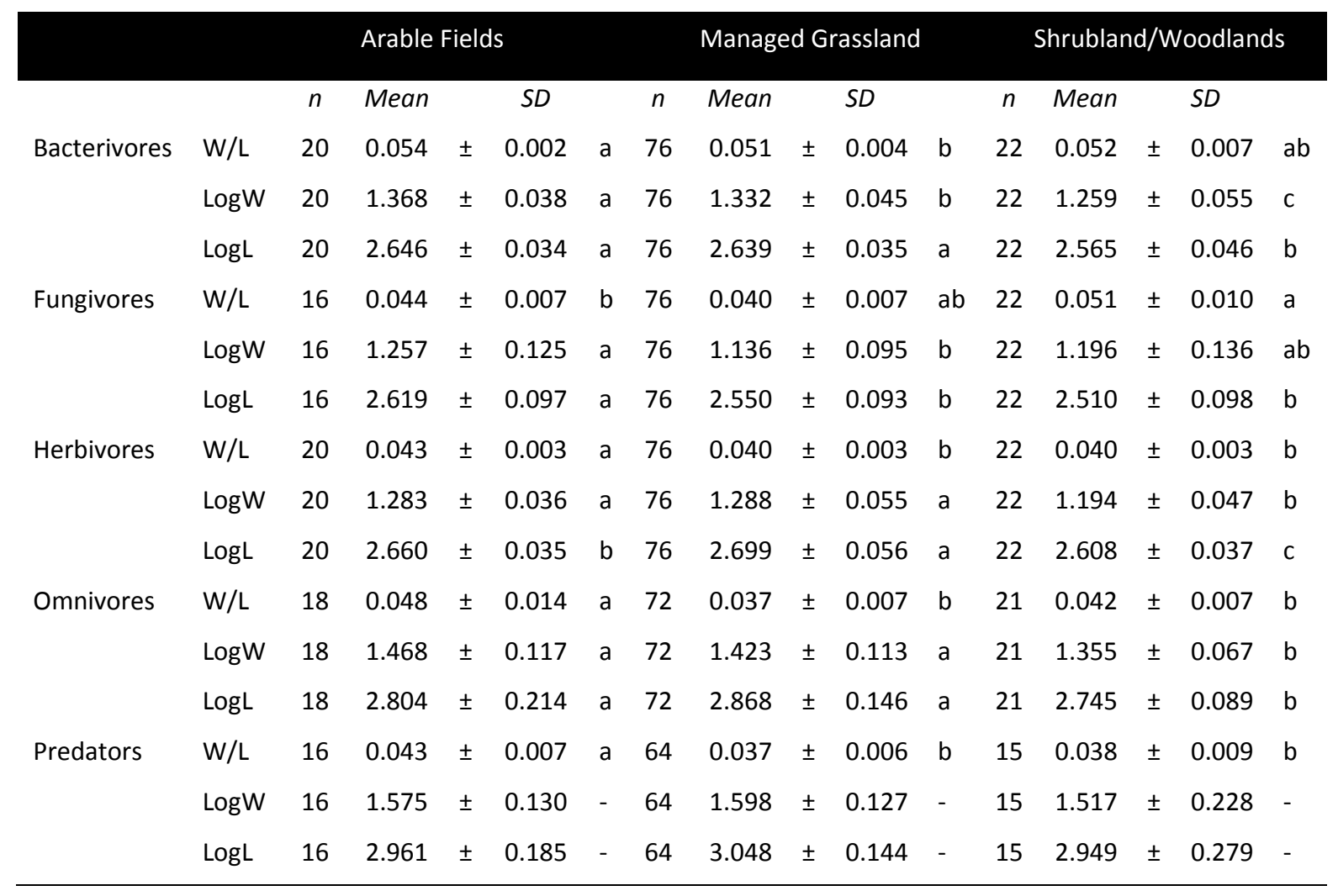



Chapter 6

General discussion 



\section{General discussion}

\section{Functional traits}

Functional traits are defined as characteristics of living organisms determining their individual performances (Mouillot et al. 2013). Investigating soil systems from a trait-based perspective offers an opportunity to study the function of organisms, how they respond to environmental changes and how they influence ecological processes. Firstly used in plant and aquatic ecology (Cummins 1973, Woodward and Cramer 1996, Smith et al. 1997), the word trait has been lately adopted in soil ecology (Statzner et al. 2001). With the growing application of the trait concept in different fields of ecology, divergence arose in terminologies, methodologies and the concept itself (Kearney and Porter 2006, McGill et al. 2006b, Violle et al. 2007). To a certain extent, clear conceptual and methodological frameworks were missing in soil ecology, as addressed by Pey et al. (2014). Originally, as for vascular plants, most studies assessed soil invertebrate responses to their environment classifying organisms based on a priori functional groups such as epigeic, anecic and endogeic groups of earthworms (Bouché 1972), or epiedaphic, hemiedaphic and euedaphic groups of springtails (Gisin 1943). This kind of a priori classification is easier to assess than to measure continuous traits at individual level and, as demonstrated in recent ecological research with soil organisms (Makkonen et al. 2011, Fournier et al. 2012, Salmon et al. 2014, Martins da Silva et al. 2016), is able to give insights on the response of the soil community to environmental pressures.

The application of traits in soil research relates to research question 1 of this thesis:

"To what extent is a trait-based approach in soil ecosystem studies suitable for detecting changes in the soil community and giving insight into soil functioning? Which traits are suitable?”

In Chapters 2 and 3 significant relationships between a priori functional traits and environmental pressures were found. Against the expectations, farm treatments (ryegrass, white clover and a mixture of those, Chapter 2) did not have a considerable effect on 
collembolan functional diversity and decrease in the heterogeneity of trait composition was mainly due to species loss. Soil animals are often able to switch between food sources and, due to an intrinsically high degree of omnivory, species within the same functional group may act differently depending on resource availability. Therefore, a priori functional traits may turn out to be unsuitable to detect changes in trophic relations. In this context, molecular techniques and stable isotope analysis are promising techniques to elucidate food preference in soil animals (Chapter 2) and can provide insight into trophic connections and interaction strength (Morriën et al. 2017).

Although the concept of trait goes far beyond the outstanding issue of species definition, allowing to scale-up from organism to higher organizational levels (i.e. the community and ecosystem levels), few trait-based studies are focusing on the soil community as a whole. Due to the incredible heterogeneity of existing life forms, it is not as easy to generalize about patterns in the biological traits of animals as it is for plants (de Visser et al. 2011, Mulder et al. 2013, but see Weemstra et al. 2016). Dealing with multiple soil fauna groups means dealing with different morphological characteristics, dimensional scale and abundances. These practical problems become even more evident when we look at the divergence between microbial and invertebrate trait-related studies in soil. Whereas microbial studies often quantify traits at scales ranging from populations (e.g. physiological characteristics of strains) to communities (e.g. functional gene pools or substrate utilization) (Yergeau et al. 2010, Krause et al. 2014), invertebrate studies mostly stick to the definition of trait as a characteristic only measurable at individual level. This dichotomy is one of the biggest limitations of soil ecology, especially considering that microbes represent the main basal resource of the detrital soil food web. The difficulty of studying microbes at the level of individuals excludes the possibility to consider the components of a community at the same taxonomic resolution and, hence, to apply an integrated trait-based approach. A specific approach is obviously bound to the context where it has been developed and difficulties often emerge when crossing disciplines. Debates on fundamental terminology on the concept of trait are still ongoing. As a possible way out, Chapter 3 tested a trait-based approach based on a selection of traits hypothesized to be applicable to the entire soil community. The study of 
the effect of agricultural management on soil trophic interactions demonstrated that a more holistic trait approach is possible. Moreover, trophic groups and body mass were shown to be suitable traits in detecting responses of the soil community to environmental pressure.

In general, our integrated methodologies, combining a taxonomic and functional approach with isotopic ratio studies in one case (Chapter 2), and trophic grouping with body mass variation and microbial parameters measured at community level in the other (Chapter 3) represented a suitable option to reveal functionally important relationships between soil biota, community structure, ecological processes, and agricultural management. However, these integrated trait approaches (Chapter 2 and 3) present possible pitfalls:

- Changes of species-specific body-mass averages at local level reflected less than expected the environmental pressure on soil biota (Chapter 2 and 3). Measuring body mass of each individual - instead of using species-specific averages - can increase the accuracy in detecting effects of environmental pressures on the biological community.

- Gathering species into functional groups (e.g. life forms or trophic groups, Chapter 2 and 3 , respectively) imposes a discrete structure that can mask variability and there is a growing consensus on the fact that traits should be measured on continuous scales (Mason et al. 2005, McGill et al. 2006a). The current classification in functional groups implies that only variations in abundances can be detected; due to the high number of species belonging to the same functional group, changes in species assemblage will rarely result in a complete disappearance of a specific functional group from the soil community. In this case, the isotopic signature would enable the identification of trophic positions and carbon sources used within the soil food web (Mulder et al. 2013, Morriën et al. 2017).

- Microbial traits were not measured at individual level and it remains unresolved how to include both microorganisms and soil fauna at a specific functional level (Chapter 3). Also in this case, the use of isotopic ratios may disclose differences in the trophic response of the soil community to environmental conditions, overcoming the problem of differences in taxonomic resolution (Morriën et al. 2017). 


\section{Body size and allometric scaling}

Body mass values measured for each individual separately promise higher resolution in comparison to categorical traits. Body mass reflects the general life strategy and the individual adaptations of organisms to their environment and has the advantage of being a trait that can potentially be measured for all soil life forms. This concept relates to the first part of research question 2:

"To what extent do body mass and the related allometric scaling change as a function of environmental gradients? Does taxonomic or functional classification matter?”

In Chapters 2, 3 and 4, body mass responded less than expected to environmental changes. This is in contrast with the research done in aquatic ecosystems, where body mass is used as indicator of structure and function of ecosystems (Briers 2009). The apparent lack of evidence for body-mass response is an important limitation of trait approaches. However, several considerations can be made to explain and possibly overcome such limitations:

- As previously mentioned, the use of species-specific body-mass values (Chapters 2 and 3) could have partially affected the sensitivity of this trait to reflect responses of the soil community. However, in contrast with Mulder et al. (2006a), mass-abundance relationships did not change according to stoichiometric gradients even when sitespecific body-mass values were used (Chapter 4).

- Body mass is an expression of ecological processes (i.e. biological interactions, environmental and sexual selection) and of energetic trade-offs at an evolutionary time-scale. It also reflects current resource availability and environmental conditions. This implies that interspecific body-mass variation can reflect both the variation in species composition and the individual responses to environmental pressure. These two components converge when studying biological communities and can influence the ability of recognizing and interpreting the response of the soil community as a whole.

- The soil community is functionally redundant: in contrast to aquatic systems, trophic levels in soil food webs are not so strongly linked to body mass (Chapter 4). It means 
that changes in the food-web structure are hardly detectable due to overlapping body-mass ranges between trophic levels. In addition, overlapping of body-mass ranges between species hides shifts in species composition.

Despite these considerations, results from Chapters 3, 4 and 5 provide evidence that the abundance and distribution of body-mass classes, more than averaged body-mass variations, reveal responses of the soil community to the environmental conditions. In particular, using the body-mass distribution within single trophic groups partially overcame the redundancy of the body-size classes across trophic levels and allowed identifying community responses to environmental conditions (Chapters 3 and 5).

Comparisons between contrasting ecosystems (i.e. woodland/shrubland, managed grassland and arable fields) likely showed a more evident switch in the binned body-size compositions than could have been observed in less heterogenic soil conditions such as those analysed in Chapter 4.

The apparent lack of sensitivity of the allometric scaling to environmental gradients could also be due to opposite responses of specific taxonomic groups: inverse changes in body mass and/or abundance can counterbalance the slope of the allometric scaling resulting in an unchanged body mass-abundance relationship. This hypothesis is supported by Ehnes et al. (2014), who found that phylogenetic groups, more than the effect of land-use type, affected the allometric scaling. This means that there is a trade-off between being able to study and visualize energetic paths of the entire soil food web and keeping the resolution that can be obtained by studying single soil taxonomic groups.

In Chapter 4, allometric scaling (i.e. body mass - abundance relationship) has been studied using body mass values measured at individual level and averaged per taxonomic (mostly per species or genus) and trophic group. In both cases, the allometric scaling did not change as a function of stoichiometric gradients, providing evidence that taxonomic and functional approaches do not differ in the ability to identify biotic-mediated responses to environmental gradients. In contrast, differences in taxonomic and trophic classification emerged. This finding is related to the last part of research question 2:

\section{"Does taxonomic or functional classification matter?"}


In case of a taxonomic approach, the allometric scaling was -0.79 , closely resembling the scaling power of 3/4, often claimed to be universal (Agutter and Wheatley 2004, Brown et al. 2004). In the case of a functional group approach, a scaling power of -1 (isometry) was found, implying a constant biomass distribution along the body-mass gradient.

The inverse abundance-body mass relationships have been ascribed to the energy use (i.e. the metabolic rate) of differently sized individuals (Reuman et al. 2008). Currently, no ecological theory explains scaling differences between taxonomic and functional approaches and, like for the other trait-based approach applied in chapter 3, also for the allometric scaling it remains unsolved how to study microorganisms and soil fauna at the same specific functional or taxonomic level. However, when the allometric scaling is built using trophic groups the body-size classes redundancy between species is reduced and the isometric scaling reflects more closely the energy flux through the soil food web than when taxonomic classification is adopted (Chapter 4 ).

\section{Functional diversity}

Because taxonomic identity is often linked to functional aspects of the organisms, changes in species composition can be used as indicator of changes in ecosystem functioning. However, limitations arise in trying to understand how taxonomic diversity influences ecosystem processes. In this sense, functional diversity enables to understand functional responses and their links to ecosystem functioning (Fig. 1.1). Regarding question 3:

"How do body size traits and the related functional diversity in a soil community change in response to environmental pressures?"

Chapter 5 empirically correlates the trait-mediated response of the soil community in contrasting ecosystems (i.e. woodland/shrubland, managed grassland and arable fields) applying functional diversity indices based on body size. In this study, similar patterns in richness and evenness emerged calculated for single trophic groups between ecosystems (i.e. woodland/shrubland, managed grassland and arable fields). This implies that the interpretation of functional diversity indices cannot be generalized and strictly depends on the environment, the organisms and the functional trait applied. However, the integrated 
study of functional diversity indices in combination with the shifts in body length and width, and with changes in body-size distribution, contributed to the identification of environmental filters and the interpretation of the response of soil nematodes. A combined trait-based approach, more than the functional diversity itself, disclosed soil food-web structure and identified trait responses related to abiotic and biotic factors.

\section{General conclusions}

Despite the relative popularity of the conceptual framework on functional traits and the fact that the use of functional traits has been referred to as a 'Holy Grail' in plant ecology (Lavorel and Garnier 2002), their application often presents the same limitations as found for the classical taxonomic approaches. Functional traits can be used to connect trait responses to ecosystem functioning. However, this link can be identified only theoretically and empirical evidence is still lacking.

Trait approaches based on single taxonomic groups can detect biotic responses to environmental changes (Krause et al. 2014, Pey et al. 2014). However, both the specifics of the different organisms in responding to environmental pressure and the deep interconnectivity of biotic interactions, make these studies hard to be generalized and translated into changes in ecosystem functioning. In this context, the more holistic approach presented in this thesis appears to be potentially more suitable to give insight into the effect of anthropogenic pressure on ecosystem functioning than approaches based on single taxonomic groups.

Soil is a highly resilient system, probably because of its high functional redundancy and trophic plasticity (Cárdenas et al 2017). However, to avoid underestimating the effects of anthropogenic pressure on soil functionality, it is of paramount importance to explore whether the nature of this functional redundancy is not a matter of lack of resolution of the methodology applied.

The observed lack of response of allometric scaling has consequences for its use as sitespecific measure of anthropogenic pressure. Considering the potential of allometric scaling to provide synthetic information on the structure of the soil food web, it will be worth to 
explore whether this can be generalized to larger scales and in more contrasting conditions than currently tested.

In addition to the work done in Chapter 5, a comparison of functional diversity across environmental gradients within the same ecosystem types can help to generalize the interpretation of functional diversity as indicator of ecosystem functionality and thus to better assess ecosystem services.

A methodology for the quantification of ecosystem services, providing a transparent and rational underpinning of alternatives for environmental decisions, is still lacking due to the current difficulties to link and quantify the effect of anthropogenic pressure to ecosystem functioning in soil. For this reason, it is essential that methods analysed in the current study be further explored under different environmental pressures to enable the development of tools to be used at the interface of science and society for socio-economic sustainable development. 
References 



\section{References}

Abrahamsen G., 1973. Studies on body-volume, body-surface area, density and live weight Enchytraeidae (Oligochaeta). Pedobiologia 13: 6-15.

Adams, E.C.G., Salmon, J.T., 1972. The mouth-parts and feeding methods of Brachystomella parvula (Schaeffer) (Collembola: Brachystomellidae). Transactions of the Royal Entomological Society of London 124: 269-286.

Adhikari, K., Hartemink, A.E., 2016. Linking soils to ecosystem services - A global review. Geoderma 262: 101-111.

Agutter, P.S., Wheatley D.N., 2004. Metabolic scaling: consensus or controversy? Theoretical Biology and Medical Modelling 1:13.

Albers, D., Schaefer, M., Scheu, S., 2006. Incorporation of plant carbon into the soil animal food web of an arable system. Ecology 87: 235-245.

Alebeek, F., Wiersma, M., van Rijn, P.C.J., Wäckers, F.L., Den Belder, E., Willemse, J., Gurp H.V., 2006. A regio-wide experiment with functional agrobiodiversity (FAB) in arable farming in the Netherlands. IOBC WPRS Bulletin 29: 141-144.

Alef, K., Nannipieri P., 1995. Microscopic Methods for Counting Bacteria and Fungi in Soil. Academic Press, London.

Anderson, T.-H., Domsch, K.H., 1993. The metabolic quotient for $\mathrm{CO}_{2}\left(\mathrm{qCO}_{2}\right)$ as a specific activity parameter to assess the effects of environmental conditions, such as $\mathrm{pH}$, on the microbial biomass of forest soils. Soil Biology and Biochemistry 25: 393-395.

Anderson, T.-H., Joergensen, R.G., 1997. Relationship between SIR and FE estimates of microbial biomass $\mathrm{C}$ in deciduous forest soils at different $\mathrm{pH}$. Soil Biology and Biochemistry 29: 1033-1042.

Andrássy, I., 1956. Die Rauminhalts- und Gewichtsbestimmung der Fadenwürmer (Nematoden). Acta Zoologica Academia Scientiarum Hungaricae 2: 1-15.

Bakken, L.R., Olsen, R.A., 1983. Buoyant densities and dry-matter contents of microorganisms: conversion of a measured biovolume into biomass. Applied and Environmental Microbiology 45: 1188-1195.

Bardgett, R.D., 1998. Functional aspects of soil animal diversity in agricultural grasslands. Applied Soil Ecology 10: 263-276.

Bardgett, R.D., Bowman, W.D., Kaufmann, R., Schmidt, S.K., 2005. A temporal approach to linking aboveground and belowground ecology. Trends Ecol Evol 20: 634-641. 
Berg, M.P., Stoffer, M., van den Heuvel, H.H., 2004. Feeding guilds in Collembola based on digestive enzymes. Pedobiologia 48: 589-601.

Bender, S.F., van der Heijden, M.G.A., 2015. Soil biota enhance agricultural sustainability by improving crop yield, nutrient uptake and reducing nitrogen leaching losses. Journal of Applied Ecology 52: 228-239.

Birkhofer, K., Diekötter, T., Boch, S., Fischer, M., Müller, J., Socher, S., Volkmar, W., 2011. Soil fauna feeding activity in temperate grassland soils increases with legume and grass species richness. Soil Biology and Biochemistry 10: 2200-2207.

Blanchard, A., Aubry, D., Bellmann, A.,Neill, C., Toussaint, J.-P., 2004. Plant functional markers capture ecosystem properties during secondary succession. Ecology 85: 26302637.

Bloem, J., Lebbink, G., Zwart, K.B., Bouwman, L.A., Burgers, S.L.G.E., de Vos, J.A., de Ruiter, P.C., 1994. Dynamics of microorganisms, microbivores and nitrogen mineralisation in winter wheat fields under conventional and integrated management. Agriculture, Ecosystems and Environment 51: 129-143.

Bloem, J., Veninga, M., Shepherd, J., 1995. Fully automatic determination of soil bacterium numbers, cell volumes, and frequencies of dividing cells by confocal laser scanning microscopy and image analysis. Applied and Environmental Microbiology 61: 926-936.

Blum, W.E.H., 2005. Functions of Soil for Society and the Environment. Reviews in Environmental Science and Bio/Technology 4: 75-79.

Boit, A., Martinez, N.D., Williams, R.J., Gaedke, U., 2012. Mechanistic theory and modelling of complex food-web dynamics in Lake Constance. Ecology Letters 15: 594-602.

Botta-Dukát, Z., 2005. Rao's quadratic entropy as a measure of functional diversity based on multiple traits. Journal of Vegetation Science 16: 533-540.

Bouché, M.B., 1972. Lombriciens de France: écologie et systématique. Institut National de la Recherche Agronomique.

Briand, F., Cohen, J.E., 1984. Community food webs have invariant-scale structure. Nature 5948: 264-267.

Briers, R., 2009. Body size: The structure and function of aquatic ecosystems. Freshwater Biology 54: 434-434.

Brown, J.H., Gillooly, J.E., 2003. Ecological food webs: high-quality data facilitate theoretical unification. Proceedings of the National Academy of Sciences of the USA 100: 14671468.

Brown, J.H., Gillooly, J.F., Allen, A.P., Savage, V.M., West, G.B., 2004. Toward a metabolic 
theory of ecology. Ecology 85: 1771-1789.

Brussaard, L., 2012. Ecosystem Services Provided by the Soil Biota. In: Soil Ecology and Ecosystem Services (ed. Wall D.H.). Oxford University Press, pp. 45-58.

Bryant, J.A., Stewart, F.J., Eppley, J.M., DeLong, E.F., 2012. Microbial community phylogenetic and trait diversity declines with depth in a marine oxygen minimum zone. Ecology 93: 1659-1673.

Calder, W.A., 1984. Size, Function, and Life History. Harvard University Press, Cambridge, MA.

Cárdenas, R.E., Donoso, D.A., Argoti, A., Dangles, O., 2017. Functional consequences of realistic extinction scenarios in Amazonian soil food webs. Ecosphere 8:e01692.

Carpenter, S.R., Mooney, H.A. , Agard, J., Capistrano, D., de Fries, R.S., Díaz, S., Dietz, T., Duraiappah, A.K., Oteng-Yeboah, A., Pereira, H.M., Perrings, C., Reid, W.V., Sarukhan, J., Scholes R.J., Whyte, A., 2008. Science for managing ecosystem services: Beyond the Millennium Ecosystem Assessment. Proceedings of The National Academy of Sciences 106: $1305-1312$.

Chahartaghi, M., Langel, R., Scheu, S., Ruess, L., 2005. Feeding guilds in Collembola based on nitrogen stable isotope ratios. Soil Biology and Biochemistry 37: 1718-1725.

Chamberlain, P.M., Bull, I.D., Black, H.I.J., Ineson, P., Evershed, R.P., 2006. Collembolan trophic preferences determined using fatty acid distributions and compound-specific stable carbon isotope values. Soil Biology and Biochemistry 38: 1275-1281.

Christiansen, K., 1964. Bionomics of Collembola. Annual Review of Entomology 9, 147-178.

Clough, Y., Kruess, A., Tscharntke, T., 2007. Organic versus conventional arable farming systems: Functional grouping helps understand staphylinid response. Agriculture, Ecosystems and Environment 118: 285-290.

Cohen, J.E., 1991. Food webs as a focus for unifying ecological theory. Ecological International Bulletin 19: 1-13.

Cohen, J.E., 1994. Marine and continental food webs: three paradoxes? Philosophical Transactions of the Royal Society (London) Series B 343: 57-69.

Cohen J.E., Carpenter, S.R., 2005. Species' average body mass and numerical abundance in a community food web: statistical questions in estimating the relationship. In: Dynamic Food Webs: Multispecies Assemblages, Ecosystem Development, and Environmental Change (eds. de Ruiter, P.C., Wolters, V., and Moore, J.C.). Academic Press, San Diego, CA, pp. 137-156.

Cohen, J.E., Mulder C., 2014. Soil invertebrates, chemistry, weather, human management, 
and edaphic food webs at 135 sites in The Netherlands: SIZEWEB. Ecology 95: 578.

Cohen, J.E., Jonsson, T., Carpenter S.R., 2003. Ecological community description using the food web, species abundance, and body size. Proceedings of the National Academy of the Sciences 100: 1781-1786.

Cohen, J., Schittler, E., D.N., Raffaelli, D.G., Reuman, D.C., 2009. Food webs are more than the sum of their tritrophic parts. Proceedings of the National Academy of $\mathrm{the}$ Sciences 106: 22335-22340.

Costanza, R., d'Arge, R., de Groot, R., Farber, S., Grasso, M., Hannon, B., Limburg, K., Naeem, S., O'Neill, R.V., Paruelo, J., Raskin G.R., Sutton, P., van den Belt, M., 1997. The value of the world's ecosystem services and natural capital. Nature 387: 253-260.

Crittenden, S.J., Huerta, E., de Goede, R.G.M., Pulleman, M.M., 2015. Earthworm assemblages as affected by field margin strips and tillage intensity: An on-farm approach. European Journal of Soil Biology 66: 49-56.

Cummins, W.K., 1973. Trophic Relations of Aquatic Insects. Annual Review of Entomology 18: 183-206.

de Groot, R.S., Alkemade, R., Braat, L., Hein, L., Willemen, L., 2010. Challenges in integrating the concept of ecosystem services and values in landscape planning, management and decision making. Ecological Complexity 7: 260-272.

de Visser, S.N., Freymann, B.P., Olff, H., 2011. The Serengeti food web: empirical quantification and analysis of topological changes under increasing human impact. Journal of Animal Ecology 80: 484-494.

de Vries, F.T., Hoffland, E., van Eekeren, N., Brussaard, L., Bloem, J., 2006. Fungal/bacterial ratios in grasslands with contrasting nitrogen management. Soil Biology and Biochemistry 38: 2092-2103.

Díaz, S., Cabido, M., 2001. Vive la différence: plant functional diversity matters to ecosystem processes. Trends in Ecology and Evolution 16: 646-655.

Díaz, S., Lavorel, S., de Bello, F., Quetier, F., Grigulis, K., Robson, T.M., 2007. Incorporating plant functional diversity effects in ecosystem service assessments. Proceedings of the National Academy of the Sciences 104: 20684-20689.

Díaz, S., Purvis, A., Cornelissen, J.H.C., Mace, G.M., Donoghue, M.J., Ewers, R.M., Jordano, P., Pearse, W.D., 2013. Functional traits, the phylogeny of function, and ecosystem service vulnerability. Ecology and Evolution 3: 2958-2975.

Dilly, O. Munch, J.C., 1998. Ratios between estimates of microbial biomass content and microbial activity in soils. Biology and Fertility of Soils 27: 374-379. 
Ehnes, R.B., Pollierer, M.M., Erdmann, G., Klarner, B., Eitzinger, B., Digel, C., Ott, D., Maraun, M., Scheu, S., Brose, U., 2014. Lack of energetic equivalence in forest soil invertebrates. Ecology 95: 527-537.

Eisenhauer, N., Sabais, A.C.W., Scheu, S., 2011. Collembola species composition and diversity effects on ecosystem functioning vary with plant functional group identity. Soil Biology and Biochemistry 43: 1697-1704.

Elton, C.S. 1927. Animal Ecology. Macmillan, New York.

Endlweber, K., Ruess, L., Scheu, S., 2009. Collembola switch diet in presence of plant roots thereby functioning as herbivores. Soil Biology and Biochemistry 41: 1151-1154.

Eriksen, J., Askegaard, M., Kristensen, K., 1999. Nitrate leaching in an organic dairy/crop rotation as affected by organic manure type, livestock density and crop. Soil Use and Management 15: 176-182.

Eriksen, J., Askegaard, M., Kristensen, K., 2004. Nitrate leaching from an organic dairy crop rotation: the effects of manure type, nitrogen input and improved crop rotation. Soil Use and Management 20: 48-54.

Ferris, H., 2010. Form and function: Metabolic footprints of nematodes in the soil food web. European Journal of Soil Biology 46: 97-104.

Ferris, H., Bongers, T., de Goede, R.G.M., 2001. A framework for soil food web diagnostics: Extension of the nematode faunal analysis concept. Applied Soil Ecology 18: 13-29.

Finlay, B.J., Black, H.I., Brown, S., Clarke, K., Esteban, G., Hindle, R.M., Olmo, J.L., Rollett, A., Vickerman, K., 2000. Estimating the growth potential of the soil protozoan community. Protist 151: 69-80.

Fitter, A.H., 2005. Darkness visible: reflections on underground ecology. Journal of Ecology 93: 231-243.

Fjellberg, A., 1998. The Collembola of Fennoscandia and Denmark, Part I: Poduromorpha. Brill, Leiden, Boston.

Fjellberg, A., 2007. The Collembola of Fennoscandia and Denmark. Part II: Entomobryomorpha and Symphypleona. Brill, Leiden.

Fließbach, A., Martens, R., Reber, H.H., 1994. Soil microbial biomass and microbial activity in soils treated with heavy metal contaminated sewage sludge. Soil Biology and Biochemistry 26: 1201-1205.

Fonseca, C.R., Ganade, G., 2001. Species functional redundancy, random extinctions and the stability of ecosystems. Journal of Ecology 89: 118-125. 
Fournier, B., Samaritani, E., Shrestha, J., Mitchell, E.A.D., Le Bayon, R.-C., 2012. Patterns of earthworm communities and species traits in relation to the perturbation gradient of a restored floodplain. Applied Soil Ecology 59: 87-95.

Freedman, D., Diaconis, P., 1981. On the histogram as a density estimator: $L_{2}$ theory. Zeitschrift für Wahrscheinlichkeitstheorie und Verwandte Gebiete 57: 453-476.

Fry, J.C., 1990. Direct methods and biomass estimation. Methods in Microbiology 22: 41-85.

Gagic, V., Bartomeus, I., Jonsson, T., Taylor, A., Winqvist, C., Fischer, C., Slade, E.M., Steffan-Dewenter, I., Emmerson, M., Potts, S.G., Tscharntke, T., Weisser, W., Bommarco, R., 2015. Functional identity and diversity of animals predict ecosystem functioning better than species-based indices. Proceedings of the Royal Society (London) Series B 282: 20142620.

Garlaschelli, D., Caldarelli, G., Pietronero, L., 2003. Universal scaling relations in food webs. Nature 423: 165-168.

Garnier, E., Cortez, J., Billès, G., Navas, M.L., Roumet, C., Debussche, M., Laurent, Gérard

Gisin, H., 1943. Ökologie und Lebensgemeinschaften der Collembolen im Schweizerischen Exkursionsgebiet Basels. Revue Suisse de Zoologie 50: 131-224.

Green, J.L., Bohannan, B.J.M., Whitaker, R.J., 2008. Microbial biogeography: From taxonomy to traits. Science 320: 1039-1043.

Griffiths, B.S., Kuan, H.L., Ritz, K., Glover, L.A., McCaig, A.E., Fenwick, C., 2004. The relationship between microbial community structure and functional stability, tested experimentally in an upland pasture soil. Microbial Ecology 47: 104-113.

Grime, J.P., 1973. Competitive exclusion in herbaceous vegetation. Nature 242: 344-347.

Harrington, R., Anton, C., Dawson, T.P., de Bello, F., Feld, C.K., Haslett, KluvánkovaOravská, T., Kontogianni, A., Lavorel, S., Luck, G.W., Rounsevell, M.D.A., Samways, M.J., Settele, J., Skourtos,M., Spangenberg, J.H., Vandewalle, M., Zobel, M., Harrison, P.A., 2010. Ecosystem services and biodiversity conservation: concepts and a glossary. Biodiversity and Conservation 19: 2773-2790.

Hausmann, K., Hülsmann, N., Radek, R., 2003. Protistology. Schweizerbart'sche, Berlin.

Hechinger, R.F., Lafferty, K.D., Dobson, A.P., Brown, J.H., Kuris, A.M., 2011. A common scaling rule for abundance, energetics, and production of parasitic and free-living species. Science 333: $445-448$.

Heijting, S., Bruin, S., Bregt, A.K., 2011. The arable farmer as the assessor of within-field soil variation. Precision Agriculture 12: 488-507. 
Hendriks, A.J., Mulder, C., 2008. Scaling of offspring number and mass to plant and animal size: Model and meta-analysis. Oecologia 155: 705-716.

Hirst, A G., Glazier, D.S., Atkinson D., 2014. Body shape shifting during growth permits tests that distinguish between competing geometric theories of metabolic scaling. Ecology Letters 17: 1274-1281.

Hooper, D.U., Chapin, F.S. III, Ewel, J.J., Hector, A., Inchausti, P., Lavorel, S., Lawton, J.H., Lodge, D.M., Loreau, M., Naeem, S., Schmid, B., Setälä, H., Symstad, A.J., Vandermeer, J,. Wardle, D.A., 2005. Effect of biodiversity on ecosystem functioning: a consensus of current knowledge. Ecological Monographs 75: 3-35.

Hooper, D.U., Dukes, J.S., 2004. Overyielding among plant functional groups in a long-term experiment. Ecology Letters 7: 95-105.

Hopkin, S.P., 1997. Biology of the springtails (Insecta: Collembola). Oxford University Press, Oxford.

Hudson, L.N., Emerson, R., Jenkins, G.B., Layer, K. Ledger, M.E., Pichler, D.E., Thompson, M.S.A., O'Gorman, E.J., Woodward, G., Reuman, D.C., 2013. Cheddar: analysis and visualisation of ecological communities in R. Methods in Ecology and Evolution 4: 99104.

Hunt, H.W., and Wall, D.H., 2002. Modeling the effects of loss of soil biodiversity on ecosystem function. Global Change Biology 8: 32-49.

Hunt, H.W., Coleman, W., D.C., Ingham, E.R., Ingham, R.E., Elliott, E.T., Moore, J.C., Rose, S.L., Reid, C. P.P, Morley, C.R., 1987. The detrital food web in a shortgrass prairie. Biology and Fertility of Soils 3: 57-68.

Ilieva-Makulec, K., Olejniczak, I., Szanser, M., 2006. Response of soil micro- and mesofauna to diversity and quality of plant litter. European Journal of Soil Biology 42: S244-S249.

Jandl, R., Sollins, P., 1997. Water-extractable soil carbon in relation to the belowground carbon cycle. Biology and Fertility of Soils 25: 196-201.

Jonsson, T., Cohen, J.E., Carpenter, S.R., 2005. Food webs, body size, and species abundance in ecological community description. Advances in Ecological Research 36: 1-84.

Kearney, M., Porter, W., 2006. Ecologists have already started rebuilding community ecology from functional traits. Trends in Ecology and Evolution 21: 481-482.

Keeney, D.R., Nelson, D.W., 1982. Nitrogen - inorganic forms. In: Methods of Soil Analysis. Part 2 (eds. Black, C.A., Evans, D.D., White, J.L., Ensminger, L.E., and Clark, F.E.). American Society of Agronomy, Madison, WI, USA, pp. 682-687.

Kolokotrones, T., Savage, V., Deeds, E.J., Fontana, W., 2010. Curvature in metabolic scaling. 
Nature 464: 753-756.

Kooistra, G., 1964. Some data concerning the presence and behaviour of springtails (Collembola) on grass and white clover. European Journal of Plant Pathology 70: 136141.

Krause, S., Le Roux, X., Niklaus, P.A., van Bodegom, P.M., Lennon, J.T., Bertilsson, S., Grossart, H.-P., Philippot, L., Bodelier, P.L.E., 2014. Trait-based approaches for understanding microbial biodiversity and ecosystem functioning. Frontiers in Microbiology 5: 1-10.

Küchenmeister, F., Küchenmeister, K., Wrage, N., Kayser, M., Isselstein, J., 2012. Yield and yield stability in mixtures of productive grassland species: Does species number or functional group composition matter? Grassland Science 58: 94-100.

Kušlienė, G., Rasmussen, J., Kuzyakov, Y., Eriksen, J., 2014. Medium-term response of microbial community to rhizodeposits of white clover and ryegrass and tracing of active processes induced by ${ }^{13} \mathrm{C}$ and ${ }^{15} \mathrm{~N}$ labelled exudates. Soil Biology and Biochemistry 76: 22-33.

Laliberté, E., Legendre P., 2010. A distance-based framework for measuring functional diversity from multiple traits. Ecology 91: 299-305.

Larsen, T., Gorissen, A., Krogh, P.H., Ventura, M., Magid, J., 2007. Assimilation dynamics of soil carbon and nitrogen by wheat roots and Collembola. Plant and Soil 295: 253-264.

Larsen, T., Pollierer, M.M., Holmstrup, M., D’Annibale, A., Maraldo, K., Andersen, N., Eriksen, J., 2016a. Substantial nutritional contribution of bacterial amino acids to earthworms and enchytraeids: A case study from organic grasslands. Soil Biology and Biochemistry 99: 21-27.

Larsen, T., Ventura, M., Maraldo, K., Triadó-Margarit, X., Casamayor, E.O., Wang, Y.V., Andersen, N., O'Brien, D.M., 2016b. The dominant detritus-feeding invertebrate in Arctic peat soils derives its essential amino acids from gut symbionts. Journal of Animal Ecology 85: 1275-1285.

Lavorel, S., Garnier E., 2002. Predicting changes in community composition and ecosystem functioning from plant traits: revisiting the Holy Grail. Functional Ecology 16: 545-556.

Lavorel, S., Grigulis, K., 2012. How fundamental plant functional trait relationships scale-up to trade-offs and synergies in ecosystem services. Journal of Ecology 100: 128-140.

Lavorel, S., Grigulis, K., McIntyre, S., Williams, N.S.G., Garden, D., Dorrough, J., Dorrough, J., Berman, S., Quétier, F., Thébault, A., Bonis, A., 2008. Assessing functional diversity in the field - Methodology matters! Functional Ecology 22: 134-147. 
Lavorel, S., McIntyre, S., Landsberg, J., Forbes, T.D.A., 1997. Plant functional classifications: From general groups to specific groups based on response to disturbance. Trends in Ecology and Evolution 12: 474-478.

Lavorel, S., Storkey, J., Bardgett, R.D., de Bello, F., Berg, M.P., Le Roux, X. Moretti, M., Mulder, C., Pakeman, R.J., Díaz, S., Harrington, R., 2013. A novel framework for linking functional diversity of plants with other trophic levels for the quantification of ecosystemservices. Journal of Vegetation Science 24: 942-948.

Leaper, R., Raffaelli, D., Emes, C., Manly, B., 2001. Constraints on body-size distributions: an experimental test of the habitat architecture hypothesis. Journal of Animal Ecology 70: 248-259.

Lennon, J.T., Aanderud, Z.T., Lehmkuhl, B.K., Schoolmaster, D.R., 2012. Mapping the niche space of soil microorganisms using taxonomy and traits. Ecology 93: 1867-1879.

MacFadyen, A., 1961. Improved funnel-type extractors for soil arthropods. Journal of Animal Ecology 30: 171-184.

Makkonen, M., Berg, M.P., van Hal, J.R., Callaghan, T.V., Press, M.C., Aerts, R., 2011. Traits explain the responses of a sub-arctic Collembola community to climate manipulation. Soil Biology and Biochemistry 43: 377-384.

Maraun, M., Erdmann, G., Fischer, B.M.M., Pollierer, M.M., Norton, R.A., Schneider, K., Scheu, S., 2011. Stable isotopes revisited: Their use and limits for oribatid mite trophic ecology. Soil Biology and Biochemistry 43: 877-882.

Marshall, E.J.P., 2002. Introducing field margin ecology in Europe. Agriculture, Ecosystems and Environment 89: 1-4.

Marshall, E.J.P., West, T.M., Kleijn D., 2006. Impacts of an agri-environment field margin prescription on the flora and fauna of arable farmland in different landscapes. Agriculture, Ecosystems and Environment 113: 36-44.

Martins da Silva, P., Carvalho, F., Dirilgen, T., Stone, D., Creamer, R., Bolger, T., Sousa, J.P., 2016. Traits of collembolan life-form indicate land use types and soil properties across an European transect. Applied Soil Ecology 97: 69-77.

Martiny, J.B.H., Bohannan, B.J.M., Brown, J.H., Colwell, R.K., Fuhrman, J.A., Green, J.L., Horner-Devine, M.C., Kane, M., Krumins, J.A., Kuske, C.R., Morin, P.J., Naeem, S.Ovreas, L., Reysenbach, A.-L., Smith, V.H., Staley, J.T., 2006. Microbial biogeography: putting microorganisms on the map. Nature Review Microbiology 4: 102-112. 
Mason, N.W.H., Mouillot, D., Lee, W.G., Wilson, J.B., 2005. Functional richness, functional evenness and functional divergence: the primary components of functional diversity. Oikos 111: 112-118.

McGill, B.J., Enquist, B.J., Weiher E., Westoby, M., 2006a. Rebuilding community ecology from functional traits. Trends in Ecology and Evolution 21: 178-185.

MEA, 2005. Ecosystems and Human Well-being: Biodiversity Synthesis. Washington, DC.

Meehan, T.D., Drumm, P.K., Farrar, R.S., Oral, K., Lanier, K.E., Pennington, E.A, Stafurik, I.T., Valore, D.V., Wylie, A.D., 2006. Energetic equivalence in a soil arthropod community from an aspen-conifer forest. Pedobiologia 50: 307-312.

Meehan, T.J., 2006. Mass and temperature dependence of metabolic rate in litter and soil invertebrates. Physiological and Biochemical Zoology 79: 878-884.

Meek, B., Loxton, D., Sparks, T., Pywell R., Pickett, H., Nowakowski, M., 2002. The effect of arable field margin composition on invertebrate biodiversity. Biological Conservation 106: 259-271.

Milcu, A., Partsch, S., Langel, R., Scheu, S., 2006. The response of decomposers (earthworms, springtails and microorganisms) to variations in species and functional group diversity of plants. Oikos 112: 513-524.

Minagawa, M., Wada, E., 1984. Stepwise enrichment of ${ }^{15} \mathrm{~N}$ along food chains: Further evidence and the relation between $\delta^{15} \mathrm{~N}$ and animal age. Geochimica et Cosmochimica Acta 48, 1135-1140.

Morriën, E., Hannula, S.E., Snoek, L.B., Helmsing, N.R., Zweers, H., de Hollander, M., Soto, R.L., Bouffaud, M.-L., Buée, M., Dimmers, W., Duyts, H., Geisen, S., Girlanda, M., Griffiths, R.I., Jørgensen, H.-B., Jensen, J., Plassart, P., Redecker, D., Schmelz, R.M., Schmidt, O., Thomson, B.C., Tisserant, E., Uroz, S., Winding, A., Bailey, M.J., Bonkowski, M., Faber, J.H., Martin, F., Lemanceau, P., de Boer, W., van Veen, J.A., van der Putten, W.H., 2017. Soil networks become more connected and take up more carbon as nature restoration progresses. Nature Communications 8: 14349.

Mouchet, M.A., Villéger, S., Mason, N.W.H., Mouillot, D., 2010. Functional diversity measures: an overview of their redundancy and their ability to discriminate community assembly rules. Functional Ecology 24: 867-876.

Mouillot, D., Graham, N.A.J., Villéger, S., Mason, N.W.H., Bellwood, D.R., 2013. A functional approach reveals community responses to disturbances. Trends in Ecology and Evolution 28: 167-177. 
Mouillot, D., Wilson, J.B., 2002. Can We Tell How a Community Was Constructed? A Comparison of Five Evenness Indices for Their Ability to Identify Theoretical Models of Community Construction. Theoretical Population Biology 61: 141-151.

Mulder, C.P.H., Jumpponen, A., Högberg, P., Huss-Danell, K., 2002. How plant diversity and legumes affect nitrogen dynamics in experimental grassland communities. Oecologia 133: 412-421.

Mulder, C., 2006. Driving forces from soil invertebrates to ecosystem functioning: the allometric perspective. Naturwissenschaften 93: 467-479.

Mulder, C., Elser, J.J., 2009. Soil acidity, ecological stoichiometry and allometric scaling in grassland food webs. Global Change Biology 15: 2730-2738.

Mulder, C., Vonk, J.A., 2011. Nematode traits and environmental constraints in 200 soil systems: scaling within the 60-6000 $\mu \mathrm{m}$ body size range. Ecology 92: 2004-2004.

Mulder, C., Cohen, J.E., Setälä, H., Bloem, J., Breure, A.M., 2005a. Bacterial traits, organism mass, and numerical abundance in the detrital soil food web of Dutch agricultural grasslands. Ecology Letters 8: 80-90.

Mulder, C., van Wijnen, H.J., van Wezel, A.P., 2005b. Numerical abundance and biodiversity of below-ground taxocenes along a $\mathrm{pH}$ gradient across the Netherlands. Journal of Biogeography 32: 1775-1790.

Mulder, C., den Hollander, H., Schouten, T., Rutgers, M., 2006a. Allometry, biocomplexity, and web topology of hundred agro-environments in The Netherlands. Ecological Complexity 3: 219-230.

Mulder, C., Wouterse, M., Raubuch, M., Roelofs, W., Rutgers, M., 2006b. Can Transgenic Maize Affect Soil Microbial Communities? PLoS Computational Biology, 2: 1165-1172.

Mulder, C., Wouterse, M., Rutgers, M., Posthuma, L., 2007. Transgenic maize containing the Cry1Ab protein ephemerally enhances soil microbial communities. Ambio, 36, 359-361.

Mulder, C., den Hollander, H.A., Hendriks, J.A., 2008. Aboveground Herbivory Shapes the Biomass Distribution and Flux of Soil Invertebrates. PLoS ONE 3: e3573.

Mulder, C., Boit, A., Bonkowski, M., de Ruiter, P.C. Mancinelli, G., van der Heijden, M.G.A., van Wijnen, H.J., Vonk, J.A., Rutgers, M., 2011. A belowground perspective on Dutch agroecosystems: how soil organisms interact to support ecosystem services. Advances in Ecological Research 44: 277-357.

Mulder, C., Boit, A., Mori, S., Vonk, J.A., Dyer, S.D., Faggiano, L., Geisen, S., González, A.L., Kaspari, M., Lavorel, S., Marquet, P.A., Rossberg, A.G., Sterner, R.W., Voigt, W., Wall, 
D.H., 2012. Distributional (In)Congruence of Biodiversity-Ecosystem Functioning. Advances in Ecological Research 46: 1-88.

Mulder, C., Ahrestani, F.S., Bahn, M., Bohan, D.A., Bonkowski, M., Griffiths, B.S., Guicharnaud, R.A., Kattge, J., Krogh, P.H., Lavorel, S., Lewis, O.T., Mancinelli, G., Naeem, S., Peñuelas, J., Poorter, H., Reich, P.B., Rossi, L., Rusch, G.M., Sardans, J., Wright, I.J., 2013. Connecting the Green and Brown Worlds: Allometric and Stoichiometric Predictability of Above- and Below-Ground Networks. Advances in Ecological Research 49: 69-175.

Mulder, C., Sechi, V., Woodward, G., Bohan, D.A., 2017. Ecological networks in managed ecosystems: Connecting structure to services. In: Adaptive Food Webs: Science for Impact (eds. Moore, J.C., de Ruiter, P.C., McCann, K.S., and Wolters, V.). Cambridge University Press, Cambridge UK (in press).

Nakaya, F., Saito, Y., Motokawa, T., 2003. Switching of metabolic-rate scaling between allometry and isometry in colonial ascidians. Proceedings of the Royal Society (London) Series B 270: 1105-1113.

Ngosong, C., Raupp, J., Richnow, H.-H., Ruess, L., 2011. Tracking Collembola feeding strategies by the natural ${ }^{13} \mathrm{C}$ signal of fatty acids in an arable soil with different fertilizer regimes. Pedobiologia 54: 225-233.

Nyfeler, D., Huguenin-Elie, O., Suter, M., Frossard, E., Lüscher, A., 2011. Grass-legume mixtures can yield more nitrogen than legume pure stands due to mutual stimulation of nitrogen uptake from symbiotic and non-symbiotic sources. Agriculture, Ecosystems and Environment 140: 155-163.

O'Connor, F.B., 1955. Extraction of enchytraeid worms from a coniferous forest soil. Nature 175: 815-816.

Oostenbrink, M., 1960. Estimate nematode populations by some selected methods. In: Nematology (eds. Sasser, J.N. and Jenkins, W.R.). University of North Carolina Press, Chapel Hill, NC, USA, pp. 85-102.

Ostle, N., Briones, M.J.I., Ineson, P., Cole, L., Staddon, P., Sleep, D., 2007. Isotopic detection of recent photosynthate carbon flow into grassland rhizosphere fauna. Soil Biology and Biochemistry 39: 768-777.

Pakeman, R.J., 2011. Functional diversity indices reveal the impacts of land use intensification on plant community assembly. Journal of Ecology 99: 1143-1151.

Paradis, E., Claude, J., Strimmer, K., 2004. APE: analyses of phylogenetics and evolution in R language. Bioinformatics 20: 289-290. 
Pedersen, J.B., Pedersen, C.A., 2013. Oversigt over landsforsøgene 2013 (in Danish).

Pelosi, C., Pey, B., Hedde, M., Caro, G., Capowiez, Y., Guernion, M., Peigné, J., Piron, D., Bertrand, M., Cluzeau, D., 2014. Reducing tillage in cultivated fields increases earthworm functional diversity. Applied Soil Ecology 83: 79-87.

Peñuelas, J., Sardans J., 2009. Elementary factors. Nature 460: 803-804.

Petchey, O.L., Gaston, K.J., 2002. Functional diversity (FD), species richness and community composition. Ecology Letters 5: 402-411.

Peters, R.H., 1983. The ecological implication of body size. Cambridge University Press, Cambridge, UK.

Petersen, H., Luxton, M., 1982. A comparative analysis of soil fauna populations and their role in decomposition processes. Oikos 39: 287-338.

Pey, B., Nahmani, J., Auclerc, A., Capowiez, Y., Cluzeau, D., Cortet, J., Decaëns, T., Deharveng, L., Dubs, F., Joimel, S., Briard, C., Grumiaux, F.,Laporte, M. -A., Pasquet, A., Pelosi, C., Pernin, C., Ponge, J.-F., Salmon, S., Santorufo, L., Hedde, M., 2014. Current use of and future needs for soil invertebrate functional traits in community ecology. Basic and Applied Ecology 15: 194-206.

Pinheiro J., Bates D., DebRoy S., Sarkar D., R Core Team2016. nlme: Linear and Nonlinear Mixed Effects Models. R package version 3.1-131

Ponge, J-F., Salmon, S., Santorufo, L., Hedde, M., 2014. Current use of and future needs for soil invertebrate functional traits in community ecology. Basic and Applied Ecology 15: 194-206.

Polis, G.A., Strong, D.R., 1996. Food web complexity and community dynamics. The American Naturalist 147: 813-846.

Pollierer, M.M., Langel, R., Körner, C., Maraun, M., Scheu, S., 2007. The underestimated importance of belowground carbon input for forest soil animal food webs. Ecology Letters 10: 729-736.

Potapov, A.A., Semenina, E.E., Korotkevich, A.Y., Kuznetsova, N.A., Tiunov, A.V., 2016. Connecting taxonomy and ecology: Trophic niches of collembolans as related to taxonomic identity and life forms. Soil Biology and Biochemistry 101: 20-31.

Potapov, A.M., Tiunov, A.V., 2016. Stable isotope composition of mycophagous collembolans versus mycotrophic plants: Do soil invertebrates feed on mycorrhizal fungi? Soil Biology and Biochemistry 93: 115-118. 
Potapov, A.M., Semenyuk, I.I., Tiunov, A.V., 2014. Seasonal and age-related changes in the stable isotope composition $\left({ }^{15} \mathrm{~N} /{ }^{14} \mathrm{~N}\right.$ and $\left.{ }^{13} \mathrm{C} /{ }^{12} \mathrm{C}\right)$ of millipedes and collembolans in a temperate forest soil. Pedobiologia 57: 215-222.

Potapov, A.M., Goncharov, A.A., Tsurikov, S.M., Tully, T., Tiunov, A.V., 2016. Assimilation of plant-derived freshly fixed carbon by soil collembolans: not only via roots? Pedobiologia 59: 189-193.

R Core Team 2013. R: a Language and Environment for Statistical Computing. R Foundation for Statistical Computing, Vienna, Austria.

Reuman, D.C., Mulder, C., Raffaelli, D., Cohen, J.E., 2008. Three allometric relations of population density to body mass: theoretical integration and empirical tests in 149 food webs. Ecology Letters 11: 1216-1228.

Rockström, J., Steffen, W., Noone, K., Persson, A., Chapin, F.S., Lambin, E.F., Lenton, T.M., Scheffer, M., Folke, C., Schellnhuber, H.J., Nykvist, B., de Wit, C.A., Hughes, Terry., van der Leeuw, S., Rodhe, H., Sorlin, S., Snyder, P.K., Costanza, R., Svedin, U., Falkenmark, M., Karlberg, L., Corell, R.W., Fabry, Victoria J., Hansen, J., Walker, B., Liverman, D., Richardson, K., Crutzen, P.,Foley, J.A., 2009. A safe operating space for humanity. Nature 461: 472-475.

Fabry, V.J., Hansen, J., Walker, B., Liverman, D., Richardson, K., Crutzen, P., Foley, J.A., 2009. A safe operating space for humanity. Nature 461: 472-475.

Ruess, L., Schütz, K., Migge-Kleian, S., Häggblom, M.M., Kandeler, E., Scheu, S., 2007. Lipid composition of Collembola and their food resources in deciduous forest standsImplications for feeding strategies. Soil Biology and Biochemistry 39: 1990-2000.

Rusek, J., 1998. Biodiversity of Collembola and their functional role in the ecosystem. Biodiversity and Conservation 7: 1207-1219.

Rutgers, M., Breure, A.M., Insam, H., 2006. Substrate utilization in Biolog ${ }^{\mathrm{TM}}$ plates for analysis of CLPP. In: Microbiological Methods for Assessing Soil Quality (eds. Bloem, J., Benedetti, A., and Hopkins, D.W.). CABI Wallingford, Oxfordshire, UK, pp. 212-227.

Rutgers, M., Schouten, A.J., Bloem, J., van Eekeren, N., de Goede, R.G.M., Jagers op Akkerhuis, G.A.J.M., van der Wal, A., Mulder, C., Brussaard, L., Breure, A.M., 2009. Biological measurements in a nationwide soil monitoring network. European Journal of Soil Science 60: 820-832.

Rutgers, M., van Wijnen, H.J., Schouten, A.J., Mulder, C., Kuiten, A.M., Brussaard, L., Breure, A.M., 2012. A method to assess ecosystem services developed from soil attributes with stakeholders and data of four arable farms. Science of the Total Environment 415: 3948. 
Sabais, A.C.W., Scheu, S., Eisenhauer, N., 2011. Plant species richness drives the density and diversity of Collembola in temperate grassland. Acta Oecologica 37: 195-202.

Sabais, A.C.W., Eisenhauer, N., König, S., Renker, C., Buscot, F., Scheu, S., 2012. Soil organisms shape the competition between grassland plant species. Oecologia 170: 102132.

Salamon, J., Schaefer, M., Alphei, J., Schmid, B., 2004. Effects of plant diversity on Collembola in an experimental grassland ecosystem. Oikos 106: 51-60.

Salmon, S., Ponge, J.F., 2012. Species traits and habitats in springtail communities: A regional scale study. Pedobiologia 55: 295-301.

Salmon, S., Ponge, J.F., Gachet, S., Deharveng, L., Lefebvre, N., Delabrosse, F., 2014. Linking species, traits and habitat characteristics of Collembola at European scale. Soil Biology and Biochemistry 75: 73-85.

Santorufo, L., Cortet, J., Nahmani, J., Pernin, C., Salmon, S., Pernot, A., Morel, J.L., Maisto, G., 2015. Responses of functional and taxonomic collembolan community structure to site management in Mediterranean urban and surrounding areas. European Journal of Soil Biology 70: 46-57.

Schon, N., Mackay, A., Hedley, M., 2011. Influence of soil faunal communities on nitrogen dynamics in legume-based mesocosms. Soil Research 49: 190-201.

Schrama, M., Heijning, P., Bakker, J.P., van Wijnen, H.J., Berg, M.P. Olff H., 2013. Herbivore trampling as an alternative pathway for explaining differences in nitrogen mineralization in moist grasslands. Oecologia 172: 231-243.

Sechi, V., D’Annibale, A., Ambus, P., Sárossy, Z., Krogh, P.H., Eriksen, J., Holmstrup, M., 2014a. Collembola feeding habits and niche specialization in agricultural grasslands of different composition. Soil Biology and Biochemistry 74: 31-38.

Sechi V., Brussaard, L., de Goede, R.G.M., Rutgers, M., Mulder, C., 2014b. Data from: Choice of resolution by functional trait or taxonomy affects allometric scaling in soil food webs. Dryad Digital Repository: http: //dx.doi.org/10.5061/dryad.t5347

Sechi, V., Brussaard, L., De Goede, R.G.M., Rutgers, M. and Mulder, C., 2015. Choice of resolution by functional trait or taxonomy affects allometric scaling in soil food webs. The American Naturalist, 185: 142-149.

Smith, B., and Wilson, J.B., 1996. A Consumer's Guide to Evenness Indices. Oikos 76: 7082. 
Smith, T.M., Shugart, H.H., and Woodward, F.I., 1997. Plant Functional Types: Their Relevance to Ecosystem Properties and Global Change. Cambridge University Press, Cambridge, MA.

Solga, A., Burkhardt, J., Zechmeister, H.G., Frahm, J.-P., 2005. Nitrogen content, ${ }^{15} \mathrm{~N}$ natural abundance and biomass of the two pleurocarpous mosses Pleurozium schreberi (Brid.) Mitt. and Scleropodium purum (Hedw.) Limpr. in relation to atmospheric nitrogen deposition. Environmental Pollution 134: 465-73.

Sparling, G., Vojvodić-Vuković, M., Schipper, L.A., 1998. Hot-water-soluble C as a simple measure of labile soil organic matter: The relationship with microbial biomass C. Soil Biology and Biochemistry 30: 1469-1472.

Statzner, B., Hildrew, A.G. \& Resh, V.H., 2001. Species traits and environmental constraints: Entomological research and the history of ecological theory. Annual Review of Entomology 46:291-316.

Suding, K.N., Lavorel, S., Chapin, F.S., Cornelissen, J.H.C., Díaz, S., Garnier, E., Goldberg, D., Hooper, D.U., Jackson, S.T., Navas, M.-L., 2008. Scaling environmental change through the community-level: a trait-based response-and-effect framework for plants. Global Change Biology 14: 1125-1140.

Tilman, D., Naeem, S., Knops, J., Reich, P., Siemann, E. Wedin, D., Ritchie, M., Lawton, J., 1997a. Biodiversity and Ecosystem Properties. Science 278: 1865-1869.

Tilman, D., Knops, J., Wedin, D., Reich, P., Ritchie, M., Siemann, E., 1997b. The Influence of Functional Diversity and Composition on Ecosystem Processes. Science 277: 13001302.

Trebilco, R., Baum, J.K., Salomon, A.K., Dulvy, N.K., 2013. Ecosystem ecology: size-based constraints on the pyramids of life. Trends in Ecology and Evolution 28: 423-431.

Turnbull, M.S., George, P.B.L., Lindo, Z., 2014. Weighing in: size spectra as a standard tool in soil community analysis. Soil Biology and Biochemistry 68: 366-372.

van der Heijden, M.G.A., Klironomos, J.N., Ursic, M., Moutoglis, P., Streitwolf-Engel, R., Boller, T., Wiemken, A., Sanders, I.R., 1998. Mycorrhizal fungal diversity determines plant biodiversity, ecosystem variability and productivity. Nature 396: 69-72.

van Eekeren, N., Murray, P.J., Smeding, F.W., 2007. Soil biota in grassland, its ecosystem services and the impact of management. Grassland Science in Europe 12: 247-258.

van Eekeren, N., van Liere, D., de Vries, F.T., Rutgers, M., de Goede, R.G.M., Brussaard, L., 2009. A mixture of grass and clover combines the positive effects of both plant species on selected soil biota. Applied Soil Ecology 42: 254-263. 
van Veen, J.A., Paul, E.A., 1979. Conversion of biovolume measurements of soil organisms, grown under various moisture tensions, to biomass and their nutrient content. Applied Environmental Microbiology 37: 686-692.

Verberk, W.C.E.P., van Noordwijk, C.G.E., Hildrew, A.G., 2013. Delivering on a promise: integrating species traits to transform descriptive community ecology into a predictive science. Freshwater Science 32: 531-547.

Villéger, S., Mason, N.W.H., Mouillot, D., 2008. New multidimensional functional diversity indices for a multifaceted framework in functional ecology. Ecology 89: 2290-2301.

Violle, C., Navas, M.-L., Vile, D., Kazakou, E., Fortunel, C., Hummel, I., Garnier, E., 2007. Let the concept of trait be functional! Oikos 116: 882-892.

Vonk, J.A., Breure, A.M., Mulder, C., 2013. Environmentally-driven dissimilarity of traitbased indices of nematodes under different agricultural management and soil types. Agriculture, Ecosystems and Environment 179: 133-138.

Wallace, H.R., 1958a. Movement of eelworms. II. A comparative study of the movement in soil of Heterodera schachtii Schmidt and Ditylenchus dipsaci (Kühn) Filipjev. Annals of Applied Biology 46: 86-94.

Wallace, H.R., 1958b. Movement of eelworms. III. The relationship between eelworm length, activity and mobility. Annals of Applied Biology 46: 662-668.

Weemstra, M., Mommer, L., Visser, E.J.W., van Ruijven, J., Kuyper, T.W., Mohren, G.M.J., Sterck, F.J., 2016. Towards a multidimensional root trait framework: a tree root review. New Phytologist 211: 1159-1169.

West G.B., Brown, J.H., 2005. The origin of allometric scaling laws in biology from genomes to ecosystems: towards a quantitative unifying theory of biological structure and organization. Journal of Experimental Biology 208: 1575-1592.

West, G.B., Brown, J.H., Enquist, B.J., 1997. A general model for the origin of allometric scaling laws in biology. Science 276: 122-126.

Widenfalk, L., Bengtsson, J., Berggren, Å., Zwiggelaar, K., Spijkman, E., Huyer-Brugman, F., Berg, M.P., 2015. Spatially structured environmental filtering of collembolan traits in late successional salt marsh vegetation. Oecologia 179: 537-549.

Woodward, F.I., Cramer, W., 1996. Plant functional types and climatic change: Introduction. Journal of Vegetation Science 7: 306-308.

Woodward, G., Brown, L.E., Edwards, F.K., Hudson, L.N., Milner, A.M., Reuman, D.C., Ledger, M.E., 2012. Climate change impacts in multispecies systems: drought alters 
food web size structure in a field experiment. Philosophical Transactions of the Royal Society (London) Series B 367: 2990-2997.

Yeates, G.W., 1993. Feeding habits in nematode families and genera - An outline for soil ecologists. Journal of Nematology 25: 315-331.

Yeates, G.W., Bongers, T., de Goede, R.G.M., Freckman, D.W., Georgieva, S.S., 1993. Feeding Habits in Soil Nematode Families and Genera - An Outline for Soil Ecologists. Journal of Nematology 25: 315-331.

Yergeau, E., Bezemer, T.M., Hedlund, K., Mortimer, S.R., Kowalchuk, G.A., Van Der Putten, W.H., 2010. Influences of space, soil, nematodes and plants on microbial community composition of chalk grassland soils. Environmental Microbiology 12: 2096-2106.

Young, I.M., Crawford, J.W., 2004. Interactions and Self-Organization in the Soil-Microbe Complex. Science 304: 1634-1637.

Yvon-Durocher, G., Montoya, J.M., Trimmer, M., Woodward, G., 2011. Warming alters the size spectrum and shifts the distribution of biomass in freshwater ecosystems. Global Change Biology 17: 1681-1694. 
Summary 



\section{Summary}

Ensuring the continuous delivery of the benefits humankind obtains from ecosystems, i.e. ecosystem services, is a key challenge for the future of our society and for our planet.

Recent emphasis on ecosystem services as a framework to evaluate ecosystems and to promote their sustainable use has drawn attention to how organisms contribute to the delivery of services.

Soil attributes and biotic interactions play important roles in ecological processes (e.g. soil formation, nutrient turnover, carbon sequestration and transformation) and, consequently, in the related delivery of ecosystem services.

Despite its importance, soil has often been considered a black box and, hence, understanding how soil organisms interact and how they respond to environmental conditions is fundamental to preserve soil functioning and provide a meaningful assessment of ecosystem services.

Ecosystem functioning and related services are strongly influenced by the characteristics (i.e. functional traits) of living organisms. Functional traits determine individual responses to pressures and their effects on ecosystem functioning. Therefore, investigating soil ecosystems from a trait-based perspective offers an interesting opportunity to link the functional responses of the organisms to environmental pressures and to give insight into how the entire community influences ecological processes.

The main objective of this thesis is to develop and to test concepts for a trait-driven quantification of ecosystem services through the assessment of the effects of land management on soil processes. In particular, it focuses on exploring the potential of a traitbased approach in identifying and better understanding the response of the soil biota to environmental pressures and analyses the responses of soil organisms in terms of changes in functional trait distribution and trophic interactions.

In Chapter 1, the aforementioned concepts underpinning this thesis are further explained and the following research questions (hereafter: RQ) are formulated:

1. To what extent is a trait-based approach in soil ecosystem studies suitable for detecting changes in the soil community and giving insight into soil functioning? Which traits are suitable?

2. To what extent do body mass and the related allometric scaling change as a function of environmental gradients? Does taxonomic or functional classification matter?

3. How do body size traits and the related functional diversity in a soil community change in response to environmental pressures?

Chapter 2 deals with RQ 1 investigating taxonomic and functional changes in Collembola in agricultural grassland with either perennial ryegrass, white clover or a mixture 
of both in the early (May) and late season (September). This chapter analyses seven morphological and four ecological traits of collembolans and the related changes in functional diversity. It also investigates trophic relationships through isotopic signatures. Stable isotope analysis showed that root-derived resources were more important for epedaphic and hemiedaphic species in the white clover than ryegrass plots. Changes in species density and traits distribution as a response to the $\mathrm{C}: \mathrm{N}$ ratio of plant material, suggest that litter quality was the main factor affecting the collembolan community, especially when comparing the two sampling occasions (May vs. September). This study shows that habitat changes, via different plant composition, can affect some functional groups, having in turn effects on the functional diversity of the community.

Chapter 3 also deals with RQ 1, investigating the trait-based responses of the entire soil community. It explores the suitability of three groups of functional traits (i.e. ecophysiological traits, behavioral traits and faunal morphological traits) to explain how different components of the soil biota (fungi, bacteria, micro- and mesofauna) respond to agricultural management (i.e. arable field vs. field margin management) and to what extent these traits affect soil functioning. Eco-physiological traits of the microbial community reflected differences in nutrient cycling dynamics and carbon storage. Micro- and mesofauna trophic grouping and body-mass distribution showed a partial shift from the bacterial- to the fungaldriven energy channels.

This comprehensive trait-based approach revealed characteristics of the soil community structure and belowground ecological processes that could not be detected by traditional methods, and proved to have potential in identifying environmental pressures and in evaluating ecosystem services.

Chapter 4 explores the potential of using body mass as a trait to detect effects of environmental conditions. Body mass - abundance relationships (i.e. allometric scaling) calculated per taxonomic or functional group, were compared in three abandoned (former organic) grasslands with different management histories.

This chapter questions whether at the local scale the choice for a taxonomic or a functional classification implies changes in allometric relationships (RQ2). Strong differences in body-mass - abundance scaling were found between taxonomic and functional classification, whilst only slight differences arose according to soil environmental conditions. For the first time, an inverse 1:1 relationship between body mass and abundance (isometry) was recognized, providing evidence for constant biomass distribution along the body mass gradient regardless of the trophic levels. This shows that in soil, in contrast to aquatic systems, increasing body mass is not a direct function of increasing trophic level.

Chapter 5 focuses on nematode body-size distribution along three contrasting ecosystem types (arable fields, managed grassland, shrublands/woodlands). Addressing RQ 3, this chapter analyses i) the three components of functional diversity (i.e. functional richness, 
evenness and divergence); ii) the shifts in the body size traits length and width; and iii) the differences in body-mass distribution of the nematode community as a whole and of five trophic groups separately. Low values of functional evenness were found to be associated with high values of functional richness. The shift in body-size traits and body mass distribution analysed per trophic group revealed environmental filters that could not have been identified only by the study of functional diversity indices. This chapter provides empirical evidence that such combined approach allows to disclose soil food-web structure and to identify trait-mediated responses to environmental condition.

Chapter 6 provides a general discussion on the main findings of this work and its perspectives, concluding that approaches taking the whole soil community into consideration are more suitable to give insight into the effect of anthropogenic pressure on ecosystem functioning than approaches based on single taxonomic groups. Moreover, performing combined analysis (e.g. analysing body-mass distribution and trophic grouping) helps to better identify community response to environmental pressure.

A clear methodology for the next step, i.e. quantification of ecosystem services, is still lacking due to the current difficulties to link and quantify the effect of anthropogenic pressure to ecosystem functioning in soil. For this reason, it is essential that methods analysed in this thesis will be further explored under different environmental pressures to enable the development of tools to be used at the interface of science and society for sustainable development. 

Riassunto

(Summary in Italian) 



\section{Riassunto}

Includere il concetto di servizio ecosistemico nella pianificazione delle politiche ambientali e nella gestione delle risorse naturali è di fondamentale importanza per la tutela ambientale poiché permette di definire gli ecosistemi e considerarli come fornitori di servizi imprescindibili per l'umanità.

Il recente interesse rivolto al concetto di servizio ecosistemico dovuto al Millennium Assessment del 2005 ha posto l'attenzione sul ruolo che gli organismi svolgono nel garantire il funzionamento degli ecosistem e sui servizi che essi forniscono.

Le caratteristiche fisico-chimiche del suolo e le interazioni biotiche che avvengono nel sottosuolo giocano un ruolo importante nei processi ecologici, come per esempio la formazione di un profilo edafico, il ciclo dei nutrienti, la trasformazione e lo stoccaggio del carbonio.

Nonostante la sua importanza, il suolo è stato spesso considerato una "vaso chiuso", perciò, capire come gli organismi del suolo interagiscono e come essi rispondono alle condizioni ambientali è essenziale per preservare il funzionamento del suolo e garantire una valutazione appropriata dei servizi ecosistemici ad esso correlati.

Le funzioni ecosistemiche e i relativi servizi sono fortemente influenzati dalle caratteristiche degli organismi, i cosidetti tratti funzionali. Questi tratti funzionali, quali per esempio le caratteristiche morfologiche o la resistenza a specifiche condizioni esterne, determinano le risposte dei singoli individui alle pressioni ambientali e il loro effetto cumulativo sui processi ecosistemici. Pertanto, studiare il suolo basandosi sui tratti funzionali offre l'opportunità di connettere la risposta degli organismi alle pressioni che essi ricevono dall'ambiente che occupano e successivamente di comprendere come l'intera comunità influenzi i processi ecologici.

Attraverso l'analisi degli effetti delle pratiche agricole sui processi ecologici che avvengono nel sottosuolo, questo studio si pone l'obiettivo di sviluppare e sperimentare metodologie di analisi basate sui tratti funzionali, utili per la quantificazione dei servizi ecosistemici.

In particolare, questa tesi esplora le potenzialità di un'analisi basata sui tratti funzionali per identificare e meglio comprendere la risposta della organismi del suolo alle pressioni ambientali e analizza la risposta degli organismi in termini di cambiamenti nelle distribuzione dei tratti e delle interazioni trofiche in relazione a differenti condizioni.

Nel Capitolo 1 i concetti sopra citati, che costituiscono le basi di questo progetto di ricerca, sono ulteriormente sviluppati e approfonditi. Inoltre vengono introdotte e formulate le seguenti domande di ricerca $(\mathrm{DR})$ : 
1. Fino a che punto un approccio basato sui tratti funzionali è capace di individuare $\mathrm{i}$ cambiamenti nella comunità del suolo e di contribuire alla comprensione dei processi ecologici che in esso avvengono?

2. "Fino a che punto la taglia degli organismi e il relativo rapporto tra massa corporea e abbondanza degli individui nella comunità cambia in funzione delle condizioni ambientali? La classificazione tassonomica e funzionale è rilevante?

3. Come cambiano i tratti morfologici (peso, larghezza e lunghezza) degli organismi (e la relativa diversità funzionale legata a questo tratto) nella comunità del suolo in risposta alle pressioni ambientali?

Il Capitolo 2 affronta la DR 1 studiando i cambiamenti tassonomici e funzionali in una comunità di collemboli in tre pascoli coltivati rispettivamente con Lolium perenne (loglio), Trifolium repens (trifoglio bianco) e un misto dei due, all'inizio della primavera (maggio) e dell'autunno (settembre). Questo capitolo analizza i) sette tratti morfologici e quattro tratti ecologici dei collemboli; ii) i relativi cambiamenti nella diversità funzionale; iii) i possibili cambiamenti nelle relazioni trofiche attraverso lo studio degli isotopi stabili (firma isotopica) ${ }^{13} \mathrm{C}$ and ${ }^{15} \mathrm{~N}$.

Lo studio della firma isotopica ha mostrato che l'importanza delle risorse derivate dalle radici per le specie epiedafiche ed emiedafiche è maggiore nei campi coltivati con trifoglio bianco che in quelli coltivati con loglio. I cambiamenti nella densità e nella distribuzione dei tratti funzionali dei collemboli in risposta al rapporto carbonio azoto (C:N) del materiale vegetale, suggerisce che la qualità della lettiera ha costituito il fattore che più ha condizionato la comunità dei collemboli, specialmente se si confrontano i campionamenti di settembre e di maggio. Questo studio mostra che il cambiamento di habitat, dovuto a una diversa composizione vegetale, può influenzare alcuni gruppi (funzionali) di collemboli e di conseguenza determinare un cambiamento nella diversità funzionale della comunità.

Come il Capitolo 2, anche il Capitolo 3 affronta la DR 1 studiando i cambiamenti nei tratti funzionali dell'intera comunità del suolo. Questo studio esplora la capacità di tre gruppi di tratti funzionali (tratti eco-fisiologici, comportamentali e morfologici) di identificare le risposte delle componenti biotiche del suolo (funghi, batteri, micro e mesofauna) a diversi condizioni ambientali. Confrontando quattro campi arati con i loro adiacenti margini erbosi, in questo capitolo si osserva in che modo e in quale misura questi tratti funzionali influenzino i processi ecologici nel suolo.

I tratti eco-fisiologici della comunità microbica hanno rispecchiato le differenze nelle dinamiche legate al ciclo dei nutrienti e allo stoccaggio del carbonio tra campi arati e margini erbosi. La suddivisione di micro- e meso-fauna in gruppi trofici e lo studio dei cambiamenti nella distribuzione della massa corporea ha mostrato un parziale slittamento del flusso energetico dell'ecosistema basato sui batteri verso un flusso basato sui funghi. 
L'approccio onnicomprensivo utilizzato in questo studio, basato sui tratti funzionali di diversi gruppi di organismi del suolo, ha rilevato caratteristiche della comunità e dei relativi processi ecologici che non sarebbe stato possibile identificare con criteri tradizionali. Questo tipo di approccio ha dimostrato inoltre di poter identificare le pressioni ambientali e di permettere la valutazione dei servizi ecosistemici.

Il Capitolo 4 esplora la potenzialità di usare la massa degli organismi come tratto funzionale per identificare gli effetti di diverse condizioni ambientali sulla comunità del suolo. La relazione tra massa e abbondanza degli organismi (relazione allometrica) ottenuta utilizzando gruppi tassonomici e funzionali è stata confrontata in tre ex pascoli biologici, attualmente abbandonati, caratterizzati ognuno da un diversa composizione chimico-nutritiva dovuta alle passate pratiche di gestione agricola.

Questo capitolo si interroga sulla possibilità che la scelta tra un approccio tassonomico e uno funzionale implichi un cambiamento nelle relazioni allometriche (DR 2).

Differenze evidenti sono emerse confrontando le relazioni di massa-abbondanza ottenute impiegando una classificazione tassonomica e funzionale degli organismi mentre differenze minime sono emerse in relazione alle condizioni ambientali. È stata identificata, per la prima volta per ciò che riguarda il suolo, una relazione 1:1 tra la massa e l'abbondanza (isometria) fornendo prove evidenti di una distribuzione costante della biomassa al crescere della massa degli organismi indipendentemente dal livello trofico a cui essi appartengono. Questo dimostra che nel suolo, contrariamente a ciò che avviene nei sistemi acquatici, l'aumento della massa non è direttamente correlata all'aumento del livello trofico.

Il Capitolo 5 si focalizza sui cambiamenti nella distribuzione della massa corporea dei nematodi in tre diversi ecosistemi (campi arati, campi agricoli a pascolo e foreste/arbusteti). Affrontando la DR 3 questo capitolo analizza i) le tre componenti della diversità funzionale (ricchezza funzionale, equitabilità e divergenza); ii) lo slittamento nei tratti funzionali di larghezza e lunghezza ; iii) la differenza nella distribuzione della massa all'interno dell'intera comunità dei nematodi e in cinque gruppi trofici. I bassi valori di equitabilità riscontrati sono risultati essere associati con alti valori di ricchezza funzionale. Lo slittamento dei tratti morfologici (larghezza e lunghezza) e la distribuzione della massa analizzata per gruppi trofici hanno rivelato alcuni effetti delle condizioni ambientali che non sarebbero potuti essere identificati studiando esclusivamente gli indici di diversità funzionale.

Questo capitolo fornisce evidenze empiriche che un approccio combinato permette di rivelare la struttura della rete trofica e di identificare la risposta alle condizioni ambientali mediata dai tratti funzionali.

Il Capitolo 6, è una discussione generale sulle principali scoperte e avanzamenti di questo lavoro e sulle sue implicazioni.

Una delle conclusioni principali che si possono trarre da questa ricerca è che un approccio che tenga in considerazione l'intera comunità del suolo risulta più adatto a fornire 
una comprensione degli effetti delle attività antropogeniche sulle funzioni ecosistemiche rispetto ad un approccio basato su singoli gruppi tassonomici. Inoltre, combinare diverse analisi, come per esempio lo studio della distribuzione della massa con lo studio dei gruppi trofici, contribuisce a meglio identificare la risposta della comunità alle pressioni ambientali.

A causa dell'attuale difficoltà nel collegare e quantificare l'effetto delle pressioni antropogeniche sui processi ecosistemici nel suolo, non è stata ancora elaborata una metodologia chiara per la quantificazione dei servizi ecosistemici. Per questa ragione si ritiene fondamentale che le metodologie utilizzare in questa tesi siano ulteriormente esplorate in diverse condizioni ambientali permettendo così lo sviluppo di strumenti che possano essere usati come raccordo tra scienza e società, contribuendo in tal modo a uno sviluppo socioeconomico sostenibile. 
Acknowledgements 



\section{Acknowledgements}

"Four years fly", I often heard from people referring to the $\mathrm{PhD}$ time. Now that I have got there, I found out they were right. At the end, four years became five, but it still feels like they flew very fast. At the same time, if I look back at the time I started my PhD project, I can see it has been a long journey, full of exciting, challenging moments; sometimes I did it wrong, I had to start all over again, and especially then I learned how to do better.

As it often happens, learning it is not just about you, but it concerns the people surrounding you who consciously, or unconsciously, sometimes the hard way, sometimes just encouraging, help you to make steps forward in the learning process that is life.

Here, I would like to take the opportunity to thank those persons that contributed in many ways to my development as a scientist and as a person and helped me during this journey.

To start with, thanks to my supervisors, Michiel Rutgers, Christian Mulder, Ron de Goede and Lijbert Brussaard who supported me during these years. It was not always easy to handle four supervisors simultaneously but I also learned from each of you.

In particular, thanks to Michiel, the first person who welcomed me when I arrived in this new country and who introduced me to the Dutch culture with nice stories. You were always present when support was needed and I thank you for that.

Christian, thanks for all the times I could drop by in all kinds of mood and for having always been supportive and patient. Thanks for the many interesting and inspiring discussions and for being able to see a path through my flow of thoughts and worries. Thanks for all the time you dedicated helping and encouraging me.

Ron, your comments and criticism made me struggle quite a lot but I learned how to deal with it and it felt then like we were a team. Thank you for insisting and struggling with my manuscripts, it often forced me to ask myself how to be clearer.

Lijbert, you pushed me to be independent and critical with my writing. Dealing with your frankness was hard for me sometimes but there was always something to learn from it. Thanks for challenging me but also thanks for your support and pragmatism that helped a lot in critical situations. 
I would also like to express my gratitude to Paul Henning Krogh, my previous supervisor in Denmark, for introducing me to the fascinating and sometimes mysterious world of soil ecology. You guided me when I still did not have any idea of what being a scientist meant. I always enjoyed our thoughtful discussions concerning science and life. I always remember you with a smile.

Thank you to Jose Ferreira for his help with statistical issue and R script. Thank you for being always ready to help me whenever I struggled with R error messages.

Many thanks also to our secretaries Esther and Marnella for being always ready to help me, answering the hundreds of questions about administrative matters I could come up with. Thank you especially for being always smiling and welcoming.

Special thanks go to Marco Grassi for designing my thesis cover and for translating so efficaciously my ideas into a drawing with his bright creativity.

Many thanks to my colleagues at WUR for the entertaining lunch discussions, especially thanks to Joana, for all the chatting and sharing about all kind of issues I encountered on the way. I always felt I could share with you thoughts and feelings.

Janna, thanks for making me feel welcome whenever I needed tips and precise updates about things I missed in Atlas or even in the Dutch systems. Thanks to Carmen and Giulia for our entertaining 2 pm meetings.

Special thanks to Erik for helping out with field work at the beginning of my $\mathrm{PhD}$, but especially for all lunches, coffees and walks we had together. You were always able to pull me from behind my computer to take a break. Thank you for listening and laughing with me, but overall, thank you for being a good friend.

Thank you Narda and Nivine, we shared the office for a short time but I enjoyed so much having you there, I will never forget our laughing and gossiping.

Thank you to my friends, to those who are in Italy waiting for me when I travel back, and to the ones I had the fortune to meet in the different places where I lived and who make me feel at home. Anju, Chiara, Anna, Elisa, Tommaso, Marzia, Marta and Francesca, Narda, Giulia, Umberto, Alessandra, Lara, Andreas, Alessandro and Simone, each one of you has a special place in my memories and your being there means a lot for me. 
Finally thank you to my parents, because who I am in the present relies on my past. For the person I am, I have to thank you.

Mom, thanks for always being there, your trust has always been comforting and encouraging for me. Thanks for always listening and making me feel beloved. You know already, you will always be the person I enjoy the most for shopping.

Thanks to my father, for teaching me to always ask when you do not understand something, to think with my head and to believe in me. I really miss you.

Thanks to my sister, for the one you are, for all the long chatting we had ever since I can remember, you are part of me and you will always be.

My deepest thanks go to Silvio, my life partner, you make me feel unique and special and I am grateful to share my days with you. Thank you for all the times you took my hand and made me look out from the black clouds of my thoughts.

Arturo, you are still so little and yet I learned so much form you, you lightened my life up from the first day I held you in my arms. 

Curriculum Vitae 



\section{Curriculum Vitae}

Valentina Sechi was born in Rome on 20 June 1983. Her love for the environment led her to start the bachelor studies in Ecology and Evolution at the University of Rome Tor Vergata in 2002.

Fascinated and thrilled by the complex dynamics occurring between living organisms and the environment, she started a Master in Ecology in 2006.

In 2008 she joined the ERASMUS program and spent one year at the Complutense Universidad de Madrid where she conducted a study on the ecological restoration of the

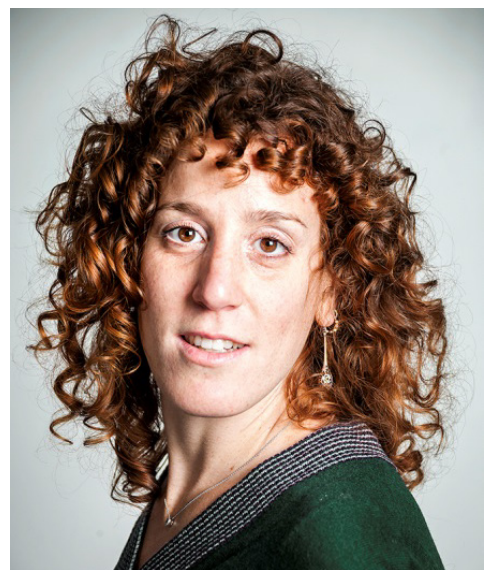
Peruvian wood "loma" of Atiquipa that became the topic of her Master thesis. She graduated in 2009. In the same year she started a Master specialization in Environmental Evaluation and Planning at the Polytechnic University of Turin. After one year of working experience in the field of environmental consultancy, she returned to academic research.

Between 2010 and 2012 she worked at Aarhus University, first as research assistant on the effects of pesticides on the soil community at the Department of Soil Ecology, and afterward as guest researcher on the identification of trophic relations of soil mesofauna in agricultural grasslands at the Department of Bioscience and Agroecology. These research activities opened the way to her $\mathrm{PhD}$ project on trophic relations in soil, which she conducted at the Department of Soil Quality at Wageningen University and at the National Institute for Public Health and the Environment (RIVM), Bilthoven, the Netherlands, which also funded her PhD project. She defended her thesis in June 2017.

\section{PUBLICATIONS}

Sechi, V., de Goede, R.G.M., Rutgers, M., Brussaard, L. \& Mulder, C. (2017). A community trait-based approach to ecosystem functioning in soil. Agriculture, Ecosystems \& Environment, 239: 265-273.

Sechi, V., Brussaard, L., de Goede, R.G.M., Rutgers, M. \& Mulder, C. (2015). Choice of resolution by functional trait or taxonomy affects allometric scaling in soil food webs. The American Naturalist, 185: 142-149.

Sechi, V., D'Annibale, A., Ambus, P., Sárossy, Z., Krogh, P.H., Eriksen, Holmstrup, M. (2014). Collembola feeding habits and niche specialization in agricultural grasslands of different composition. Soil Biology and Biochemistry, 74: 31-38. 
Sechi, V., D'Annibale, A., Maraldo, K., Johansen, A., Bossi, R., Jensen, J. Krogh, P. H. (2014). Species composition of a soil invertebrate multi-species test system determines the level of ecotoxicity. Environmental Pollution, 184: 586-596.

D'Annibale, A., Larsen, T., Sechi, V., Cortet, J., Strandberg, B., Vincze, É., Filser, J., Audisio, P.A., Krogh, P.H. (2015). Influence of elevated $\mathrm{CO}_{2}$ and $\mathrm{GM}$ barley on a soil mesofauna community in a mesocosm test system. Soil Biology and Biochemistry, 84: 127-136. 
PE\&RC Training and Education Statement 



\section{PE\&RC Training and Education Statement}

With the training and education activities listed below the $\mathrm{PhD}$ candidate has complied with the requirements set by the C.T. de Wit Graduate School for Production Ecology and Resource Conservation (PE\&RC) which comprises of a minimum total of 32 ECTS (= 22 weeks of activities)

Review of literature (4.5 ECTS)

- Literature on ecosystem services

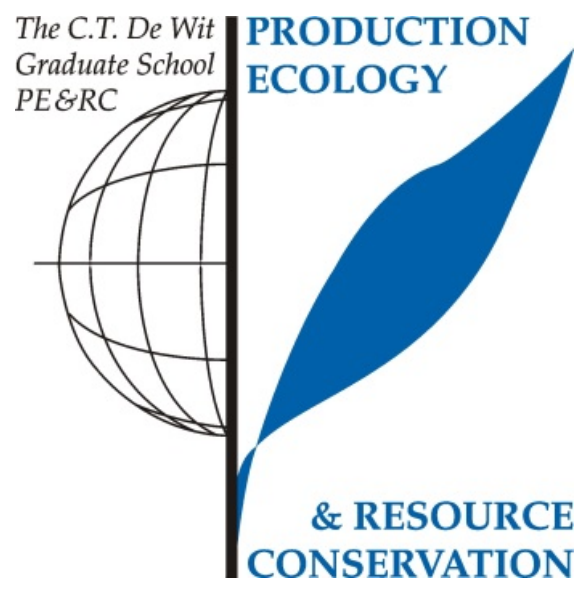
assessment

Writing of project proposal (3 ECTS)

- Biotic interactions and trait-based ecosystem functioning in soil

Post-graduate courses (5.1 ECTS)

- Organic matter turnover and stabilization in soil; Aarhus university (2012)

- Soil ecology; PE\&RC (2012)

- Introduction to R; PE\&RC (2013)

- Multivariate analysis; PE\&RC (2014)

Invited review of (unpublished) journal manuscript (3 ECTS)

- Applied Soil Ecology: recovery from reindeer gazing depends on soil characteristics in a low Arctic meadow ecosystem (2013)

- Journal of Applied Ecology: effects of agricultural management practices on earthworm populations and soil fertility (2014)

- Journal of Hazardous Materials: ecotoxicological characteristic of residues from different biogas (2015)

\section{Competence strengthening / skills courses (8.6 ECTS)}

- Reviewing a scientific paper; WGS (2012)

- Competence assessment; WGS (2013)

- Scientific writing; Language School (2013)

- Data management; WGS (2014)

- PhD Peer consultation - as support in academic skills development (PC); WGS (2014)

- Information literacy for PhDs including EndNote; WUR Library (2014)

- Career orientation; Graduate School EPS (2016)

- Career coaching; HRM (2016-2017) 
PE\&RC Annual meetings, seminars and the PE\&RC weekend (3 ECTS)

- PE\&RC Weekend first years (2012)

- PE\&RC Symposium (2012)

- PE\&RC Day (2012, 2014)

- Current themes in ecology $(2013,2014)$

- PE\&RC Weekend last years (2015)

Discussion groups / local seminars / other scientific meetings (7.7 ECTS)

- Soil quality discussion group (2013-2016)

- Netherlands Annual Ecology Meeting (2013-2014)

International symposia, workshops and conferences (11.6 ECTS)

- Annual meeting of the Ecological Society of Germany, Austria and Switzerland (2013)

- EU Ecofinders meeting (2013)

- First Global Soil Biodiversity conference (2014)

- Annual conference of the Society of Environmental Toxicology and Chemistry (2014)

- 5th International EcoSummit (2016) 


The research described in this thesis was financially supported by the National Institute for Public Health and the Environment (RIVM), Bilthoven.

Financial support from Wageningen University for printing this thesis is gratefully acknowledged.

Cover design by Marco Grassi 